\title{
High Latitude Changes in Ice Dynamics and Their Impact on Polar Marine Ecosystems
}

\author{
Mark A. Moline, ${ }^{a}$ Nina J. Karnovsky, ${ }^{b}$ Zachary Brown, ${ }^{b}$ \\ George J. Divoky, ${ }^{c}$ Thomas K. Frazer, ${ }^{d}$ Charles A. Jacoby, ${ }^{d}$ \\ Joseph J. Torres, ${ }^{e}$ and William R. Fraser $f$ \\ ${ }^{a}$ Biological Sciences Department and Center for Coastal Marine Sciences, California \\ Polytechnic State University, San Luis Obispo, California, USA \\ ${ }^{b}$ Department of Biology, Pomona College, Claremont, California, USA \\ ${ }^{c}$ Institute of Arctic Biology, University of Alaska Fairbanks, Fairbanks, Alaska, USA \\ ${ }^{d}$ Department of Fisheries and Aquatic Sciences, Institute of Food and Agricultural \\ Sciences, University of Florida, Gainesville, Florida, USA \\ ${ }^{e}$ Department of Marine Sciences, University of South Florida, St. Petersburg, Florida, USA \\ ${ }^{f}$ Polar Oceans Research Group, Sheridan, Montana, USA
}

\begin{abstract}
Polar regions have experienced significant warming in recent decades. Warming has been most pronounced across the Arctic Ocean Basin and along the Antarctic Peninsula, with significant decreases in the extent and seasonal duration of sea ice. Rapid retreat of glaciers and disintegration of ice sheets have also been documented. The rate of warming is increasing and is predicted to continue well into the current century, with continued impacts on ice dynamics. Glimate-mediated changes in ice dynamics are a concern as ice serves as primary habitat for marine organisms central to the food webs of these regions. Ghanges in the timing and extent of sea ice impose temporal asynchronies and spatial separations between energy requirements and food availability for many higher trophic levels. These mismatches lead to decreased reproductive success, lower abundances, and changes in distribution. In addition to these direct impacts of ice loss, climate-induced changes also facilitate indirect effects through changes in hydrography, which include introduction of species from lower latitudes and altered assemblages of primary producers. Here, we review recent changes and trends in ice dynamics and the responses of marine ecosystems. Specifically, we provide examples of ice-dependent organisms and associated species from the Arctic and Antarctic to illustrate the impacts of the temporal and spatial changes in ice dynamics.
\end{abstract}

Key words: polar ecosystems; climate change; sea ice; trophic cascade; matchmismatch; phenology

\section{Introduction}

The Earth's atmosphere is warming. Over the past 100 years, the average temperature has increased by approximately $0.6^{\circ} \mathrm{C}$ (IPCG 2001). Since the mid-1970s, the rate of atmospheric warming has nearly doubled and global warming trends are forecast to continue (IPCG
2001, 2007). These forecasts generate significant concern as polar regions are especially vulnerable in global climate change scenarios, with even relatively small deviations in atmospheric temperatures profoundly influencing oceanographic and ecological processes. Concerns extend from the effects of these increased 
atmospheric temperatures on the timing and extent of seasonal sea-ice formation in both the Arctic and Antarctic regions to the consequences for organisms that are linked to these dynamics by nature of their life histories. Seaice coverage is, in fact, declining (Liu et al. 2004; Yuan 2004; Serreze et al. 2007). This is a concern as sea ice serves as an essential habitat in polar ecosystems, with components of the system requiring the ice as substrate, for consistent light and chemical environments, as a source for prey, and as a general resource for part or all of many organisms' life cycles. In addition to documented broad-scale declines in sea ice, there has been a significant retreat of coastal glaciers and ice sheets, increasing the degree of oceanographic stratification in these regions, with further influences on important ecological processes and interactions. Changes in global climate are not manifest uniformly, thus, there is likely to be significant variability in the location and timing of warming, with an asymmetric influence on ice dynamics and ocean processes. Polar ecosystems respond to these heterogeneous regional changes within a relatively brief window suitable for growth and reproduction (Winder \& Schindler 2004). Therefore, the issue of scale, both spatial and temporal, cannot be ignored when examining these especially pronounced trophic interactions. This paper reviews the recent changes and trends in ice dynamics and observed and predicted responses in the Arctic and Antarctic marine ecosystems.

\subsection{Sea-ice Dynamics}

Over an annual cycle, large expanses of seawater in the high-latitude marine environments undergo the cycle of freezing and melting. In winter, sea ice covers up to $7 \%$ of the earth's surface. In general, sea ice forms as a relatively thin layer up to $3 \mathrm{~m}$ thick, but ridges up to $20 \mathrm{~m}$ thick can form. Sea ice acts as a physical barrier to ocean-atmosphere exchange of gases (i.e., oxygen and carbon dioxide) and to the fluxes of heat and moisture. Sea ice prevents direct con- tact between the relatively warm ocean and the colder atmosphere. During winter, when the temperature gradients between the surface ocean and atmosphere are maximal, the loss of heat to the atmosphere can be up to two orders of magnitude smaller over sea-ice cover than in open ocean. With its high albedo, the ice and its snow cover reduce the amount of incoming solar radiation absorbed at the ocean surface by reflecting much of it back to space. The transfer of momentum from the atmosphere to the ocean, which influences upperocean currents, is also modified by the presence of ice.

The annual formation of sea ice is critical to the movement of ocean currents worldwide. Salt rejected from the ice structure during its formation and growth increases the salinity and density of the underlying water, which can influence the formation of bottom water that contributes to the upwelling of nutrients and to the overall thermohaline circulation on continental shelves and in the deep ocean. Following the initial freezing of sea water, sea ice is continually modified by the interaction of physical, biological, and chemical processes to form an extremely heterogeneous semisolid matrix. It is within this matrix that sea-ice biota thrive. When the sea ice - which is considerably less salty than sea water - melts in spring, fresher water is released, forming a stable low-salinity surface layer that can affect primary production. Despite the general similarities in the annual cycle of sea ice, the dynamics between the Arctic Ocean and the Southern Ocean differ significantly.

The Antarctic is unbounded at its northern extent, with a very deep continental shelf margin. As a result, sea ice undergoes cyclical periods of convergence and divergence under the influence of winds and ocean currents. North of $\sim 65^{\circ} \mathrm{S}$, the sea ice generally moves from west to east in the Antarctic Circumpolar Current, but with a net northward component of drift. The unconstrained nature of the Antarctic sea ice results in a large annual range in geographic extent, from 3 to 18 million $\mathrm{km}^{2}$ 


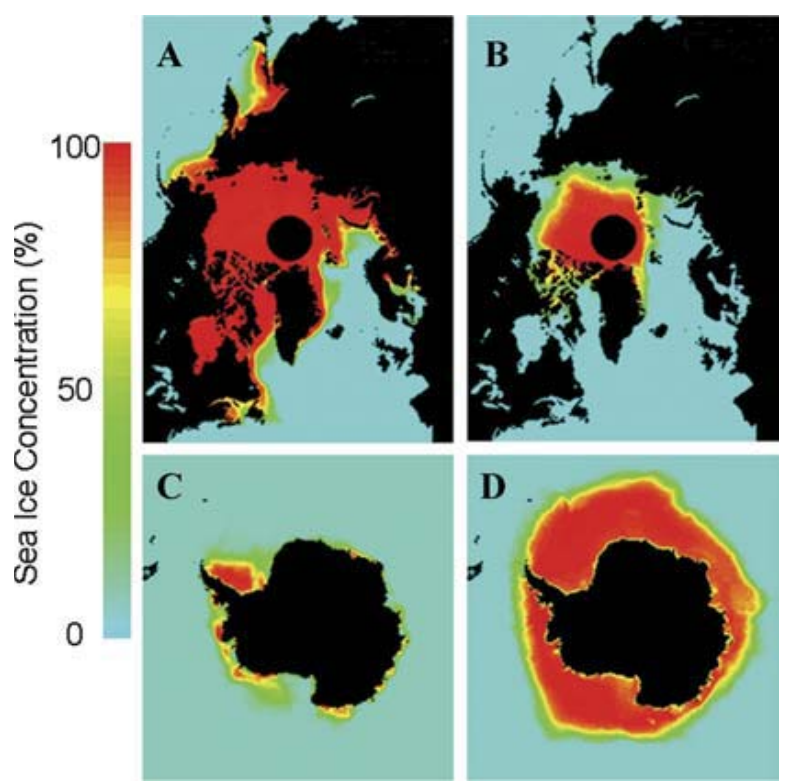

Figure 1. Maximum and minimum sea-ice cover for the (A, B) Arctic and (C, D) Antarctic. Boreal winter is depicted for both poles on the left panels, while austral winter is on the right panels. The black circles in the center of the Northern Hemisphere images are areas lacking data due to limitations in satellite coverage at the North Pole. Image courtesy of the National Snow and Ice Data Center, University of Colorado, Boulder, Colorado. (In color in Annals online.)

over the summer minimum and winter maximum, respectively (Fig. 1). Because of this large seasonal variability, only a comparatively small fraction of the sea ice persists more than one season. In contrast, the Arctic is composed of predominantly land-locked shallow shelf seas, which retain a greater proportion of thicker multiyear ice. The extent of the Arctic sea ice swells to almost 14 million $\mathrm{km}^{2}$ in the winter, with the summer minimum approximately $40 \%$ of the winter maximum (Fig. 1). The extent and thickness of the perennial multiyear ice, however, has been significantly decreasing (see below).

The melting process is another difference between Arctic and Antarctic sea ice. In the Arctic, the sea ice melts at the surface, forming melt pools, increasing absorption of solar radiation and enhancing the melt process. In the Antarctic, melting occurs from contact with the ocean on the bottom and sides of the ice. Openings in sea ice develop and increase in size as the surface layer of the ocean warms. The interplay between macronutrients and trace elements (particularly iron) within the two polar regions also vary. The land-ocean exchange in the Antarctic is restricted due to the polar ice cap and ice shelves extending into the ocean. Sea ice is, therefore, largely sediment free with few trace elements. Primary production in the Southern Ocean is principally iron limited, with concentrations of macronutrients rarely exhausted. As the Arctic is generally land-locked, the ocean is supplied with trace elements from river runoff and from atmospheric deposition of dust. During ice formation, sea ice incorporates these sediment particles, which are later available to primary producers upon melting. As a result of this source of iron, intense Arctic production along the sea-ice margins, unlike the Antarctic, is limited by nitrate (Smetacek \& Nicol 2005).

\subsection{Present Trends in Large-scale Ice Dynamics}

Sea ice is relatively thin and is therefore vulnerable to small perturbations by the ocean and/or atmosphere. These disturbances can significantly alter the extent and thickness of the cover, and the rates of sea-ice formation and melting. Such changes have been documented in both polar regions and linked to the current rate of climate warming. As the physical and chemical dynamics of both systems are distinct, the impacts of current climate change and the ecosystem responses are also varied.

\subsubsection{The Arctic Ocean}

Over the past few decades the Arctic sea-ice cover has significantly decreased in spatial extent. Analyses of temperature records and seaice cover between 1961 and 1990 showed a significant and distinct warming that was strongest over northern land areas during the winter and spring (Chapman \& Walsh 1993). In an 11year record from 1978 to 2000, Comiso (2002a) found the rate of Arctic perennial sea-ice cover 


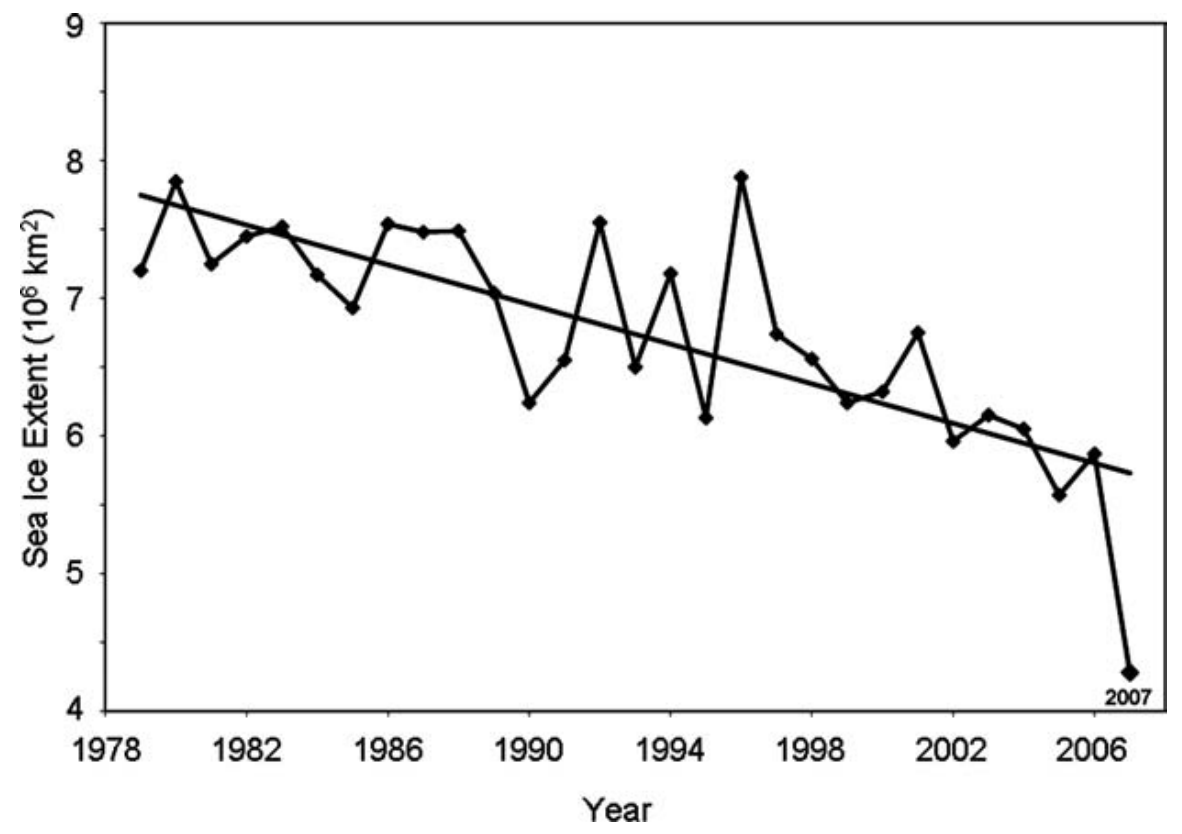

Figure 2. September Arctic sea-ice extent from 1979 to 2007 showing a precipitous decline. The September rate of sea-ice decline since 1979 is now approximately 10\% per decade, or $72,000 \mathrm{~km}^{2}$ per year. Image courtesy of the National Snow and Ice Data Center, University of Colorado, Boulder, Colorado.

decline to be relatively fast at $8.9 \pm 2.0 \%$ per decade. This rate coincided with a positive trend in the ice temperature of about $1.2^{\circ} \mathrm{C}$ per decade, leading to earlier onset of melt, retreat of perennial ice cover, and delayed onset of ice formation (Parkinson 2002a, 2006). These changes have been documented in various regions: a 12\% decrease in April sea-ice extent in the Kara Sea from 1953 to 1990 (Divine et al. 2003), a decrease in the Barents Sea sea ice from 1850 to 2001 (Shapiro et al. 2003), and increased rate of melting in the Bering Sea from 1971 to 2001 (Hunt et al. 2002). Johannessen and colleagues (2004) identified two pronounced $20^{\text {th }}$-century warming events, which were amplified in the Arctic and linked to variability in sea ice. Observations and model simulations of surface air temperature indicated that the nature of the warming in the past 20 years is distinct from the earlier warm period (Stroeve et al. 2007), and strongly suggested the recent temperature changes are in response to anthropogenic forcing, whereas earlier warming was linked to natural, internal climate-system variability. The area of Arctic sea ice decreased about $7.5 \%$ from 1978 to 2003, with an initial record low summer extent in 2002 (Serreze et al. 2003; Johannessen et al. 2004). Since this record in 2002, sea-ice extent has continued to decrease, with new record minima in 2005 and the dramatic loss observed in September 2007 (Fig. 2). Furthermore, Serreze and colleagues (2007) found that the decreases were not restricted to summer months, occurring throughout the year from 1979-2006. The progressive retreat of perennial ice has been asymmetric, with significantly higher losses in the Chukchi Sea and adjacent areas (Fig. 3A). In contrast, sea-ice cover in Baffin Bay and Davis Strait from 1953 to 2001 was found to be largely unchanged and correlated with each previous winter North Atlantic Oscillation index (Stern \& Heide-Jørgensen 2003). Although sea ice in this region has not decreased consistently, data indicate that even these areas of lower variability have experienced recent losses (Fig. 3A). These regional differences are thought to be linked to a number of processes (Fig. 4): regional warming differences (Chapman \& Walsh 1993; Serreze et al. 2007; Stroeve et al. 2007), 


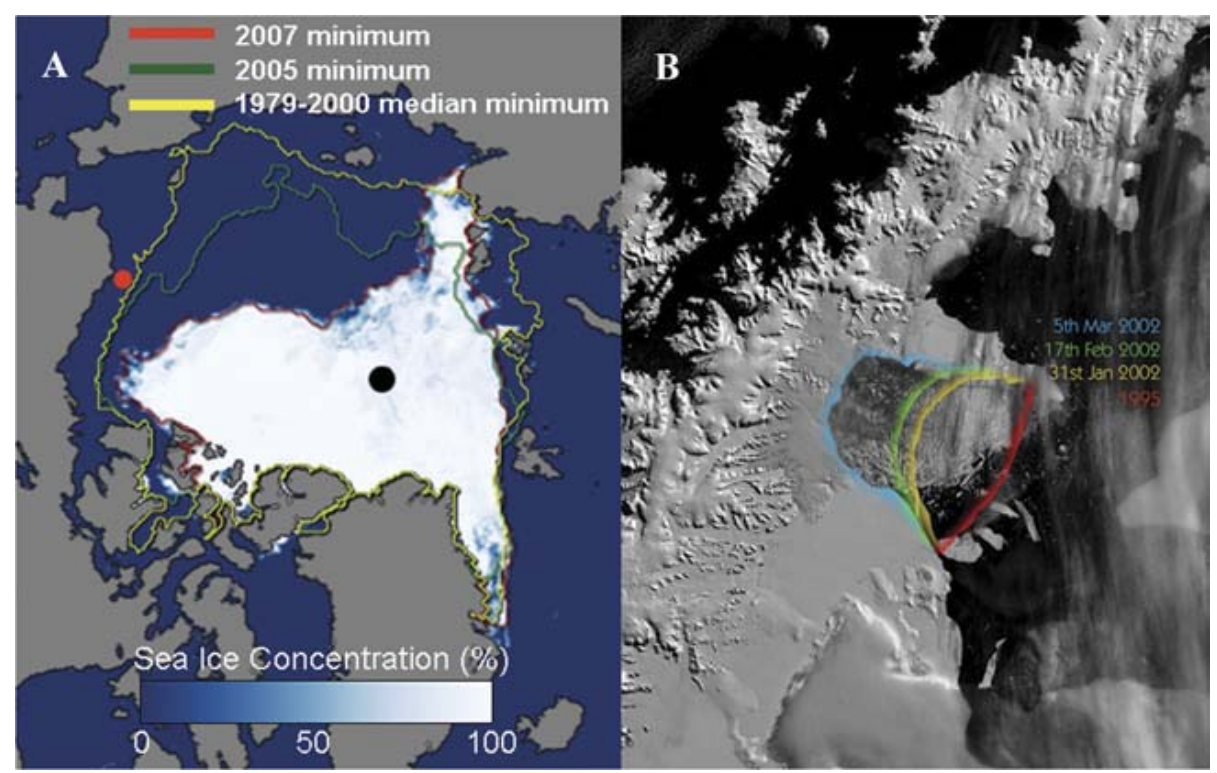

Figure 3. (A) The spatial distribution of the sea-ice extent in the Arctic Ocean on September 16, 2007 compared to the 2005 minimum (green line) and the mean minimum for the years between 1979 and 2000 (yellow line). The filled red circle indicates the location of Cooper Island (see Section 2.1.2). (B) The time sequence of the Larson-B Ice Shelf collapse along the Antarctic Peninsula in January (yellow), February (green), and March (blue) of 2002 compared with the mean ice cover during the same months in 1995 (red). (In color in Annals online.)

anomalous cloud cover (NSIDC 2007), atmospheric forcing (Ogi \& Wallace 2007), and ocean circulation patterns (Proshutinsky et al. 1999; Shapiro et al. 2003). The fact that the sea-ice retreat has largely occurred in the primary openings to the Arctic Ocean in the Barents and Chukchi Seas illustrates the importance of ocean circulation. This is consistent with studies showing the extent of sea ice tied to warmer water intrusions from the Norwegian Sea into the Barents Sea (Saloranta \& Svendsen 2001; Shapiro et al. 2003) and Chukchi Sea (Mizobata \& Wang 2006) and the anticyclonic circulation patterns in the Chukchi Sea (Proshutinsky et al. 1999).

The environmental feedbacks associated with changes in sea ice have also been explored. The loss of perennial sea ice at the time of peak solar radiation has been found to decrease the surface albedo, allowing more solar heating of the upper ocean (Fig. 4). An increase in the solar energy deposited in the upper ocean over the past few decades was found in $89 \%$ of the
Arctic (Perovich et al. 2007). The largest increases in total yearly solar heat input, as much as $4 \%$ per year, occurred in the Chukchi Sea and adjacent areas (Perovich et al. 2007). The increase in latent heat has the potential to delay ice formation and/or decrease sea-ice extent (Nihashi \& Cavalieri 2006). The trend in decreased sea-ice extent throughout the year is further supportive of increased heat storage (Serreze et al. 2007). The increase in heat may also increase the degree of stratification, reduce vertical circulation (Aagaard \& Carmack 1989), restrict the availability of limiting nutrients to the upper ocean, and reduce primary production (Smetacek \& Nicol 2005).

Documented changes in ice dynamics in the Arctic illustrate the highly variable and complex physical and chemical mechanisms and feedbacks that have potential to fundamentally influence the structure and function of polar ecosystems. Water-column stability, nutrient availability, trace element and macronutrient ratios, salt content, heat content, and solar 


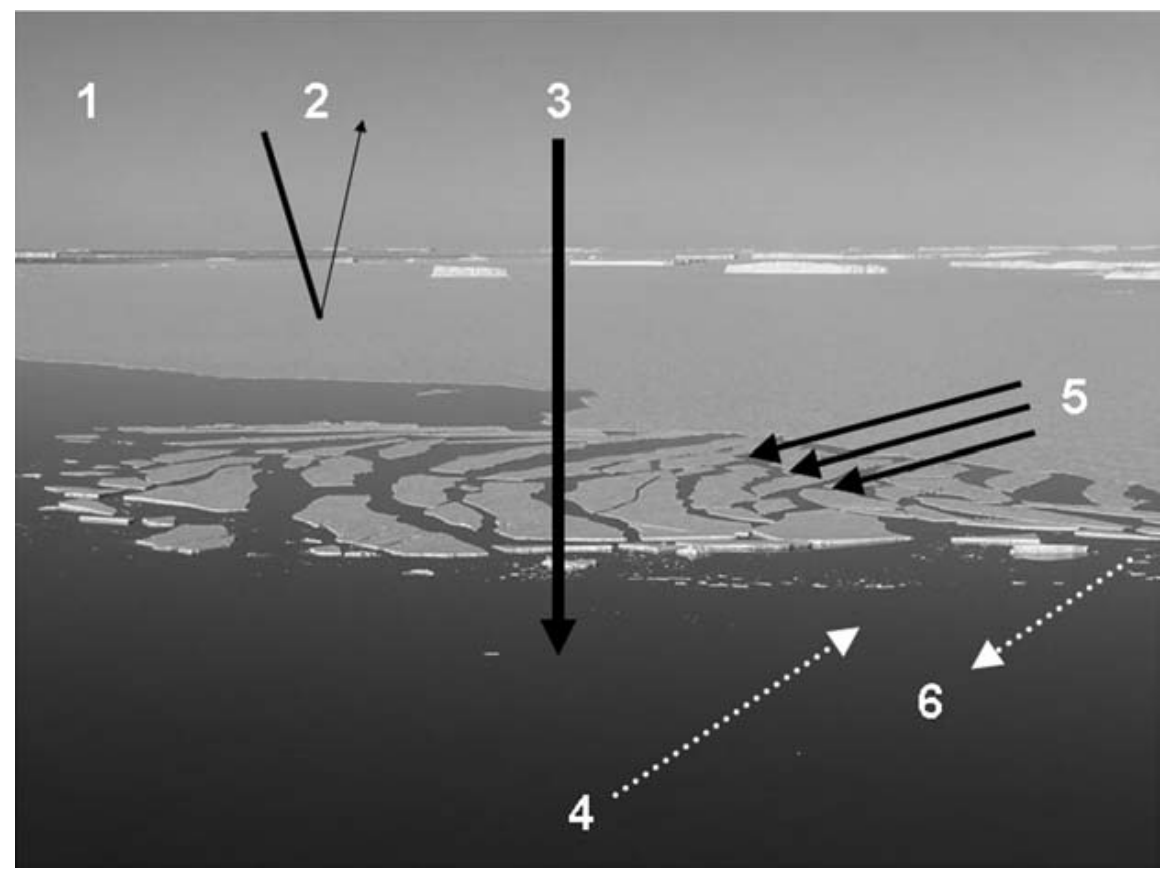

Figure 4. Atmospheric and oceanic processes influencing ice melting in polar regions. (1) Increases in ambient temperature accelerate melting of sea ice, glaciers, and ice shelves. (2) A fraction of incoming solar radiation is absorbed by the sea ice; however, because the high sea-ice albedo (0.8; Dick 2003), the majority is reflected back into the atmosphere. Air pollution traps both incoming radiation and heat radiated off the sea ice. Pollution and dust particles also land on snow and increase absorption, leading to increased melting rates of sea ice (Law \& Stohl 2007). (3) The albedo of the open ocean is approximately 0.07 (Dick 2003), so any increase in open water increases the solar heating of the upper ocean and perpetuates sea-ice melting along its margins. (4) Relatively warm ocean currents can limit the local formation and extent of sea ice and also influence the melting rates of glaciers and ice shelves. (5) Local atmospheric forcing serves to break up or consolidate ice. (6) Melting of sea ice, coastal glaciers, and ice shelves releases fresh water into the surface layer, which provides increased vertical stability in the water column.

radiation have been reported to significantly change in response to alterations in sea-ice dynamics. These environmental variables are fundamental drivers of primary production in polar regions, including timing of growth, abundance, distribution, diversity, and functional composition (Boyd 2002; Sakshaug 2004). These variables also establish whether production is primarily exported to the benthos, remineralized, and/or available to higher trophic levels (Stein \& MacDonald 2004). For example, high net production was found along a receding ice edge with low-level production in surrounding open ocean areas (Owrid et al. 2000). The ice-based food chain of the high Arctic, in which energy is transferred from ice biota to copepods and amphipods to polar cod to seals to polar bears, will likely be impacted by shrinking sea-ice cover. It is not clear however, if the loss of ice will decrease the overall oceanic productivity or increase it (Smetacek \& Nicol 1985) by the amplified effect on light field (Winther et al. 2004). It is therefore important to examine some of these broad-scale patterns in primary producers in connection with current changes in ice dynamics. This can serve as a useful preface for discussion of specific climate impacts on different components within the ecosystem.

Sea-ice loss can be coupled with higher temperatures and increased primary production. This is particularly evident in the basins 


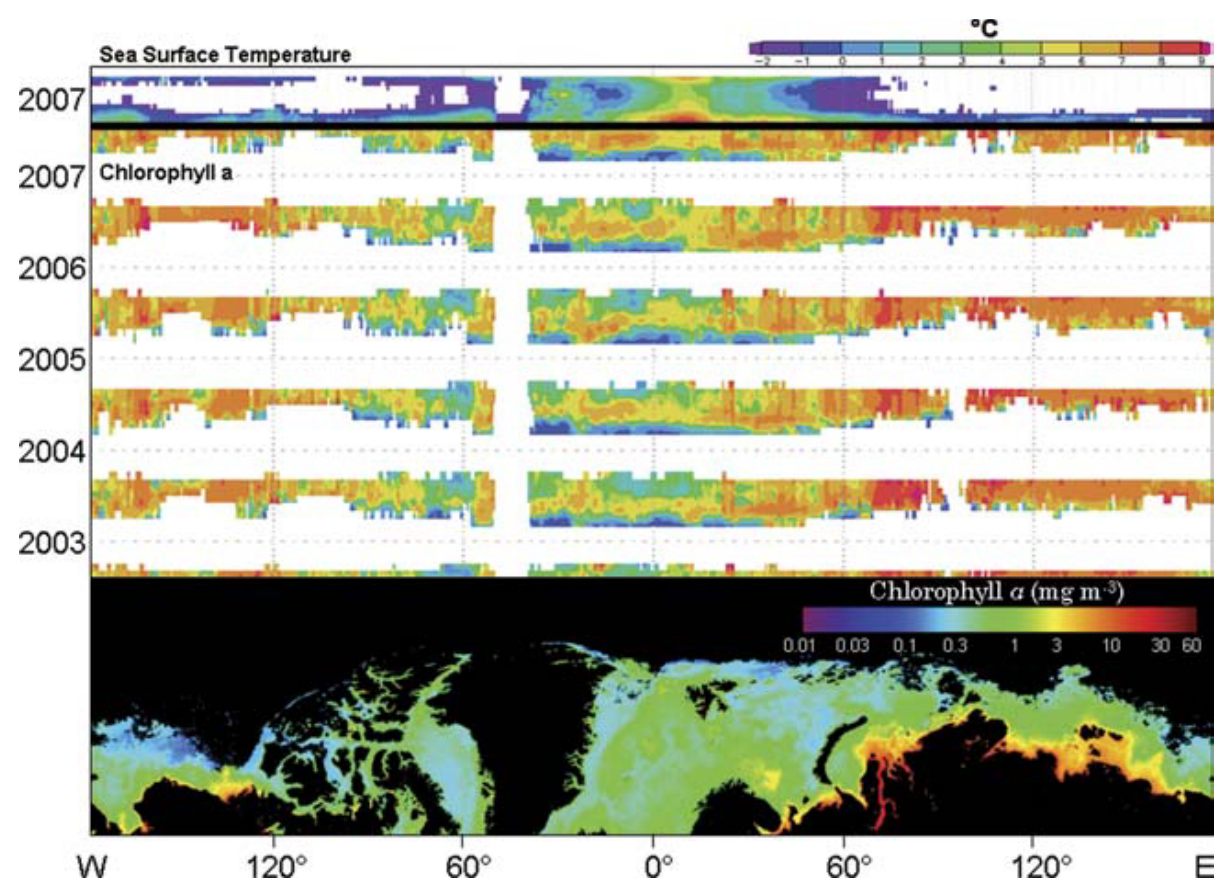

Figure 5. A temporal and spatial record of temperature and chlorophyll for the Arctic. The top panel is the latitudinal mean $\left(65^{\circ} \mathrm{N}\right.$ to $\left.85^{\circ} \mathrm{N}\right)$ nighttime Sea Surface Temperature $\left({ }^{\circ} \mathrm{C}\right)$ for the period of August 2006 through August 2007 as a function of longitude. The middle panels are the latitudinal mean $\left(65^{\circ} \mathrm{N}\right.$ to $\left.85^{\circ} \mathrm{N}\right)$ chlorophyll a $\left(\mathrm{mg} \mathrm{m}^{-3}\right)$ concentrations from August 2002 through August 2007 as a function of longitude. The bottom panel is the spatial distribution of the mean chlorophyll a $\left(\mathrm{mg} \mathrm{m}^{3}\right)$ concentrations from August 2002 through August 2007. Data are derived from the OBPG MODIS-Aqua monthly global 9-km products. The images and data used in this study were acquired using the GES-DISC Interactive Online Visualization and Analysis Infrastructure (Giovanni) as part of the NASA's Goddard Earth Sciences (GES) Data and Information Services Center (DISC). (In color in Annals online.)

adjacent to openings to lower latitude waters (Serreze et al. 2007; Stroeve et al. 2007). Sea-surface temperatures from August 2006 to August 2007 were significantly higher in the Chukchi Sea, Davis Straits, and Fram Straits, showing the intrusion of Atlantic water into the region (Fig. 5). In addition, these locations experienced higher temperatures into the winter. High concentrations of algal biomass are seen in the Beaufort Sea $\left(120^{\circ} \mathrm{W}-180^{\circ} \mathrm{W}\right)$, along the eastern side of Greenland in Baffin Bay $\left(50^{\circ} \mathrm{W}\right)$, and particularly along the coastline of the Barents, Kara, and Laptev Seas $\left(30^{\circ} \mathrm{E}-180^{\circ} \mathrm{E}\right)$. The latitudinal mean concentrations do show dramatic interannual changes, with the exception of the region between $0^{\circ}$ and $30^{\circ} \mathrm{W}$, where the biomass appears to have increased over the 5 -year period (Fig. 5). The location of this increase appears to be in the northern extent of the Greenland Sea, between Greenland and the Svalbard island group (Fig. 5, lower panel). The highest integrated biomass over the 5 years was evident along the coastlines of the Arctic Ocean and one large area in the Barents Sea. This is consistent with river runoff, nutrient availability, and increased stability along coastlines, as well as the convergence of Atlantic water and Arctic water in the Barents Sea (Smetacek \& Nicol 2005). Even though regional differences may be difficult to discern at this scale, there is an increasing trend in the amount of primary producer biomass in the Arctic (Fig. 6A). This increase appears to be a northward latitudinal advance in biomass that occur north of $76^{\circ} \mathrm{N}$, and is not influenced by the coastlines of the Barents, Kara, or Laptev Seas (Fig. 7) and is consistent with the documented retreat of the summer perennial ice 


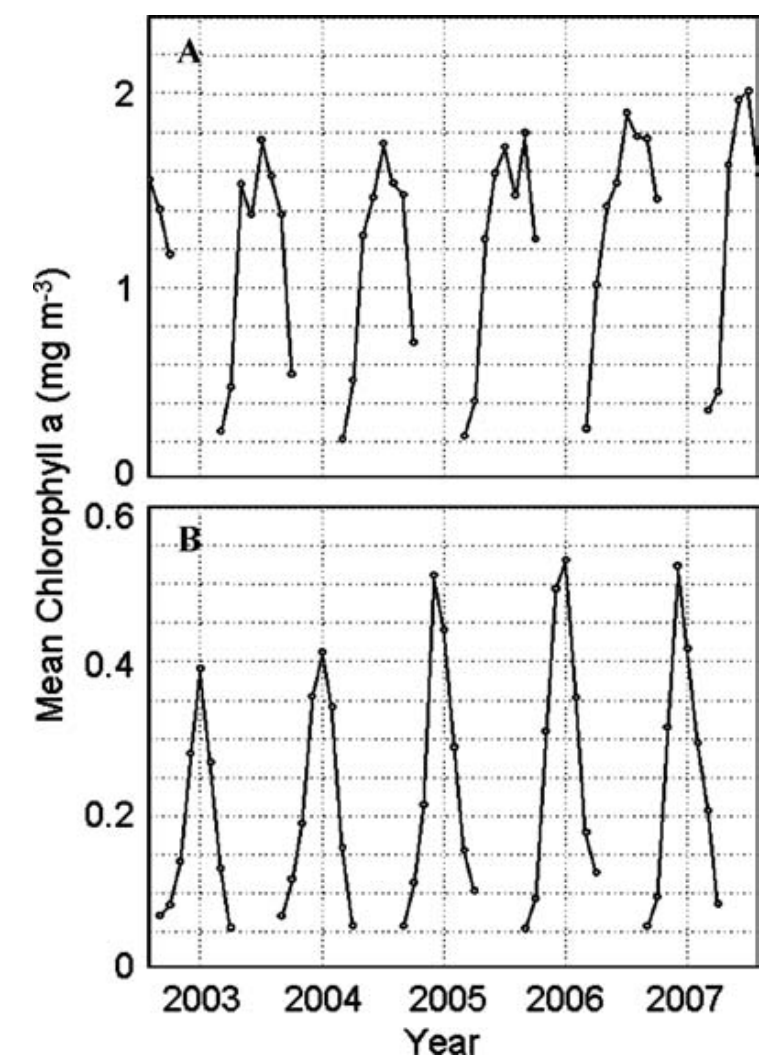

Figure 6. The monthly mean chlorophyll a $(\mathrm{mg}$ $\mathrm{m}^{-3}$ ) concentrations from August 2002 through August 2007 for the (A) Arctic $\left(65^{\circ} \mathrm{N}\right.$ to $\left.85^{\circ} \mathrm{N}\right)$ and (B) Antarctic $\left(60^{\circ} \mathrm{S}\right.$ to $\left.78^{\circ} \mathrm{S}\right)$. The images and data used in this study were acquired using the GES-DISC Interactive Online Visualization and Analysis Infrastructure (Giovanni) as part of the NASA's Goddard Earth Sciences (GES) Data and Information Services Center (DISC).

edge margins (Druzhkov et al. 2001; Serreze et al. 2007). Examination of the period from August 2006 to August 2007, clearly shows the response of the phytoplankton biomass to the receding ice edge (Fig. 8). The advance of the bloom can be seen proceeding northward as a function of time, at an approximate rate of $1^{\circ}$ per month in the boreal summer.

\subsubsection{The Southern Ocean}

The trends in sea-ice cover in the Antarctic differ markedly from those in the Arctic, as the Southern Ocean is isolated from land masses and the formation and extent of sea ice is governed largely by oceanic processes. In a study from 1979 to 1998, Zwally and co-workers
(2002) found an overall increasing trend in seaice extent of approximately $1 \%$ per decade. Similar estimates of a $1.5 \%$ increase per decade confirm this trend (Fichefet et al. 2003; Ducklow et al. 2007). The trends are not uniform across the Southern Ocean, however. There are, in fact, significant regional differences (Ackley et al. 2003). Positive decadal trends in sea-ice extent were found for the Weddell Sea, Pacific Ocean, and Ross Sea sectors, slightly negative in the Indian Ocean, and strongly negative (ca. $10 \%$ ) in the Bellingshausen-Amundsen Seas sector (Zwally et al. 2002). Although the regional definitions varied, an extension of the time series record from 1979 to 2002 yielded similar trends, with pronounced increases in the Pacific sector and significant decreases in the Bellingshausen/western Weddell sector (Liu et al. 2004; Yuan 2004). Correlations with ice core records also suggest a decline in seaice extent in the Indian sector (Curran et al. 2003). Temporal changes in sea-ice extent in these sectors were positively correlated with the Antarctic Oscillation and negatively correlated with the El Niño-Southern Oscillation (ENSO), however, these correlations did not explain regional discrepancies in the magnitude of sea-ice extent (Liu et al. 2004; Yuan 2004; Stammerjohn et al. 2008). The significant decreases in the extent of sea ice documented along the Antarctic Peninsula also coincide with a significant warming trend in this area (Chapman \& Walsh 1993). In fact, the climate of the Antarctic Peninsula is changing more rapidly than any other region in the Southern Hemisphere. Atmospheric temperatures have increased nearly $3^{\circ} \mathrm{C}$ from 1951 to 2004 (Vaughan et al. 2003; Meredith \& King 2005). Skvarca and colleagues (1998) documented the first year with a mean annual air temperature above $0^{\circ} \mathrm{C}$ on the eastern side of the Antarctic Peninsula.

In addition to decreases in sea-ice extent in this region, increased temperatures coincide with significant changes in the activity of glaciers and ice shelves. Eighty-seven percent of 244 marine glacier fronts along the Antarctic 


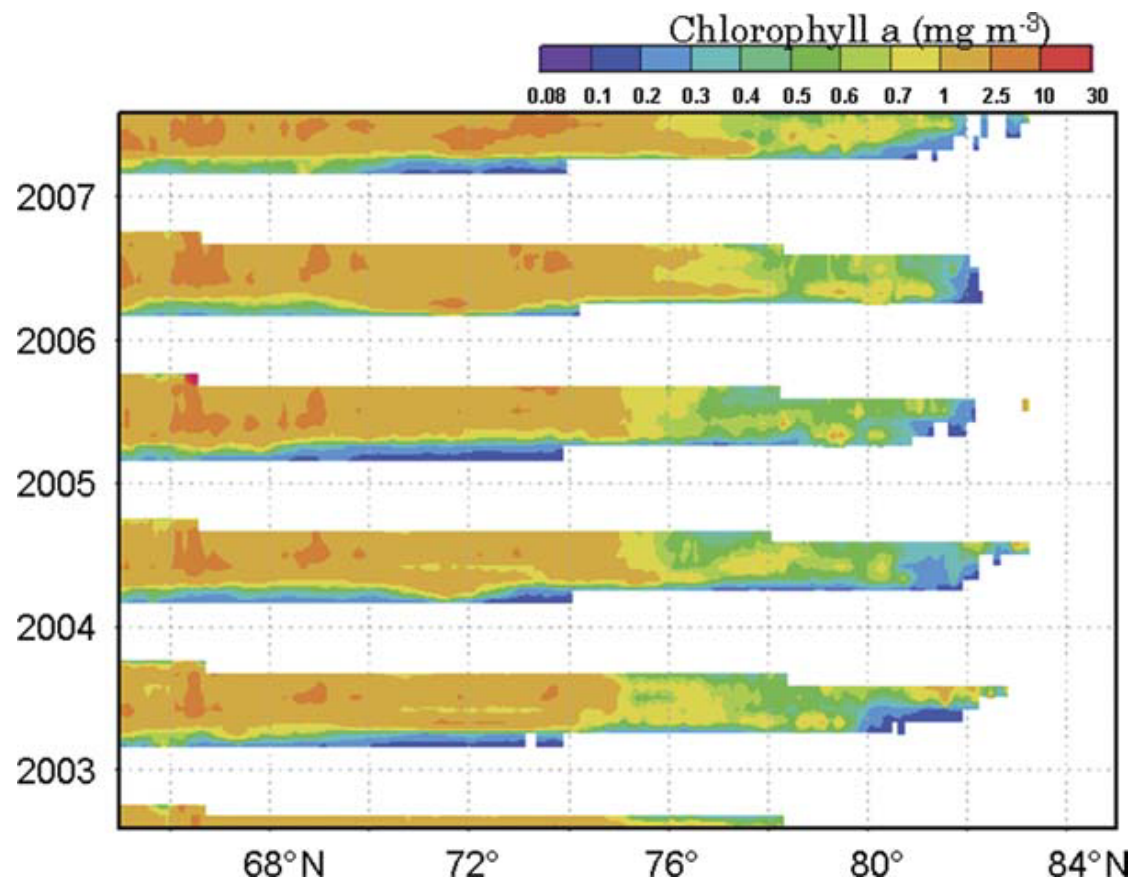

Figure 7. The latitudinal mean chlorophyll $a\left(\mathrm{mg} \mathrm{m}^{-3}\right)$ concentrations as a function of time from August 2002 through August 2007 for the Arctic $\left(65^{\circ} \mathrm{N}\right.$ to $\left.85^{\circ} \mathrm{N}\right)$. The images and data used in this study were acquired using the GES-DISC Interactive Online Visualization and Analysis Infrastructure (Giovanni) as part of the NASA's Goddard Earth Sciences (GES) Data and Information Services Center (DISC). (In color in Annals online.)
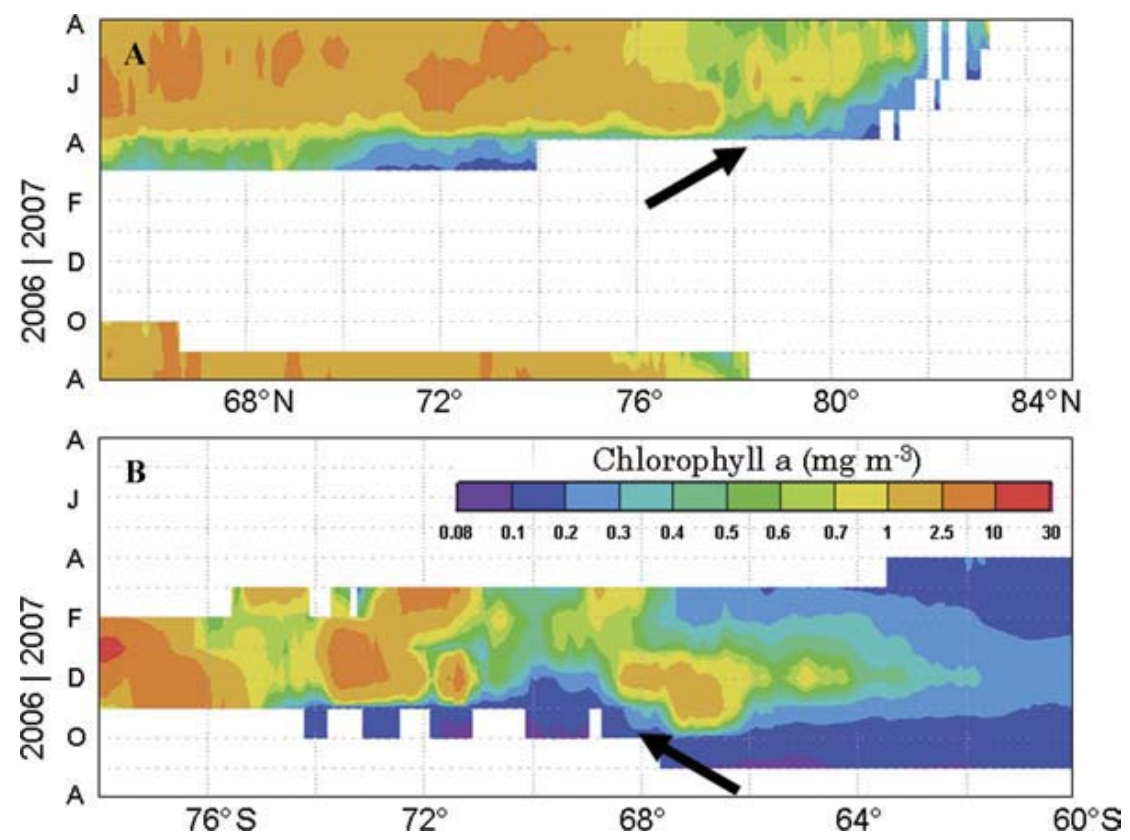

Figure 8. The latitudinal mean chlorophyll $a\left(\mathrm{mg} \mathrm{m}^{-3}\right)$ concentrations as a function of time from August 2006 through August 2007 for the (A) Arctic $\left(65^{\circ} \mathrm{N}\right.$ to $\left.85^{\circ} \mathrm{N}\right)$ and (B) Antarctic $\left(60^{\circ} \mathrm{S}\right.$ to $\left.78^{\circ} \mathrm{S}\right)$. Arrows depict the location and timing of the response of primary producers to the retreat of the marginal ice edges. The images and data used in this study were acquired using the GES-DISC Interactive Online Visualization and Analysis Infrastructure (Giovanni) as part of the NASA's Goddard Earth Sciences (GES) Data and Information Services Center (DISC). (In color in Annals online.) 
Peninsula have retreated between 1940 and 2001 , with the boundary of receding glaciers moving progressively southward over that time period (Cook et al. 2005). A history of the ice shelves along the Antarctic Peninsula also documented a southerly retreat over the same period (Skvarca et al. 1999). In fact, the Larson Ice Shelf is steadily decreasing in size, and it experienced dramatic collapses in 1995 (Skvarca et al. 1999) and 2002 (Fig. 3B). The cause of the break-up of the Larson Ice Shelf has been shown to be a combination of longterm thinning by a few tens of meters over thousands of years and short-term cumulative increases in surface air temperature that have exceeded the natural variation of regional climate over the last 10,000 years (Domack et al. 2005). Instability in regional ice shelves has also been linked to intrusions of upper Circumpolar Deep Water (CDW) onto the continental shelf (Smith et al. 2007). Intrusion of the warmer CDW has also been suggested as a mechanism for the observed retreat of glaciers and increases in air temperature in the region (Cook et al. 2005). Vaughan and colleagues (2003) suggested changing oceanographic circulation as a mechanism to explain the rapid regional warming in the area. Meredith and King (2005) reported coincident changes in surface waters along the Antarctic Peninsula, with surface temperatures in summer rising more than $1^{\circ} \mathrm{C}$, and upper layers exhibiting strong salinification. This increase was found to be driven by atmospheric warming and reduced rates of sea-ice production (Perovich et al. 2007), which may contribute significantly to the continued climate change in the region (Meredith \& King 2005; Overpeck et al. 2006). Loss of sea ice in this region will likely decrease stratification via these positive feedbacks. Conversely, increased freshwater input from melting glaciers and ice shelves will act to increase stratification along the coastal margins. Although comprehensive analyses of stratification are not available for this region, the interplay between these processes in the context of regional warming is likely to increase spatial heterogeneity in the physical and chemical environments. Ecosystem responses to these shifts will likely mimic their spatial and temporal complexity.

The warming trend along the Antarctic Peninsula is clear in sea-surface temperature data from August 2006 to August 2007 (Fig. 9). This area of warm water extends across the Bellingshausen Sea and well into the Amundsen Sea. These data also show that the arrival of warm water occurs early in the austral spring (September/October). Additional warming is evident in the Ross Sea, though it is unclear whether this pattern is unique for this year. It is interesting to note, however, the longitudinal extent of positive temperatures for much of the austral winter. The chlorophyll $a$ concentrations along the Antarctic Peninsula appear to be increasing with a propagation of high biomass to the west (Fig. 9). This westward propagation is also evident in the Amundsen Sea $\left(110^{\circ} \mathrm{W}\right)$ and off the Getz Ice Shelf $\left(170^{\circ} \mathrm{W}\right)$. Whether these apparent shifts in biomass are part of longer-term oscillations (Liu et al. 2004; Stammerjohn et al. 2008) is unclear. Comparison of longitudinal biomass between 2003 and 2007 also indicates a trend from distinct bloom locations in 2003 to more heterogeneous distribution around most of the continent in the later years. As in the Arctic, the total monthly chlorophyll $a$ concentrations for this defined region have increased in the 5-year period (Fig. $6 \mathrm{~B})$. The increased concentration appears to be trended northward (Fig. 10); however, neither sea-ice extent nor anomalies in sea ice appear to be related (data not shown). The annual retreat of the ice edge and associated bloom is clear from 2006 to 2007, with the rate of retreat similar to that in the Arctic (Fig. 8). What is apparent from the temporal record of latitudinal change is an increase in chlorophyll $a$ in the higher latitudes of the Southern Ocean (Fig. 10). This suggests the ice edge around the continental shelf has been receding further south and there has been a significant impact from melting of coastal glaciers and ice shelves (Cook et al. 2005) on the accumulation of phytoplankton biomass. 


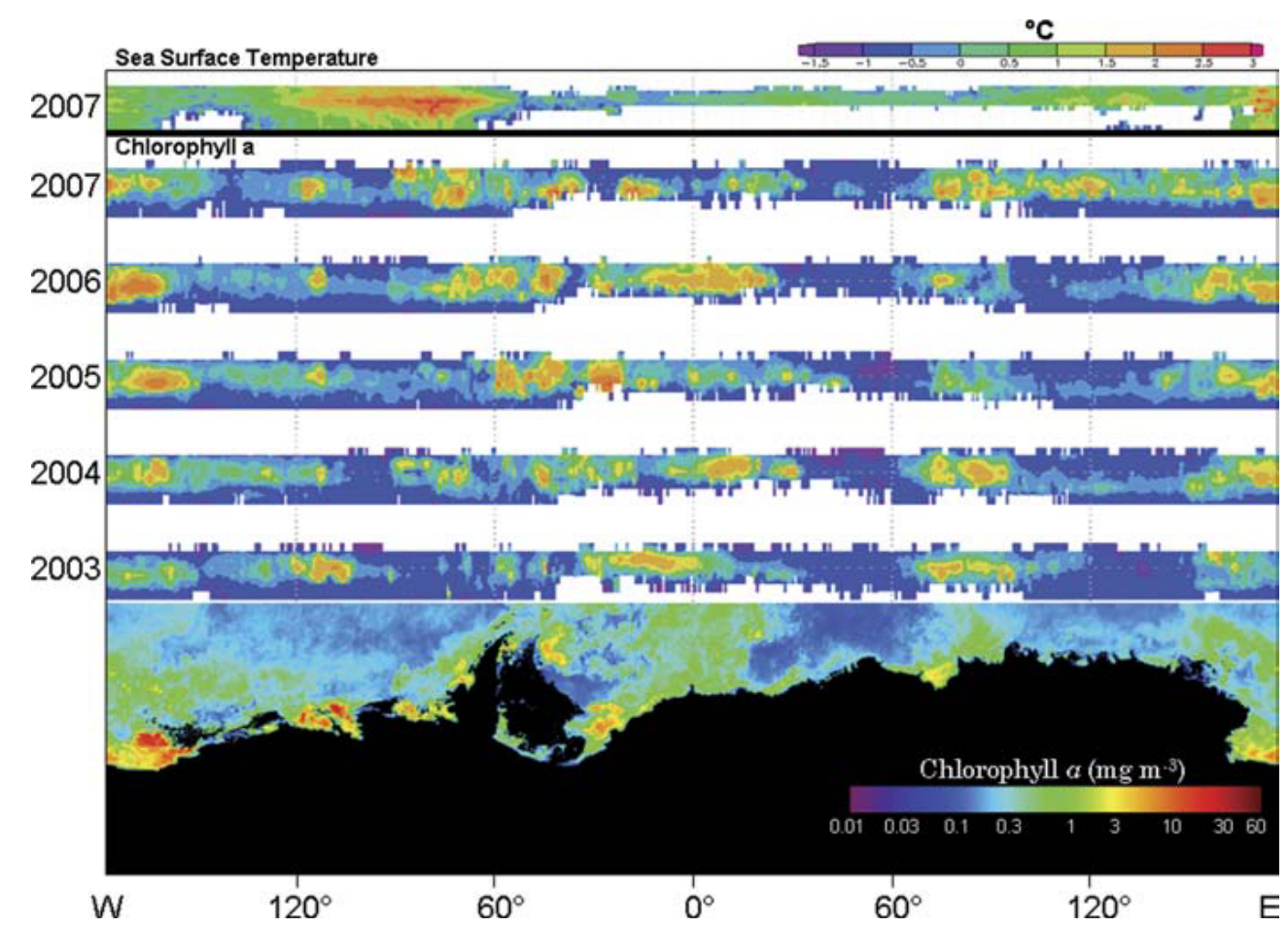

Figure 9. Same as Figure 5 except for the Antarctic $\left(60^{\circ} \mathrm{S}\right.$ to $\left.78^{\circ} \mathrm{S}\right)$. (In color in Annals online.)

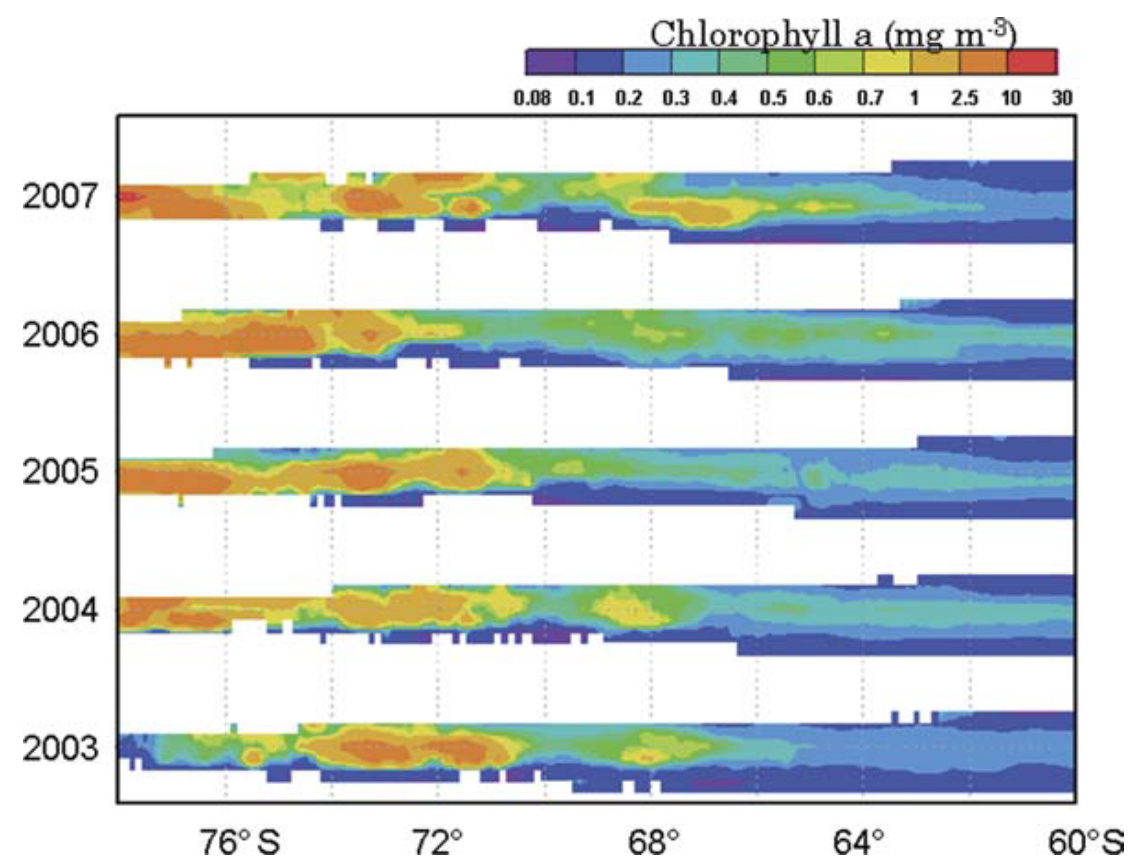

Figure 10. Same as Figure 7 except for the Antarctic $\left(60^{\circ} \mathrm{S}\right.$ to $\left.78^{\circ} \mathrm{S}\right)$. (In color in Annals online.)

These recent large-scale patterns in primary producers from both poles appear consistent with the existing literature on climate-mediated changes in ice dynamics. Although these satel- lite data provide a view of only the surface dynamics and they do not correlate directly with primary production in these regions (Behrenfeld \& Falkowski 1997; Behrenfeld et al. 2005), 
they show significant changes occurring over large spatial and temporal scales. Any alteration in primary production is likely to influence the rates of biogeochemical cycling, oceanatmosphere gas exchange, and the viability and success of higher trophic levels. Examination of the latter in the context of climate variability requires an ecological framework that addresses the response of biological systems at all levels of organization across relevant temporal and spatial scales.

\subsubsection{Direct and Indirect Impacts of Ice Dynamics on Polar Ecosystems}

Declines in sea ice may have either direct or indirect impacts on ecosystem components. Many species use sea ice as a substrate or essential habitat to successfully complete their life histories (Hop et al. 2002). The documented loss of sea ice in polar regions has had direct impacts on these species and dependent/associated species. The potential for direct impacts of sea-ice loss begins at the base of the food web, where significant numbers of obligate low-temperature, shade-adapted algal species (Lovejoy et al. 2006, 2007) and radiolarian species endemic to the Arctic Ocean Basin have been found (Lovejoy et al. 2007). The timing and rate of sea-ice loss has also been found to directly determine the degree of physiological stress in ice algae (Ralph et al. 2007) and is related to mortality in zooplankton (Hop et al. 2002). These physiological stressors have been linked to the nutritional status of ice algae (Palmisano \& Sullivan 1982), with implications for higher trophic levels. Sea ice also serves as habitat for invertebrates such as Antarctic krill (Murphy et al. 2007) and Arctic amphipods (Macnaughton et al. 2007), seabirds such as penguins (Forcada et al. 2006), and marine mammals such as Antarctic fur seals, minke whales, crabeater seals (Ribic et al. 1991), and harp and hooded seals (Johnston et al. 2005; Friedlaender et al. 2007).

Direct impacts of habitat loss can be contrasted with indirect changes that result from altered hydrography. For example, shifts in hy- drography have been linked to decreased sea ice observed in both polar regions, and altered hydrography provides a mechanism for introducing species. Reintroduction of Mytilus edulis has occurred along the west coast of Svalbard with the northward movement of North Atlantic Water (Berge et al. 2005, 2006; Blake 2006). Invasion of Pacific water into Chukchi Sea (Jiuxin et al. 2005) and Fram Strait (Shimada et al. 2004), has introduced a host of invertebrates to the Arctic basin that can sustain their reproductive cycles and overwinter because of the regional shift in hydrography and climate (Sirenko et al. 2006). The increased flow of rivers into the Arctic Ocean has been shown to decrease benthic diversity because of increased siltation and to halt feeding of Arctic cod and sand lance larvae due to increased plume depths (Fortier et al. 1996). In Antarctica, the intrusion of CDW into the shelf waters has been linked to sea-ice declines, ice-shelf disintegration, and glacial recession. These warm waters may introduce and select for different trophic assemblages (Atkinson et al. 2004), which may explain long-term trends in breeding for birds and mammals in the region (Barbraud \& Weimerskirch 2001, 2006; Rutishauser et al. 2004; Forcada et al. 2006). In fact, Biuw and co-workers (2007) documented a tight link between feeding and particular watermass types in Southern elephant seals. These water masses are partially dependent on sea-ice dynamics, with potential consequences for prey abundance and distribution and energetics of higher trophic levels.

\subsubsection{Framework for Evaluating Ecosystem Change}

Polar regions are characterized by a relatively short photic period and significant spatial variations in productivity. These constraints force organisms to meet the bulk of their energetic requirements in specific places within a narrow time window. Climatic changes are disrupting otherwise tight trophic interactions between predators and prey, and these disruptions can be both spatially and temporally 
dependent. The concept of synchronicity in food requirement and food availability and the subsequent impacts on energetics, survival, and reproduction has been cast in the match-mismatch hypothesis (Cushing 1969, 1982, 1990). The hypothesis was first developed to explain recruitment variation in a population by relating its phenology with that of prey species. The example used by Cushing (1969) was to examine how variability in the timing of peak production of zooplankton prey leads to variation in mortality of larval fishes and year-class recruitment. Although many variables are interacting to determine recruitment or breeding success of an individual or population, the application of the match-mismatch hypothesis in the polar regions is appropriate (Barbraud \& Weimerskirch 2006). Durant and colleagues (2007) advocate that two important requirements must be met in order to consider the match-mismatch hypothesis. The first is that both predators and prey must display a high degree of seasonality. The second is that the recruitment or survival of predators is governed by bottom-up control. Although strong seasonality is well established for polar organisms, debate about bottom-up controls continues (Smetacek \& Nicol 2005). In general, food availability is rarely the only factor governing survival and reproductive success, but it is accepted as a major driver in marine ecosystems (Oro et al. 2004).

A number of alternative hypotheses have been proposed in the literature to explain the impact of the physical environment on the predator-prey interactions. The member/vagrant hypothesis underlines the role of displacement of eggs and/or larvae from favorable shelf or bank areas (Sinclair 1988; Sinclair \& Iles 1989). The migration triangle hypothesis describes how organisms must migrate between spatially separate adult feeding grounds, spawning grounds, and nursery areas (Harden-Jones 1968). Although initially applied to fisheries, the benefits from migration could apply to many organisms or populations (Oro et al. 2004). More recently, the hy- drographic containment hypothesis combined the principles of the match-mismatch and migration triangle hypotheses (Cushing 1995). The oscillating control hypothesis (Hunt et al. 2002) attempts to relate the temporal dynamics of sea ice and variations in temperature at high latitudes over decadal scales to alterations in top-down and bottom-up control of piscivorous fishes. All of these hypotheses are distinct and specific to particular physical drivers, but they are arguably related to the degree separation of between predator and prey, which is the foundation of the match-mismatch hypothesis.

Initially, the basic premise of the matchmismatch hypothesis focused on temporal variability; however, factors influencing energetics, survival, and reproductive success are equally dependent on the degree of spatial overlap. For example, seabirds are known to concentrate their foraging in oceanic fronts at water masses boundaries, ice edges, and currents, which act to concentrate prey (see sections 2.1.2, 2.2.3, and 3.1.1; Hunt 1990; Schneider 1990). If these physical features are weak or the distance to concentrated prey is increased, the effective degree of spatial overlap relative the prey field decreases and can be equated to a temporal mismatch (Kooyman et al. 2007). For seabirds and marine mammals, one must also add depth to the spatial consideration. As an example, telemetry studies showed that King Penguins (Aptenodytes patagonica) exploit prey concentrated at the thermocline of the polar front located $340-450 \mathrm{~km}$ to the south of their breeding site (Charrassin \& Bost 2001). Increased distance to the polar front and/or a deeper thermocline would translate to mismatch, with negative impact on the penguins' reproductive success. In the Arctic, Hassol (2004) highlights the increased energetic costs suffered by walruses as a function of retreating ice edges. Colonies are fixed in space along coastlines, so the distance and depth of productive areas increase as the ice edge progressively retreats north in response to climate change. The increased foraging time also influenced the health of pups. 
In pelagic systems, spatial overlap itself becomes more critical for organisms that occupy higher trophic levels. This is a result of a combination of decreasing scale of organization or increasing spatial variance (Horne \& Schneider 1995), as well as a change in encounter rate probabilities between predator and prey (Sims 2006). Benthic systems have also been shown to be changing community structure and production with decreases in sea-ice cover (McMinn et al. 2004). As these systems are spatially fixed with respect to depth, any changes in the overlying water column (including sea ice) will lead to increased predator-prey mismatches. In the Northern Bering Sea, such a mismatch can be discerned from geographic displacement of marine mammal populations coinciding with a reduction in benthic prey, an increase in pelagic fish, a reduction in sea ice, and an increase in air and ocean temperatures (Grebmeier et al. 2006). These ecosystem changes in the shallow Bering Sea may serve as a model for shallow shelf systems in the Arctic Ocean.

Thus, a complex rubric of temporal and spatial overlaps establishes the upper limits of matching and predator-prey interaction. While specific predator-prey interactions are governed by this temporal and spatial dependency, from an ecosystem-level perspective, overall productivity will be determined by the interactions among matches and mismatches at all trophic levels (van Franeker et al. 2001). Additionally, in pelagic ecosystems, algaezooplankton interactions form the basis for energy flux to higher trophic levels. The recruitment success of higher trophic levels is highly dependent on synchronization with pulsed planktonic production (Edwards \& Richardson 2004). A decoupling of predator-prey relationships at lower trophic levels due to, for example, climate change, will likely lower production for all higher trophic levels, with potentially drastic ecological consequences (Winder \& Schindler 2004). Edwards and Richardson (2004) documented such climate-induced changes in the North Sea, where mismatches increased as the synchrony of peak production among successive trophic levels began to decay.

Other considerations can mediate the impacts of temporal and spatial mismatches among trophic levels. For example, Durant and colleagues (2005), found that overall food abundance could offset timing mismatches. Offsets may also be moderated by food quality (i.e., taxonomic composition) and condition of the food source. The plasticity of an organism (i.e., feeding generalist) or population is also likely to offset time and space mismatches. Walther and coworkers (2002) discuss the thermal tolerances of Antarctic organisms and the decreasing likelihood that some organisms will be exposed to their lower thermal limits because of increasing temperatures. This will thereby allow increases in both numbers and extent of these populations previously at the edge of their range, while also increasing the risk of exposure to upper thermal limits for some organisms. Some plasticity is afforded to mobile species as they are more likely to behaviorally respond to change. Plasticity is also increased in mammals as they accumulate body reserves in preparation for winter and transfer to young, which creates a temporary buffer allowing for migration to improved habitats. However, post-weaning survival for place-centered foragers, such as pinnipeds, still will be highly dependent on proximity of food resources to the rookery (Rutishauser et al. 2004). Some populations are also dependent on genetic variability and age structure. If the timing of a trophic mismatch disproportionately affects these characteristics of a population, the probability of a total year-class failure is likely to increase. This was shown in cohorts of Arctic cod in response to climate-dependent changes in temperature and prey density (Ciannelli et al. 2007). Ottersen and colleagues (2006) highlight this general concern for commercially exploited fisheries, which receive special selective pressures. Ecological changes, in turn, reshaped the fisheries, contributing 
to altered distributions of fisheries-dependent communities (Hamilton \& Haedrich 1999), making it difficult to discriminate between the effects of harvesting and ecosystem impacts driven by climate change (Smetacek \& Nicol 2005).

The match-mismatch hypothesis also applies only to predator-prey interactions that respond to different environmental cues for their phenology. The plasticity of an organism therefore decreases if the environmental cue (i.e., photoperiod) is invariable for particular latitudes. In the Arctic marine environment, the phytoplankton bloom along the marginal sea ice can occur early or late depending on sea-ice dynamics. Zooplankton is spatially coupled to phytoplankton and metabolically affected by sea temperature, leading to oscillating controls, where the system alternates between primarily bottom-up control in cold regimes and primarily top-down control in warm regimes (Hunt et al. 2002). In the same context, the rate and spatial extent of sea-ice retreat is likely to drive fish productivity and to some extent productivity of piscivorous fishes (Ciannelli \& Bailey 2005), marine birds (Croxall et al. 2002), and mammals (Grebmeier et al. 2006). Given these predator-prey dependencies, it is clear that climatic forcing will impose change in polar ecosystems. If some species are coupled to an invariant environmental cue, such as photoperiod, and other species have adapted their phenology to current climate conditions, then climate change can be expected to weaken the synchronization (match) between food availability and the food requirements for the average predator individual (Visser et al. 2004).

This introduction has provided background on ice dynamics, the mechanistic drivers for the observed changes in climate and ice dynamics, and an ecological framework for ecosystem interaction. The following case examples highlight and detail the current impacts of climatedriven changes in ice dynamics on ecosystems. They are divided into cases of direct impacts of sea-ice loss on polar organisms and interac- tions and cases of impacts related to indirect climate-induced changes.

\section{Direct Impacts of Decreasing Ice Habitat}

\subsection{The Arctic Ocean}

\subsubsection{Sympagic Fauna of the Arctic Food Web}

Historically, a broken layer of sea ice capped 4-17 $\times 10^{6} \mathrm{~km}^{2}$ of the Arctic Ocean (Fig. 1). Sea ice comprises a three-dimensional matrix of ice crystals and brine channels that does not remain static. Leads and polynyas form and shift. Specialized flora and fauna, the sympagic assemblage, occupy the brine channels in sea ice, with edge habitats being particularly productive (Gradinger 1995). Overall, the sympagic assemblage plays a critical role in the production and transfer of organic matter through Arctic food webs, especially in areas where seasonal sea ice reduces the penetration of light resulting in relatively low pelagic productivity (Carmack et al. 2006). In fact, sympagic organisms are central components of Arctic food webs and support many of the apex predators found in the Arctic (Fig. 11; Tynan \& DeMaster 1997; Hop et al. 2002; Gradinger et al. 2004; Tremblay et al. 2006). Thus, spatiotemporal patterns in the sympagic assemblage link the health of Arctic ecosystems to sea ice and its dynamics. Warming of the earth's atmosphere changes the extent of sea ice and its dynamics. Such changes represent critical forcing factors for Arctic ecosystems. Less sea ice translates directly into loss of habitat for sympagic organisms. The effects of altered dynamics may exacerbate the effects of habitat loss. In particular, a mismatch between the life histories of key players in the sympagic assemblage and the dynamics of sea ice may yield undesirable consequences.

Flora and fauna with strong ties to sympagic habitats include ice algae, amphipods, copepods, hyperiids, polar cod, and ringed seals. 


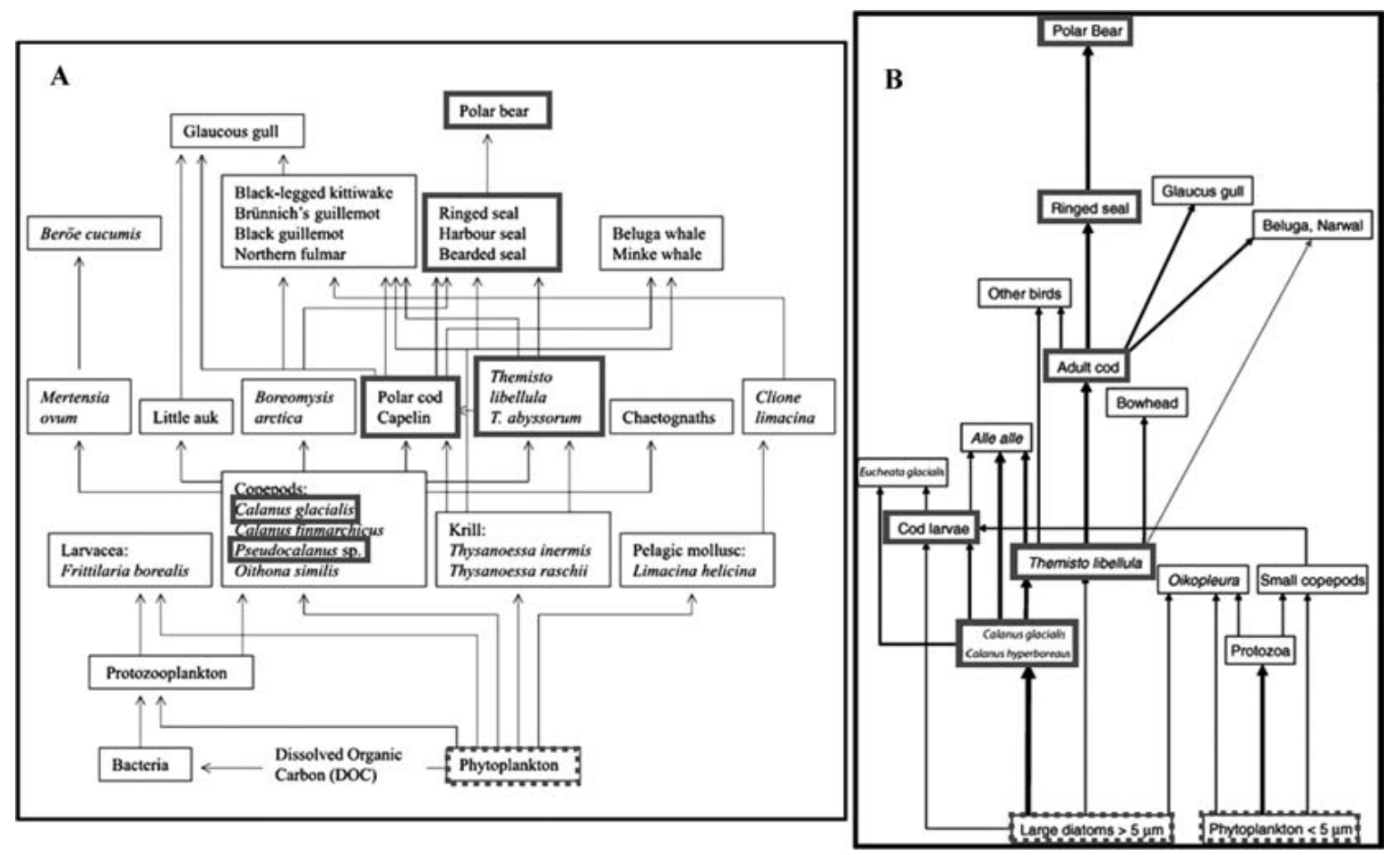

Figure 11. Depictions of Arctic food web from (A) the Svalbard region (adapted from Hop et al. 2002) and (B) from the North Water Polynya system (adapted from Tremblay et al. 2006). Sympagic organisms are highlighted in bold gray to illustrate the importance of ice to the food-web structure. Dotted lines are around phytoplankton, as not all are ice algae. Both food webs were generated based on carbon budgets, stable isotopes, gut contents, and previous literature.

Arctic ice algae comprise at least 40 taxa even in winter (Booth \& Horner 1997; Werner et al. 2007). Although ice algae represent a relatively diverse assemblage, diatoms contribute significantly to diversity and abundance (Werner et al. 2007). Key taxa include Melosira arctica, Attheya septentrionalis, Nitzschia spp., and Synedropsis hyperborean. Amphipods, such as Onisimus spp., Gammarus wilkitzkii, and Apherusa glacialis, characterize sea ice throughout the Arctic (Carey 1985; Lønne \& Gulliksen 1991a, 1991b; Poltermann et al. 2000; Werner \& Gradinger 2002; Arndt $\&$ Beuchel 2006). These species grow to be over $5 \mathrm{~mm}$ in length over a period of up to 6 years and mature in 1-2 years. They primarily occupy the interface between the sea ice and the water column. Pelagic zooplankton, such as Pseudocalanus spp., Calanus hyperboreus, and Calanus glacialis (Gradinger \& Bluhm 2004) can be found in the water column beneath sea ice. Calanus hyperboreus is the largest species at $5 \mathrm{~mm}$ in length. Multiple-year life cycles char- acterize these species. The hyperiid amphipod Themisto libellula (formerly Parathemisto libellula) ranges throughout the Arctic Ocean. These pelagic amphipods have life spans of 2-3 years and grow to $31 \mathrm{~mm}$ in length (Koszteyn et al. 1995). Boreogadus saida, the Arctic cod, represents the most northerly distributed species of Gadidae and is a key species between lower and upper trophic levels in Arctic food webs (Fig. 11; Gradinger \& Bluhm 2004). It occurs nearshore and offshore between $60^{\circ} \mathrm{N}$ and the North Pole. Ringed seals, Phoca hispida, are abundant throughout the Arctic Ocean year round (Wȩsławski et al. 1994; Born et al. 2004).

Environmental forcing factors in the Arctic undergo strong seasonal fluctuations (Werner et al. 2007). Starting in spring, increased solar radiation drives $40-50^{\circ} \mathrm{C}$ increases in air temperature, decreases in snow cover and thinning of sea ice. Increased solar radiation, decreased snow cover, and thinner sea ice result in more light impacting the sea ice-seawater 
interface. In addition, increased sea-ice temperature leads to lower brine salinity and greater brine volume. The temperature of sea ice and the salinity of brine channels restrict diatoms to the lower decimeters of the sea-ice matrix (Gradinger 1995). Increases in sea-ice temperature and the presence of more, lower salinity brine expand suitable habitat for sympagic flora and fauna. Most importantly, changes in light drive increases in the productivity and biomass of ice algae (Gradinger 1995). Ice algae have adapted to the low light levels characteristic of sea ice, and they begin growing at 2-10 $\mu \mathrm{mol} \mathrm{m} \mathrm{m}^{-2} \mathrm{~s}^{-1}$. By summer, abundances of algal cells increase by one to two orders of magnitude to yield $1-100 \mathrm{mg}$ chlorophyll $a \mathrm{~m}^{-2}$. A variety of primary consumers inhabit or utilize the highly productive interface between the lower layers of sea ice and the water column (Gradinger 1995). The endemic amphipods, Onisimus spp., Gammarus wilkitzkii, and Apherusa glacialis, which live on the undersurface of the sea ice, and pelagic copepods that migrate to this interface, feed on ice algae and each other (Arndt 2002; Prokopowicz \& Fortier 2002; Gradinger \& Bluhm 2004; Arndt \& Beuchel 2006). Gammaridean amphipods reach abundances of $1-1000$ animals $\mathrm{m}^{-2}$, and epipelagic copepods reach abundances of 5000-9000 animals m ${ }^{-3}$ (Auel \& Hagen 2002; Gradinger \& Bluhm 2004).

The hyperiid amphipod, Themisto libellula, and the Arctic cod, Boreogadus saida, represent key secondary consumers in habitats characterized by sea ice. As adults, Themisto libellula appear to feed primarily or exclusively on calanoid copepods, especially Calanus hyperboreus and Calanus glacialis (Scott et al. 1999; Auel \& Werner 2003). This hyperiid amphipod exhibits direct development, with breeding in spring and summer (Auel \& Werner 2003). Boreogadus saida associate with sea ice from their larval stage through their juvenile stages, and they can be found sheltering in brine channels (Gradinger \& Bluhm 2004). Spring and summer cohorts of larvae have been recorded, and larval survival bears a complex relationship to water temperature as effected by the break-up of sea ice and production of copepod nauplii in response to spring algal blooms (Drolet et al. 1991; Fortier et al. 1995; Michaud et al. 1996; Fortier et al. 2006). Large schools of adults move through the Arctic Ocean (Welch et al. 1993; Gradinger \& Bluhm 2004), and dense swarms of Themisto libellula can account for over 20\% of the energy content of the macrozooplankton community (Percy \& Fife 1985; Auel et al. 2002; Gradinger \& Bluhm 2004). Both Boreogadus saida and Themisto libellula exert significant predation pressure on the amphipods and copepods that graze on ice algae. In summer, larger copepods found under sea ice migrate upward to the chlorophyll-rich interface between the sea ice and the water column during the period of maximum decrease in irradiance, and return to depth well before the maximum increase in irradiance associated with dawn (Fortier et al. 2001). This normal diel vertical migration occurs despite the lack of a gradient in ultraviolet $\mathrm{B}$ radiation or temperature, and it has been interpreted as a reaction to visual predation by Themisto libellula and Boreogadus saida (Fortier et al. 2001). Ringed seals, Phoca hispida, appear to be generalists, but Boreogadus saida and Themisto libellula rank among the top five prey items (Welch et al. 1993; Wȩsławski et al. 1994; Gradinger \& Bluhm 2004). The seals primarily feed on prey less than $20 \mathrm{~cm}$ in length, which encompasses the bulk of the size distribution for Boreogadus saida and Themisto libellula (Wȩsławski et al. 1994). In fact, Phoca hispida near sea ice appeared to remain in relatively shallow water because of the distribution of these prey species (Born et al. 2004).

In concert with a warming of the ocean, the extent of the sea ice in the Arctic has decreased by an average of 3\% per decade between 1978 and 1996, and the ice has thinned by up to 40\% since 1950 (Parkinson 2002b). Predictions enhanced with data from a major reduction in sea ice observed during 2002 estimate 12$46 \%$ decreases in sea-ice extent by 2100 and essentially ice-free summers by 2099 (Walsh \& Timlin 2003; Overpeck et al. 2006). The 
ramifications of such changes in sea ice may reach to upper trophic levels. Changes to sea ice, especially a decrease in its extent, are highly likely to lead to changes in the distribution and abundance of sympagic flora and fauna. In essence, the sympagic portion of the Arctic ecosystem should shift toward a pelagic, subarctic ecosystem (Grebmeier et al. 2006). Phytoplankton productivity is predicted to increase as light allows utilization of available nutrients (Smetacek \& Nicol 2005). As a result, mesozooplankton productivity should also increase, with existing Arctic species meeting increasing competition from subarctic species that are expanding their range (Gradinger 1995). For example, numbers of Themisto libellula and Boreogadus saida may decrease due to their use of sea ice during early life-history stages and because of increased competition with subarctic species, such as Themisto abyssorum and Gadus morhua, that will expand or continue to expand their ranges northward (Gradinger 1995; Auel et al. 2002; Drinkwater 2005). Phoca hispida may not be able to adapt to a loss of habitat, especially a habitat used for birth lairs, combined with a reduction in its principal prey, including Boreogadus saida and Themisto libellula (Tynan \& DeMaster 1997).

Less certainty surrounds the effects of altered sea-ice dynamics. Temporal shifts in the expansion and reduction of sea ice may lead to mismatches with the life histories of key sympagic organisms. These links include the timing of increased activity and reproduction of primary and secondary consumers in anticipation of increased productivity of ice algae. If one or more of the links between increased light penetration, higher production by ice algae, increased activity and breeding of crustacean grazers and predators, and production and feeding of larval and juvenile Boreogadus saida fail, then effects may flow through the sympagic assemblage and on to top predators, such as Phoca hispida, various bird species (see section 2.1.2), and perhaps polar bears (Ursus maritimus; see section 2.1.3). Thus, the sympagic assemblage represents a central component of the Arctic ecosystem that is closely tied to the extent and dynamics of sea ice. The ability of the sympagic assemblage to cope with habitat loss, increased competition, and altered habitat dynamics remains a central and uncertain element in predictions of effects flowing from changes in sea ice due to warming of the earth's atmosphere (Tynan \& DeMaster 1997).

\subsubsection{Impacts of Arctic Sea-ice Loss on the Black Guillemot}

As stated in the previous section, the floating sea ice in the Arctic Ocean supports a sympagic under-ice community, with ice-adapted amphipods and a single fish species, Arctic Cod (Boreogadus saida), particularly important to marine apex predators throughout the Arctic Basin (Lønne \& Gulliksen 1989). This community provides a near-surface food source that is especially important in the high Arctic where limited mixing limits water column productivity and prey. In the western Arctic, including the Chukchi, Beaufort, and East Siberian Sea, the sympagic community is important to resident marine mammals (Hoekstra et al. 2002) and migrant and resident bird populations (Divoky 1976, 1984; Watson \& Divoky 1972).

The summer melt of the Arctic sea ice has dramatically increased in recent decades with the 2007 pack ice minimum extent only about $50 \%$ of that in the 1960 s and 1970s (Fig. 2). Western Arctic waters experienced some of the earliest and most extreme decreases in ice extent (Fig. 3A; Comiso 2002a, 2002b; Maslanik et al. 1996). The reductions in sea-ice extent could be expected to cause concurrent changes in the availability and abundance of sympagic prey to the region's trophic webs, but the consequences of these changes have been poorly documented due to a lack of systematic observations.

Annual observations of the black guillemots (Cepphus grylle) breeding on Cooper Island, in the western Beaufort Sea, $30 \mathrm{~km}$ east of Point Barrow (Fig. 3A), provide some indication of how the recent ice decrease has affected marine apex predators. The race of black 
guillemot occupying the western Arctic is apparently one of the few avian species that is a sea-ice obligate in the Arctic. It breeds north of the Bering Strait at locations where nearshore sea ice is present for at least part of the breeding season, with the largest colonies in regions where ice remains near shore throughout the summer (Portenko 1989; Kondratyev et al. 2000). While lower latitude conspecifics and congeners rely in large part on nearshore demersal prey during breeding, there is limited diversity and abundance of nearshore prey in the Arctic due to ice scour (Gutt 2001), and the zooplankton and fish associated with the underside of ice provide guillemots with an alternative to nearshore demersal prey. The effects of this change in prey availability on the marine trophic webs in the region could be expected to be major. One of the data sets that allow examination of these effects has been gathered at Cooper Island, where annual observations of black guillemot breeding biology have been made since 1975 .

The decreases in summer pack-ice extent are correlated with changes in black guillemot population size, breeding success, and prey provided to nestlings. The Cooper Island colony, where all nests are in man-made structures, had 10 pairs when it was discovered in 1972 (Divoky et al. 1974), but nest-site creation increased the colony to 200 pairs in the late 1980s (Fig. 12), when there was a population of $>100$ nonbreeders and the population was nest-site limited. Beginning in the early 1990s, however, the colony began to decline, decreasing to as low as 115 pairs in 1998 and 1999, before recovering slightly in the 21 st century. The decline in population coincided with a shift in the Arctic Oscillation, the dominant atmospheric circulation pattern in the western Arctic, that resulted in changes in sea-ice movement and rapidly increasing melt (Maslanik et al. 1996; Comiso 2002b; Rigor et al. 2002). The specific causes for the decline are being investigated, but could include decreased breeding productivity at source colonies, changes in recruitment as summer distribution of nonbreeders was modified by ice

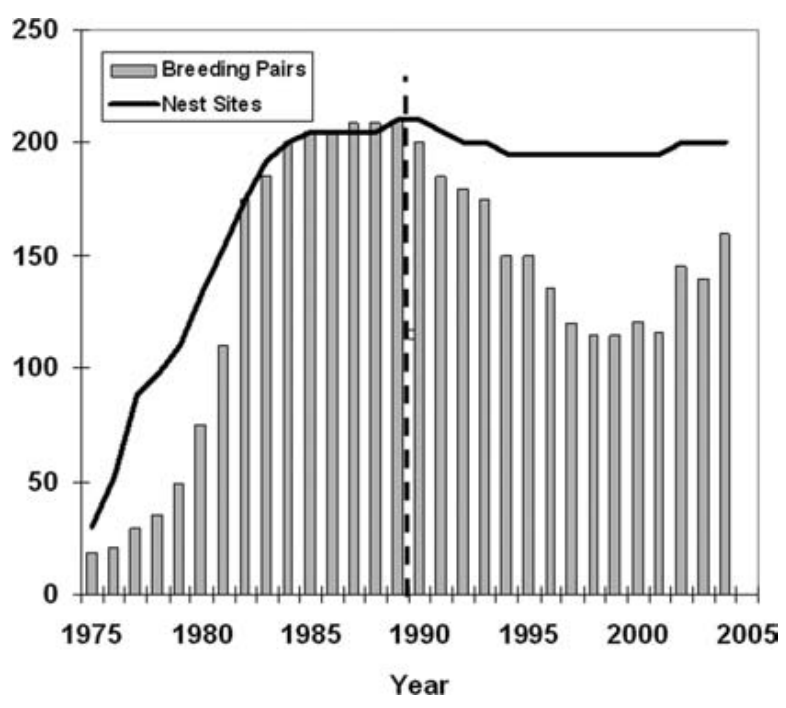

Figure 12. Number of black guillemot nest sites and breeding pairs 1975-2004. Dashed vertical line shows beginning of "warm" phase Arctic Oscillation and increased summer ice melt.

retreat, and decreased breeding productivity at the study colony. The effects of sea-ice retreat at the colony were seen, as breeding productivity dropped as the distance from the island to the ice edge increased (Fig. 13). Daily observations of black guillemot prey in 2007 showed a high correlation between the percentage of Arctic Cod in the diet and the distance to the ice edge (Fig. 14). This is evidence for spatial mismatch and the breeding success of the black guillemot being directly linked to the accessibility of the sea-ice edge, specifically to the availability of the Arctic Cod. While the ice retreat has decreased prey abundance for seabird species dependent on sympagic prey, it is concomitantly allowing more subarctic species to expand their ranges northward, with the horned puffin prospecting nest sites in the 1970s (Divoky 1982) and breeding at the Cooper Island in 1986, the first breeding record of the species in northern Alaska.

\subsubsection{Ice Loss and Population Trends in Polar Bears and Associated Species}

Perhaps the most dramatic impact of sea-ice loss on an upper trophic predator is the example of polar bears (Ursus maritimus). Polar bears depend on sea ice for many aspects of their 

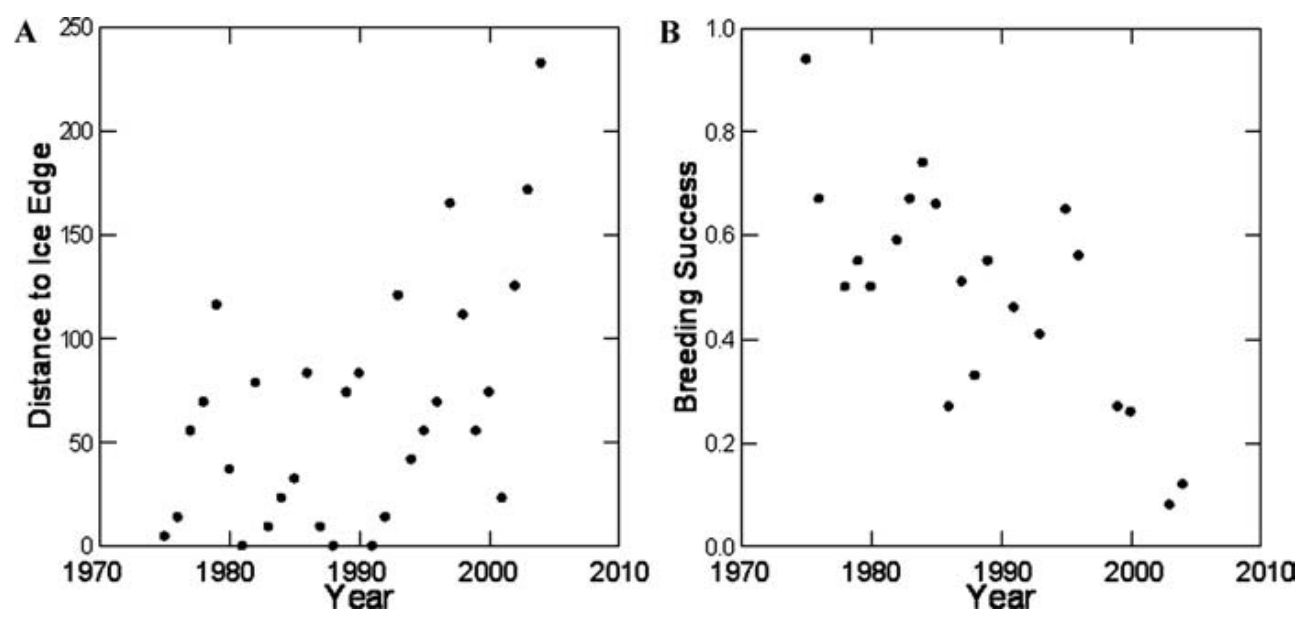

Figure 13. (A) Distance to ice edge $(\mathrm{km})$ from black guillemot colonies on Cooper Island and (B) breeding success of black guillemots on Cooper Island (omitting years with major nest predation) 1975-2004.

life history (Stirling \& Derocher 1993). Most importantly, the polar bear requires sea ice to feed: it hunts ringed (Phoca hispida) and bearded seals (Erignathus barbatus) as well as other iceassociated marine mammals (such as walrus, beluga whale, or harp seals) by lying in wait at breathing holes in the ice, by stalking their prey on ice floes, or by leaping on snow-covered seal birth lairs (e.g., Martin \& Jonkel 1983; Hammill \& Smith 1991). Sea ice can also be a platform on which polar bears seek out mates and copulate (Ramsay \& Stirling 1986) and on which they traverse long migratory routes (Schweinsburg \& Lee 1982). It is a drifting means of reaching maternity denning sites on land (Harington 1968) and can serve as a denning site itself (Lentfer 1975; Amstrup 1986). Deteriorating and retreating sea-ice conditions have been linked to decreased natality, decreased body condition, altered behaviors, increasing numbers of negative interactions with humans, and mortality in the polar bear (Stirling \& Derocher 1993; Amstrup \& Gardner 1994; Stirling et al. 1999; Regehr et al. 2005; Fischbach et al. 2007).

Declines in the duration of seasonal sea ice have been linked to declines in body condition of bears and subsequent population declines (FIG. 15). With the early break-up of sea ice, polar bears have less time to hunt

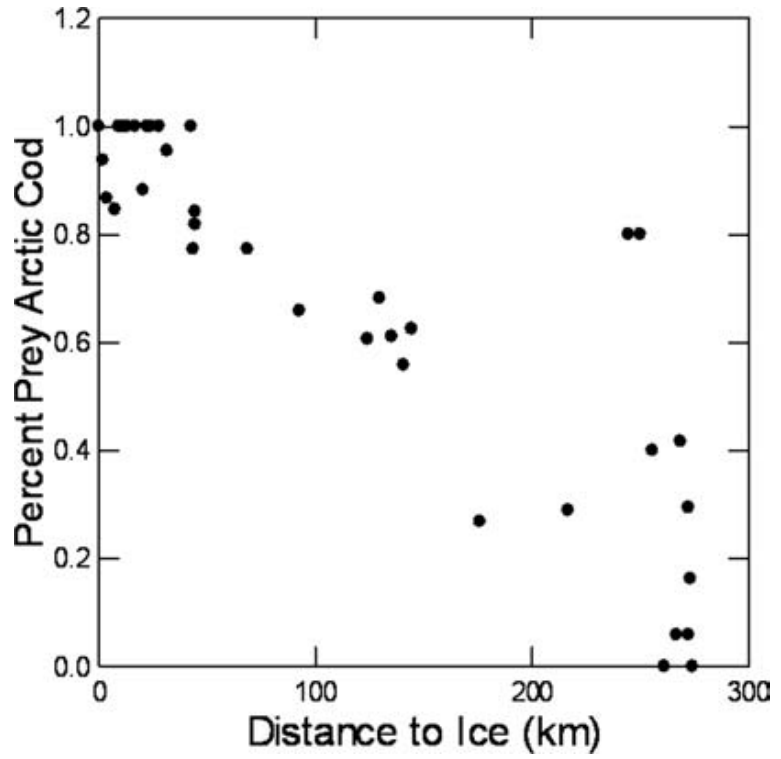

Figure 14. Percent Arctic cod of daily prey for black guillemot nestlings in relation to distance from sea ice in 2007.

for food before some populations need to begin the period when they fast. Polar bears in western Hudson Bay and James Bay fast for at least 4 ice-free months of the year (Stirling \& Derocher 1993), and pregnant females for 8 months (Stirling et al. 1977; Ramsay \& Stirling 1988). Leaner females produce smaller litters and lighter cubs (Derocher \& Stirling 1994) that are less likely to survive (Derocher \& Stirling 1996; Obbard et al. 2007). Stirling and colleagues (1999) found that body condition 


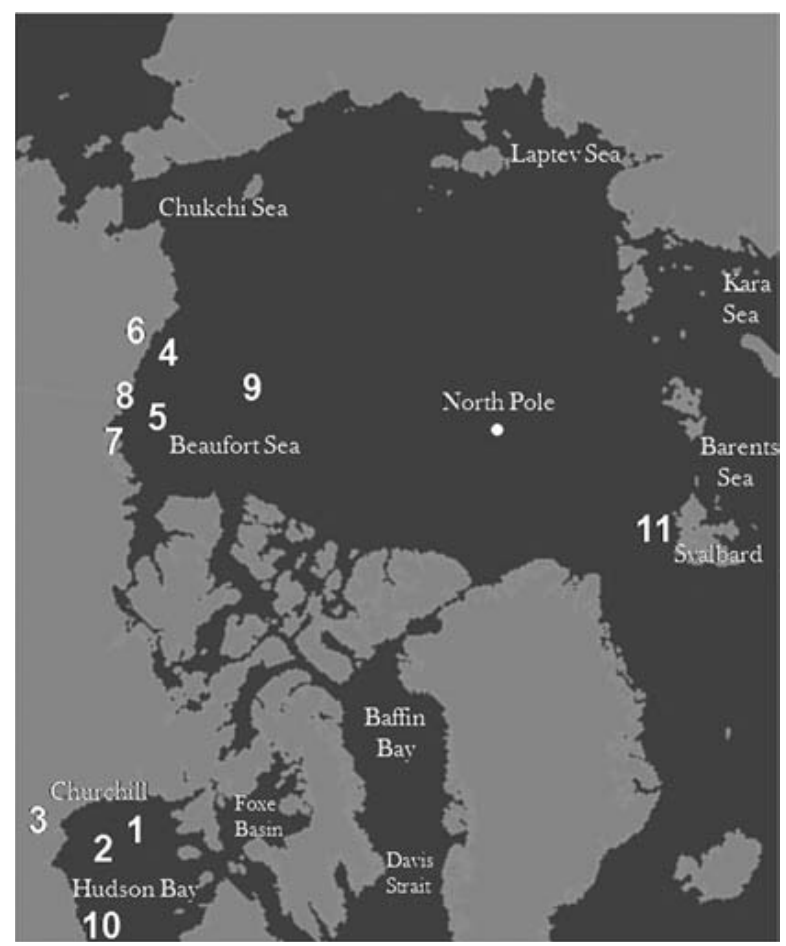

Figure 15. Numbers indicate locations of documented and cited effects of declining sea ice on polar bears. (1) A decrease in body condition in western Hudson Bay (Stirling et al. 1999). (2) A population decline of $22 \%$ in western Hudson Bay (Regehr et al. 2005). (3) Increasing bear-human interactions at Churchill (Stirling \& Derocher 1993). (4) Mortality associated with extended swimming in the Beaufort Sea (Monnett \& Gleason 2006). (5) Lower cub size and apparent survival in the southern Beaufort Sea (Rode et al. 2007). (6) Shifting to landed dens in northern Alaska (Fischbach et al. 2007). (7) Shifting to landed dens in the Beaufort Sea population (Amstrup \& Gardner 1994). (8) Pregnant females experiencing increased travel to denning habitat (Bergen et al. 2007). (9) Northern Beaufort Sea population is stable (Stirling et al. 2007). (10) Declines in body condition (but not numbers) in southern Hudson Bay (Obbard et al. 2007). (11) Declines in reproductive success negatively correlated with the Arctic Oscillation in Svalbard (Derocher 2005).

(defined as weight/length ${ }^{2}$ ) of bears in western Hudson Bay from 1981-1998 declined with the earlier break-up of sea ice. In 1991, however, when sea-ice break-up occurred 3 weeks later due to cooling from the Mt. Pinatubo eruption, body condition improved, and in the following year, female natality and cub survival were greater (Stirling \& Lunn 1997; Stirling et al.
1999). Between 1987 and 2004, this population has declined by 22\% (Regehr et al. 2005), which is likely the result of declines in body condition. A similar pattern has been found in the Southern Beaufort Sea. From 1982-2006, the number of yearlings per female there was positively related to the percent of days in which sea ice covered the continental shelf. Cub size and apparent survival were lower with poor ice coverage (Rode et al. 2007). Likewise, a study in Svalbard, Norway from 1988-2002 found that litter production rate, natality, and the body length of adults declined over the period (Derocher 2005). The reduced reproductive success was correlated with the Arctic Oscillation index: warmer years saw fewer cubs.

With increases in the period of open water in western Hudson Bay, polar bear interactions with humans have increased - in particular, more bears have been found in the town of Churchill and its dump (Stirling \& Derocher 1993). Polar bears are also forced to swim longer distances back to shore. In 2004, the ice edge north of Alaska reached a record distance from shore-over $250 \mathrm{~km}$ (Stroeve et al. 2005). An unprecedented number of polar bears were seen swimming in open water $(>2 \mathrm{~km}$ from shore) that year, including four that apparently drowned during a storm (Monnett \& Gleason 2006). Sea conditions are predicted to worsen without sea ice dampening the effect of wind (Monnett \& Gleason 2006).

Polar bears prefer to feed at near-shore zones where ice is constantly moving, opening and closing, rather than pelagic areas (Smith \& Stirling 1975; Pomeroy 1997; Stirling 1997; Durner et al. 2007). Loss of sea ice typically translates to loss of preferred polar bear habitat because the spatial pattern of melt is generally from the edge of the ice pack, polewards (Durner et al. 2007). Alaskan and Eurasian bears will either have to migrate long distances to remain on the ice or spend summers stranded on land (Durner et al. 2007).

With declines in sea ice, polar bears are changing the habitat where they build maternity dens. Pregnant females create maternity 
dens in autumn or early winter - on land or ice - where they give birth and nurture the young until spring (Amstrup \& Gardner 1994). In northern Alaska, a 20-year study of satellite collared females revealed significant changes away from dens on pack ice, in favor of dens that are land-based (Fischbach et al. 2007). The longer melt period and the replacement of stable, old ice with younger, unstable floes was likely responsible for this pattern. Furthermore, a 1981-1991 study in the Beaufort Sea population found that in later years a higher proportion of the bears made land-based dens (Amstrup \& Gardner 1994). No differences were observed in the success of these dens, but this trend toward denning on land is a matter of concern for two reasons: 1) landed dens are more susceptible to human disturbances (Amstrup 1993), and 2) if ice break-up trends continue, foraging females may not be able to return to land before their route is cut off, forcing them to den on suboptimal ice (Fischbach et al. 2007).

Bergen and colleagues (2007) used the passive microwave record of sea ice from 19792006 to estimate that polar bears returning to Alaska to den have experienced an annual increase in minimum travel of 6-8 $\mathrm{km}$ per year (>168 km over the 28-year period). This rate almost doubled after 1992. They predicted the ice-retreat rate, based on global climate models, to be $16 \mathrm{~km} /$ year over the period 2001-2060, which would mean an increase in the distance pregnant females travel from $385 \mathrm{~km}$ in 1985, to $1487 \mathrm{~km}$ in 2060 . It would take a bear 10 and 38 days, respectively, to travel these distances (Bergen et al. 2007).

While polar bears have some plasticity in their diets, they would have difficulty surviving on purely terrestrial resources. There are increasing reports of bears searching for food on land (e.g., Stempniewicz 1993, 2006), which may be due to the fact that bears are looking for alternative prey. Derocher and co-workers (2000) observed bears hunting and scavenging reindeer. Russell (1975) reported that bears in James Bay eat birds, marine algae, grasses, and berries. However, the bulk of their diet is made up of marine mammals that are associated with ice (as reviewed in Derocher et al. 2002).

Polar bear distribution is circumpolar but the direct effects of loss of sea ice impact some regions more than others. For example, Stirling and colleagues (2007) found that the population of polar bears in the Northern Beaufort Sea between 1971-2006 was fairly stable and attributed this to the fact that ice in this area does not melt completely. While the western Hudson Bay population has experienced declines linked to concomitant sea-ice changes, the numbers of the most southerly population of bears in Southern Hudson Bay have remained stable since the mid-1980s (Obbard et al. 2007). However, they have also experienced declines in body condition (Obbard et al. 2007). Declines in body condition of individuals in southern Hudson Bay were most dramatic for pregnant females and subadults and may be a precursor to a population decline (Obbard et al. 2007).

In their report to the U.S. Fish and Wildlife Service commission evaluating the status of polar bears, Amstrup and co-workers (2007) predicted a loss of two-thirds of the worldwide polar bear population by around 2050. They used two approaches to model polar bear populations in the future: 1) a model of carrying capacity based on a presumed linear relationship with average sea-ice extent, and 2) a Bayesian network model which included seaice loss as well as other stressors. They placed the world's 19 defined polar bear populations into four "ecoregions" and included 10 Global Climate Models to give minimum, maximum, and ensemble (combination of all 10) sea-ice projections, and made predictions at 45, 75, and 100 years into the future. For all combinations of time steps, global climate models, and ecoregions, both total and optimal polar bear habitat were lower than at present. Under both modeling approaches, polar bear populations were forecast to decline throughout all of their range during the 21st century. Minimal ice-extent projections predicted extirpation of bears from the "Polar Basin Divergent 
Ecoregion" (which includes the southern Beaufort, Chukchi, Laptev, Kara, and Barents sea regions of Alaska, Russia, and Norway) by 2052 and from the "Seasonal Ecoregion" (which includes the Baffin Bay, Hudson Bay, Davis Strait, and Foxe Basin areas of Canada and western Greenland) by 2082 (Amstrup et al. 2007).

Despite the overall severe negative impacts on polar bears, in some areas, sea-ice losses may be temporarily beneficial (Stirling \& Derocher 1993; Derocher et al. 2004). Bears in northern regions dominated by solid fast ice may have greater access to prey if leads and ice edges develop. In addition, declines in ice may increase levels of biological productivity. As the top marine predators of the Arctic ecosystem, they depend upon every trophic level below for survival. Thinning ice and increases in leads of open water (creation of more ice edges) may increase levels of primary production (Sakshaug et al. 1994), which leads to healthy seal populations (Stirling \& Derocher 1993). Seals themselves thrive in areas of moderate ice cover; thick, perennial, multiyear ice is poor habitat for seals (Kingsley et al. 1985). The success of polar bears is inseparable from the breeding success of seals. As many as $80 \%$ of the seals that polar bears kill are young-of-the-year (Stirling 2002). Polar bears reach their minimum weight in March, just before seal pupping begins, and rely on feeding on fatty seal pups to build sufficient fat reserves to survive in winter (Stirling et al. 1999). Indeed, especially heavy ice in the eastern Beaufort Sea in the mid-1970s and mid1980s caused a decline of ringed seal pups, and therefore, of polar bear natality (Stirling 2002; Stirling \& Lunn 1997).

Another ice-associated, upper-trophic predator facing population declines is the ivory gull (Pagophila eburnea). Ivory gull declines may even be, in part, linked to diminishing polar bear populations. The ivory gull is the most northerly breeding bird in the world (Blomqvist \& Elander 1981), and even in the nonbreeding season, they rarely leave the pack ice (Gilchrist $\&$ Mallory 2005). Because of their inaccessibility, few data are available on this species. Nev- ertheless, on the basis of local Inuit knowledge as well survey data, it appears that the ivory gull is undergoing a major crisis in population decline (Mallory et al. 2003; Chardine et al. 2004; Gilchrist \& Mallory 2005). In the Canadian High Arctic, at-sea observations in 2002 found one-fourth as many ivory gulls as in 1993 (corrected for observation effort; Chardine et al. 2004). Based on spatial surveys in Northern Canada in 2002-2003, compared with surveys in the 1980s, Gilchrist and Mallory (2005) estimated an $80 \%$ decline in numbers, noting that some previously occupied colonies are now deserted.

The exact mechanisms driving these declines are unknown. Ivory gulls often scavenge on marine mammals killed by polar bears (Summerhayes \& Elton 1928; Salomonsen 1950; Chardine et al. 2004), so their numbers may be tied to the success of polar bears. However, the role that scavenging plays in the feeding behavior of the ivory gull may be overstated. Renaud and McLaren (1982) noted scavenging behavior offshore on the pack ice during aerial surveys in 1978-1979, but Divoky (1976) concluded from stomach contents that fish and invertebrates are the primary food source for this species, with only rare, opportunistic scavenging. Chardine and colleagues (2004) also observed scavenging behavior, but Blomqvist and Elander (1981) note that it is harder to observe birds foraging from the sea than feeding on carrion on floes so that the frequency of scavenging may be overestimated.

Other possible reasons for ivory gulls' disappearance include anthropogenic contaminants (Braune et al. 2007), hunting (Stenhouse et al. 2004; Gilchrist \& Mallory 2005), and relocation to new breeding sites (deemed unlikely because of the large extent of aerial surveys; Gilchrist \& Mallory 2005). Nevertheless, for a species that spends its entire life history associated with sea ice, changes in habitat may be the ultimate problem. The ivory gull nests on nunataks, islands of bedrock surrounded by rough pack ice. As the ice around them smooths, or disappears altogether, nunataks no longer afford 
protection from predators, such as the Arctic fox (Krajick 2003). Their wintering grounds, thought to be between Greenland and Canada, may also be undergoing major change: in this area, sea ice has actually increased since the 1950 s, and may be depriving the gull of crucial ice edges needed to get at its prey (Krajick 2003). Whatever the cause of this seabird's decline, recovery will be slow. In contrast to most larids (Lack 1968), which display a fixed clutch size of three eggs, the ivory gull generally lays two, or less frequently, only one egg (Blomqvist \& Elander 1981). Like many high latitude breeders, they have a low reproductive rate which may inhibit recovery of the species.

\subsection{The Southern Ocean}

\subsubsection{Relationship between Sea Ice and Antarctic Krill}

Antarctic krill (Euphausia superba), long considered a keystone species in the Southern Ocean, are inextricably linked by nature of their life history to the dynamics of the sea-ice environment (Quetin et al. 2007). This longlived (5+ years; Siegel 2000 and references therein) zooplankter spawns in the austral summer (Siegel 2000; Quetin et al. 1996) and during the preceding months depends heavily on algal food resources including those associated with retreating sea ice to fuel reproduction (Quetin et al. 1996). Krill larvae spend their first summer and early spring feeding primarily as herbivores in the upper mixed layers, but are presumed to be largely dependent on iceassociated food resources, algae in particular, to meet their energetic demands during winter (Frazer et al. 2002a). The timing of seaice formation and the areal extent of sea-ice coverage during the winter are, in fact, critical factors affecting larval survival and subsequent recruitment to the adult population (Ross \& Quetin 1991; Quetin et al. 2007). Recently documented increases in regional air temperatures along the Antarctic Peninsula and concomitant reductions in sea-ice cover (Smith et al. 1999b; Smith \& Stammerjohn 2001) are a legitimate concern as they pose a threat not only to krill, but the myriad organisms in this region which depend on this species, either directly or indirectly (Laws 1985; Croxall et al. 1999; Everson 2000). Here, we review further the nature of the relationship between krill and sea ice.

Favorable winter ice conditions - extensive spatial extent and long duration - are key to the reproductive success of krill, particularly along the Antarctic Peninsula, where they are the dominant zooplankton (Ross et al. 1996). Adult krill in this region exhibit a high reproductive potential, but require substantial energy intake to achieve maximum reproductive output (see Quetin et al. 1996). Extensive ice-edge phytoplankton blooms associated with the retreat of annual sea ice serve as an important food resource in this regard. High-ice years, which result in a favorable food environment, promote early gonadal development and spawning (Hofmann \& Powell 1998) which, in turn, afford larvae a protracted feeding interval (Ross et al. 2000) prior to the onset of winter, when phytoplankton concentrations in the water column are extremely low (Stretch et al. 1988; Daly 1990; Smetacek et al. 1990; Ross \& Quetin 1991).

Larval krill do not tolerate prolonged periods of starvation (Ross \& Quetin 1991). This would appear to present a significant ecological challenge for these early life stages during their first winter when primary production in the Southern Ocean is at a minimum due to the marked reduction in solar irradiance (Smith et al. 1996). It is now generally accepted, however, that krill larvae survive the winter by exploiting food resources, algae in particular, that are closely associated with and often concentrated in the annual sea-ice habitat (Marschall 1988; Daly 1990; Smetacek et al. 1990, Frazer et al. 1997; Frazer et al. 2002a, 2002b; Quetin et al. 2003 and references therein). Prior to formation of annual sea ice in winter, larval krill feed primarily as herbivores filtering phytoplankton and other particles from the upper mixed layers of the Southern Ocean (Ross \& Quetin 1991; Frazer 1996; Ross et al. 2000). They exhibit a 
remarkable modification of this typical feeding behavior in the winter when sea ice is present: rather than filtering the water, larval krill scrape algae (and other food sources) from its surfaces (Frazer et al. 1997).

The onset of sea-ice formation and maximum areal coverage are hypothesized to be two of the most important factors affecting the over-winter survival and recruitment success of larval krill (Quetin et al. 1996). If ice formation is delayed, that is, if it occurs late in the winter, then growth and development may be delayed and starvation is possible (Quetin $e t$ al. 2003). Similarly, if the areal extent of ice cover is reduced, larvae that occupy waters farthest offshore may not encounter suitable habitat and may suffer a similar fate. Ross and Quetin (1991) demonstrated, in fact, that larval krill collected during the winter in a heavy-ice year (1987) were in better physiological condition than larvae collected during a winter with low ice cover (1989). During the winter with high ice cover, larvae exhibited higher growth rates and had higher lipid content and increased condition factors.

Sea-ice cover during winter has been demonstrated by numerous investigators to be correlated with recruitment success of krill. Siegel and Loeb (1995) found that both the spatial and temporal components of winter ice cover affected krill recruitment in the Antarctic Peninsula region. Quetin and Ross (2001) in a separate time series analysis also found a strong correlation between the timing and extent of winter sea-ice formation and krill recruitment. In both cases, krill recruitment success was greatest during high-ice years. Quetin and colleagues (2003) suggest, however, that the complexities in sea ice-krill interactions are not yet fully understood and the mechanisms resulting in increased growth and survival of larval krill are likely multifaceted.

There is now compelling evidence for recent climate-induced changes in the timing and extent of sea-ice coverage in the Southern Ocean (Stammerjohn \& Smith 1996; Smith \& Stammerjohn 2001). These changes are most pro- nounced along the western Antarctic Peninsula (WAP) (Smith et al. 1999b; Domack et al. 2003; Vaughan et al. 2003), a region where krill stocks have historically dominated the zooplankton assemblage (Ross et al. 1996). A reduction in sea-ice cover and concomitant changes in hydrographic patterns (see Hofmann et al. 1996; Nicol 2006) are likely to have a profound influence on the abundance and distribution of krill (and other zooplankton; see Loeb et al. 1997) and also those species that depend on krill, either directly or indirectly (Smetacek \& Nicol 2005; Nicol 2006; Ducklow et al. 2007). The immediate consequence to adult krill of reduced sea-ice coverage, especially along the Antarctic Peninsula, is a change in the production characteristics of the phytoplankton assemblage that typify the region. Melting sea ice in the austral spring is thought to "seed" the surface waters with algae (Smetacek et al. 1990; Nicol 2006), which, in turn, stimulates extensive ice-edge phytoplankton blooms (see Smith et al. 1996) that provide an abundant food source to fuel krill reproduction. Reduced seaice cover and resultant decrease in the availability of phytoplankton associated with ice-edge blooms is expected to be manifest as poor reproductive output by krill and subsequent reduction in year-class strength (see Hofmann \& Powell 1998; Siegel 2005). Recurrent reductions in the spatial extent of ice coverage are likely to have marked effects on the age structure and population size of krill (Siegel 2005), with cascading food-web effects (Smetacek \& Nicol 2005). Changing sea-ice and oceanographic conditions may, in fact, favor other zooplankton species (see Loeb et al. 1997) resulting in fundamental changes in the structure of the pelagic food web (Moline et al. 2004). Krill larvae, too, are clearly susceptible to declines in sea-ice cover (Ross \& Quetin 1991). Annual sea ice provides both a forage and refuge habitat (Ross \& Quetin 1991; Quetin et al. 1994; Frazer 1996; Frazer et al. 1997) for larval and juvenile krill. A reduction or absence of annual sea-ice cover (in both space and time) is likely to compromise the physiological condition of 
these vulnerable early life stages (Ross \& Quetin 1991; Quetin et al. 2003), and under extreme circumstances, starvation and year-class failure might be expected to occur.

Interannual variation in the timing of sea-ice formation and extent of areal ice coverage is an inherent characteristic of polar environments. In fact, ecosystem dynamics in the Southern Ocean are dominated by the seasonal processes of ice formation and ice retreat (Ducklow et al. 2007). Krill, by virtue of their relatively long life span, are adapted to deal with this dynamic, and occasional years of reduced reproductive output or poor larval survival in response to unfavorable ice conditions are not generally reason for alarm (Siegel \& Loeb 1995; Hofmann \& Powell 1998). However, any change in climate that results in chronic delays in the timing of ice formation and/or the extent of areal coverage is indeed a legitimate reason for concern. Successive year-class failures as a consequence of low ice cover are likely to have profound effects on krill population structure and may lessen this species' resilience to other potential anthropogenic influences, such as commercial fishing (see Agnew \& Nicol 1996; Hofmann \& Powell 1998). By way of analogy, we point out that the combined effects of largescale climate anomalies - ENSO events - and commercial harvest led to the collapse of the Peruvian anchovy fishery. It may be premature to draw such a parallel, but it does serve to reinforce the potential significance of the issue.

\subsubsection{Dependence of Antarctic Fishes on Sea Ice}

The fish biota of the Antarctic is composed of two faunal types: Antarctic endemics that are primarily benthic as adults, and representatives of fish families that are widely distributed in the world ocean (DeWitt 1970; Eastman 1993). About 95 species belonging to five families in the perciform suborder Notothenioidii (Artedidraconidae, Bathydraconidae, Channichthyidae, Harpagiferidae, and Nototheniidae) dominate the shelf and slope of the
Antarctic benthos (Andriashev 1965; Eastman 1993). However, in most regions of the coastal Antarctic, only two species occupy the pelagic waters between surface and bottom as adults, the Antarctic silverfish, Pleuragramma antarcticum, and the Antarctic toothfish, Dissostichus mawsoni. The WAP shelf is an exception to the prevalent Antarctic pattern. Oceanic species are present as adults in appreciable numbers (up to $50 \%$ of the pelagic fish biomass) in the pelagic regions of the WAP shelf, the most important being the lanternfish, Electrona antarctica (Lancraft et al. 2004; Donnelly \& Torres 2008).

For fishes, the influence of sea ice and the cold temperatures that accompany it go beyond the simple "roof on the ocean" that acts as a barrier to penetration of light. Temperatures below $-1{ }^{\circ} \mathrm{C}$ will normally freeze the blood of marine fishes (DeVries 1986) unless they are protected by biological antifreezes. Most continental shelves in the Antarctic have surface to bottom temperatures $\left(-2^{\circ} \mathrm{C}\right.$; Dinniman et al. 2003) that would rapidly freeze unprotected fishes. Once again, the WAP shelf is an exception, with largely positive temperatures in waters below $100 \mathrm{~m}$ (Smith et al. 1999a), making it a more hospitable environment for fishes. In most coastal systems of the Antarctic, the edge of the continental shelf defines the boundary between the coastal and oceanic systems (DeWitt 1970; Donnelly et al. 2004; Donnelly \& Torres 2008), with the oceanic fishes not present landward of the shelf break. It has been tacitly assumed, though never experimentally demonstrated, that oceanic species are excluded by the very low temperatures in shelf waters. Recently acquired data (Sorge, DeVries, and Torres, unpublished data) suggest that oceanic species lack antifreezes, giving credence to the hypothesis.

Changes in the maximum extent of winter sea ice and timing of sea-ice advance and retreat have the potential to influence fishes living in both coastal and oceanic systems. A priori, it would be expected that the most critical changes would be those influencing vulnerable periods in species' life histories. What first 
springs to mind when critical periods are being considered is the period of larval development. Fish species that use sea ice for spawning and as an early nursery, such as the silverfish, Pleuragramma antarcticum (Vacchi et al. 2004), and the yellowbelly rock cod, Notothenia coriiceps (Kellermann 1996), or as a site for first-feeding pelagic larvae such as the channichthyid Chionodraco rastrispinosus (Kellermann 1996), will be heavily impacted by changes in sea-ice timing and extent. In contrast, species that show little direct dependence, such as the lanternfishes Electrona antarctica and Gymnoscopelus braueri, (Efremenko 1986) will likely show minimal impact.

Assessment of the effects of a changing ice cover on the Antarctic fish community is complicated by the diversity of Antarctic fish life histories and reproductive strategies, even among the notothenioids. Reproductive strategies range from demersal spawning followed by a prolonged period of nest-guarding until the eggs hatch (e.g., Harpagifer bispinis and Lepidonotothen nudifrons; Daniels 1978; Hourigan \& Radtke 1989, respectively) to broadcast spawning of pelagic eggs (Electrona antarctica and Pleuragramma antarcticum; Efremenko 1986; Vacchi et al. 2004).

It will be most instructive to briefly describe elements of the reproduction, early life, and growth pattern of four Antarctic fishes to gain an appreciation for the diversity embedded in the system; two pelagic species (Electrona antarctica and Pleuragramma antarcticum), the semipelagic icefish Chionodraco rastrispinosus (Channichthyidae), and a nest-guarding nototheniid species (Lepidonotothen nudifrons). Seaice extent, the timing of its retreat and advance, and the initiation of the productive season have been variables in the lives of all fishes living in the seasonal ice zone over the course of evolutionary time. As a consequence, a considerable amount of tolerance has been incorporated into their early life histories.

Electrona antarctica is the southernmost representative of the globally distributed family Myctophidae. Its distribution is primarily oceanic
(Hulley 1990), ranging from the Antarctic Polar Front to the edge of the Antarctic continental shelf in all but the WAP, where it is common in shelf waters (Donnelly \& Torres 2008). It is an important prey item in the diets of flighted seabirds and penguins (Ainley et al. 1986). Electrona lives for approximately 4 years, with the females reaching a length of just over $100 \mathrm{~mm}$ in their fourth year of life (Greely et al. 1999) and is a batch spawner, reproducing multiple times in its final year (Efremenko 1986; Greely et al. 1999). Its larvae can be found year round with peak numbers in the summer and fall (Table 1; Efremenko 1986). In the winter, larvae of Electrona are found primarily below 200 $m$ of depth (Efremenko 1986; Kock 1992) in the waters of the Antarctic Circumpolar Current, specifically in the warmer $\left(2.0^{\circ} \mathrm{C}\right)$ layer formed by the CDW. During the spring and summer they rise into the 100-200 m layer (Efremenko 1986). Feeding habits of larval Electrona are undescribed, but the smaller stages ( $<45 \mathrm{~mm}$ ) feed primarily on calanoid and cyclopoid copepods (Rowedder 1979; Hopkins 1985; Pakhomov et al. 1996), which are most abundant during the productive months of the spring and summer. Older fishes are primarily euphausiid feeders (Hopkins 1985; Lancraft et al. 2004).

Pleuragramma antarcticum is the dominant pelagic fish in most coastal regions of the Antarctic. It is found between the shelf break and the continental margin in all areas of the Antarctic that have been sampled (DeWitt et al. 1990). It is considered to be a high Antarctic species (Hubold 1985; Kock 1992) though it is also found in the zone of seasonal sea ice, notably in the shelf waters of the WAP (Lancraft et al. 2004; Donnelly \& Torres 2008). In a recent review on the role of notothenioid fish in the food web of the Ross Sea, the authors state that "Pleuragramma antarcticum dominates the diet of all top predators, from the Antarctic petrel to the Weddell seal" (La Mesa et al. 2004). Several species of fishes also feed principally on Pleuragramma (Eastman 1985), making it a critical trophic link in the coastal system. 


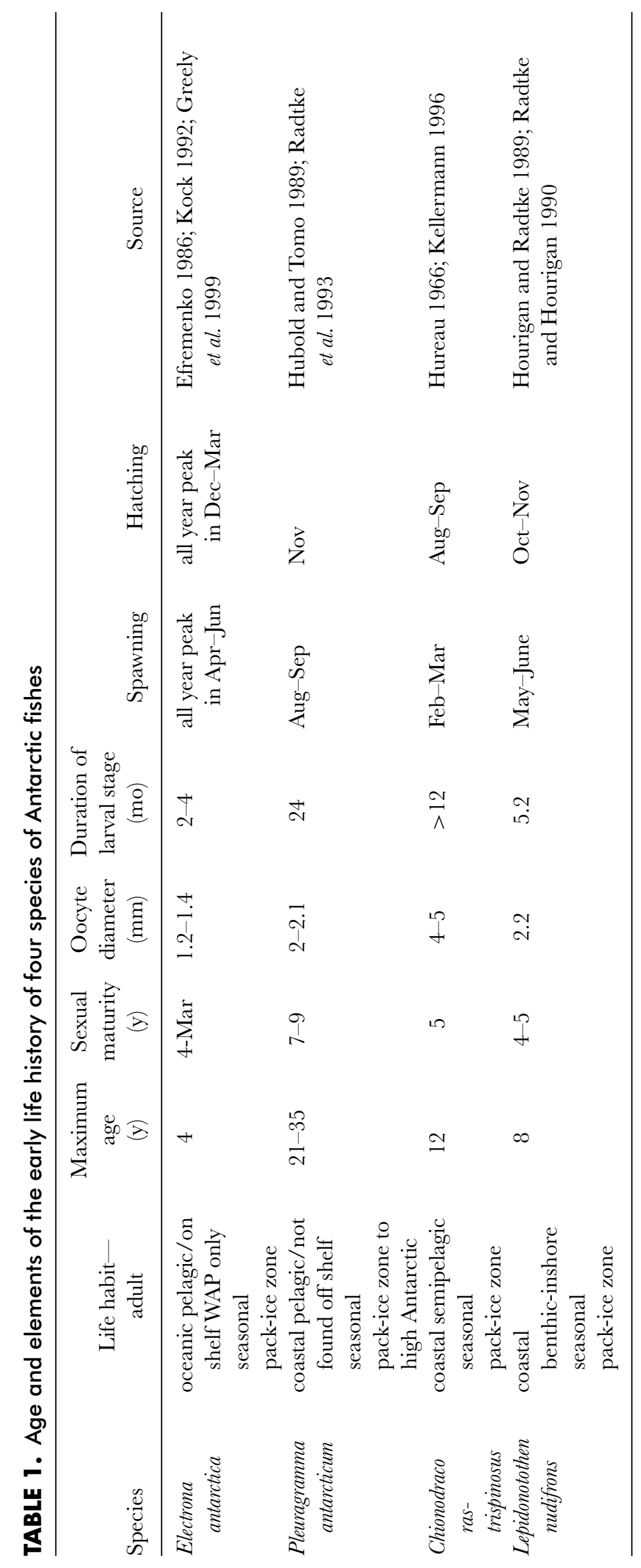


In the one place where Pleuragramma eggs were definitively located and collected, Terra Nova Bay in the Ross Sea (Vacchi et al. 2004), they were found floating in the platelet ice underneath $1.3 \mathrm{~m}$ thick sea ice. They were found to be hatching within the ice starting in midNovember. This was a very important finding, since it suggests that sea-ice cover is very important to Pleuragramma's early life history. In addition, it confirms that Pleuragramma has pelagic eggs, a conclusion first reported by Faleyeva and Gerasimchuk (1990) in a histological study on the gonads of Pleuragramma. Time of hatching is consistently in the November-December period in the three areas of the Antarctic where data are available: the Antarctic Peninsula and the Ross and Weddell Seas (Kellermann 1986; Hubold \& Tomo 1989; Kock and Kellermann 1991; Vacchi et al. 2004).

Pleuragramma hatched at an average length of $9.3 \mathrm{~mm}$ in the Ross Sea, with a range of 8-10 mm (Vacchi et al. 2004). Hubold (1990) reported an average length of $9 \mathrm{~mm}$ for newly hatched Pleuragramma in the Weddell Sea, suggesting that variability in size at hatch is minimal from place to place. Pleuragramma don't reach their juvenile "silverfish" appearance until in their third year (age class (AC) 2+) of life, at lengths of $60-90 \mathrm{~mm}$. Rings presumed to be annular in Pleuragramma otoliths suggested that the fish's largest sizes (245-250 mm) were about 21 years old (Hubold \& Tomo 1989). Data on length-at-age obtained by reading otolith microincrements (daily rings) with a scanning electron microscope suggested that Pleuragramma were far older: a $205 \mathrm{~mm}$ fish was determined to be 33.5 years of age (Radtke et al. 1993). At the moment, what is most certain is that Pleuragramma is a slow-growing, long-lived fish, even when compared to other Antarctic fishes. Fishes (AC 2+ and younger) are found primarily in the upper $200 \mathrm{~m}$, with the youngest fishes found most shallow. Larval and juvenile silverfish feed primarily on copepods, though polychaetes, pteropods, and chaetognaths are taken as well (Hubold 1985). Older fishes feed primarily on euphausiids, ei- ther Euphausia superba or crystallorophias (DeWitt \& Hopkins 1977).

Visual and histological studies (Faleyeva \& Gerasimchuk 1990) suggest that fish collected in the Mawson Sea spawn at 13-16 cm standard length (SL) for the first time. Hubold (1985) reported that fish in the Weddell Sea first show gonadal development at a size of 12.5 $\mathrm{cm}$, and Reisenbichler (1993) reported that McMurdo Sound fish showed appreciable gonad development at $16 \mathrm{~cm}$. Agreement between the three studies is reasonably good, with a consensus figure of $13-16 \mathrm{~cm}$. If the size at sexual maturity, 13-16 cm SL, is applied to the Hubold and Tomo (1989) growth curve. Pleuragramma antarcticum begins reproduction at an age of 7-9 years or about $55 \%$ of its maximum size (Kock \& Kellermann 1991) and reproduces each year thereafter for the remainder of its life.

It is believed that spawning takes place in the winter, in the August/September time frame, and that embryos develop over a period of 60-75 days prior to hatching (Kellermann \& Schadwinkel 1991). This postulated incubation time seems quite rapid, however. Most reported incubation times for Antarctic fish eggs hover in the neighborhood of 4 months (Kock 1992). Spawning behavior of Pleuragramma is unknown. However, two lines of evidence provide suggestions. First, the data of Vacchi and colleagues (2004), confirm that Pleuragramma has pelagic eggs and that they are found in high concentrations underneath the land-fast sea ice in Terra Nova Bay. Second, the observations of Daniels and Lipps (1982) that thousands of Pleuragramma were observed under land-fast sea ice on three occasions in the JuneOctober period suggests that Pleuragramma may form spawning aggregations under coastal sea ice in winter.

The icefishes exhibit a variety of lifestyles as adults, ranging from nearly pelagic to benthic (Eastman 1993) in the shelf and slope waters of continental Antarctica and outlying islands. Available data suggest that most icefishes ascend into the water column to feed on krill, even when they reside primarily on the 
bottom (Eastman 1993)-hence the designation as semipelagic for Chionodraco rastrispinosus. Though distributions within the water column differ as adults, the icefishes apparently share a common larval strategy. Large $(4-5 \mathrm{~mm})$ yolky eggs are produced, yielding a large larva (19.0 $\mathrm{mm}$ ) at hatch that is soon capable of preying on euphausiid furcilia and the smaller nototheniid larvae. Chionodraco rastrispinosus hatches in the late winter (August-September; Kellermann 1996) and remains as a pelagic larva through the spring, summer, and following winter. Its congener, C. hamatus, hatches in early winter, also with a large $(17.0 \mathrm{~mm})$ larva and similar feeding strategy. The substantial yolk sac reserve allows the larvae a greater metabolic flexibility in feeding during the winter, and its resorption is variable, depending on feeding success (Kellermann 1996). The icefishes thus show a considerable independence from the production cycle, instead keying in on the availability of their prey: nototheniid larvae and krill furcilia. All have a prolonged pelagic larval phase.

Lepidonotothen nudifrons is a small $(<166 \mathrm{~mm}$ SL) benthic species distributed in the shallow waters of the Antarctic Peninsula and outlying islands (DeWitt et al. 1990). It is accessible by divers and shallow trawls, thus allowing its breeding behavior to be observed in a laboratory setting (Hourigan \& Radtke 1989). Lepidonotothen nudifrons builds nests in crevices or on the underside of rocks during the months of May and June which are actively guarded by a male until the eggs hatch in 124 days. About $30 \%$ of the females examined were gravid in the spring (October), two of which had spawned in the previous May, suggesting that $L$. nudifrons may produce multiple clutches (Hourigan \& Radtke 1989). After hatching, the small $(7.0 \mathrm{~mm})$ larvae are positively phototaxic, swimming to the surface where they remain in a pelagic phase for a period of about 5 months (about one productive season) until they reach a length of $28 \mathrm{~mm}$ (Hourigan \& Radtke 1989), before assuming a benthic existence. Time in the plankton was estimated by calculating the time to get to $28 \mathrm{~mm}$ from the growth curve of Radtke and Hourigan (1990). They are believed to feed on copepods in their smaller stages (DeWitt et al. 1990). Lepidonotothen nudifrons reaches sexual maturity in its fifth year of life and lives for about 9 years (Table 1).

It should be clear from the brief examination of Antarctic fish life histories that the cycle of advance and retreat of the seasonal sea ice is an important element in the survival of many Antarctic fish larvae. Two of the species described here, Pleuragramma antarcticum and Chionodraco rastrispinosus, have a very direct interaction with the ice canopy. Pleuragramma apparently uses the underside of the ice as a nursery for its eggs and a feeding ground for its newly hatched larva (Vacchi et al. 2004). The larvae of Chionodraco, in contrast, use the ice canopy as a hunting ground for ice-associated biota such as krill furcilia and nototheniid larvae. In both fishes survivorship of larvae should theoretically be enhanced in those years that exhibit above-average maximum ice extent. In Pleuragramma's case the ice would more likely be present for the entire incubation period of the eggs and the beginning of first feeding for the larvae. In that of Chionodraco, the greater success of krill furcilia, its primary prey, during highice years (see section 2.2.1; Quetin et al. 1996; Loeb et al. 1997) would favor larval survivorship (cf. Kellermann 1996). The limited data available support the supposition for Chionodraco and other channichthyids in the Palmer Peninsula region. Very high catches of channichthyid larvae coincided with two years with anomalously high ice extent 1980/81 and 1987/88 (Kellermann 1996). Pleuragramma larvae also showed a peak in 1980/81, but a second peak in 1985/86 coincided with an anomalously low ice year, casting some doubt on the direct relationship (Kellermann 1996).

Larvae of Electrona and Lepidonotothen nudifrons depend more on secondary production which is enhanced at the retreating ice edge and the productive period that follows the ice decay (Smith \& Sakshaug 1990; Schnack-Schiel \& Hagen 


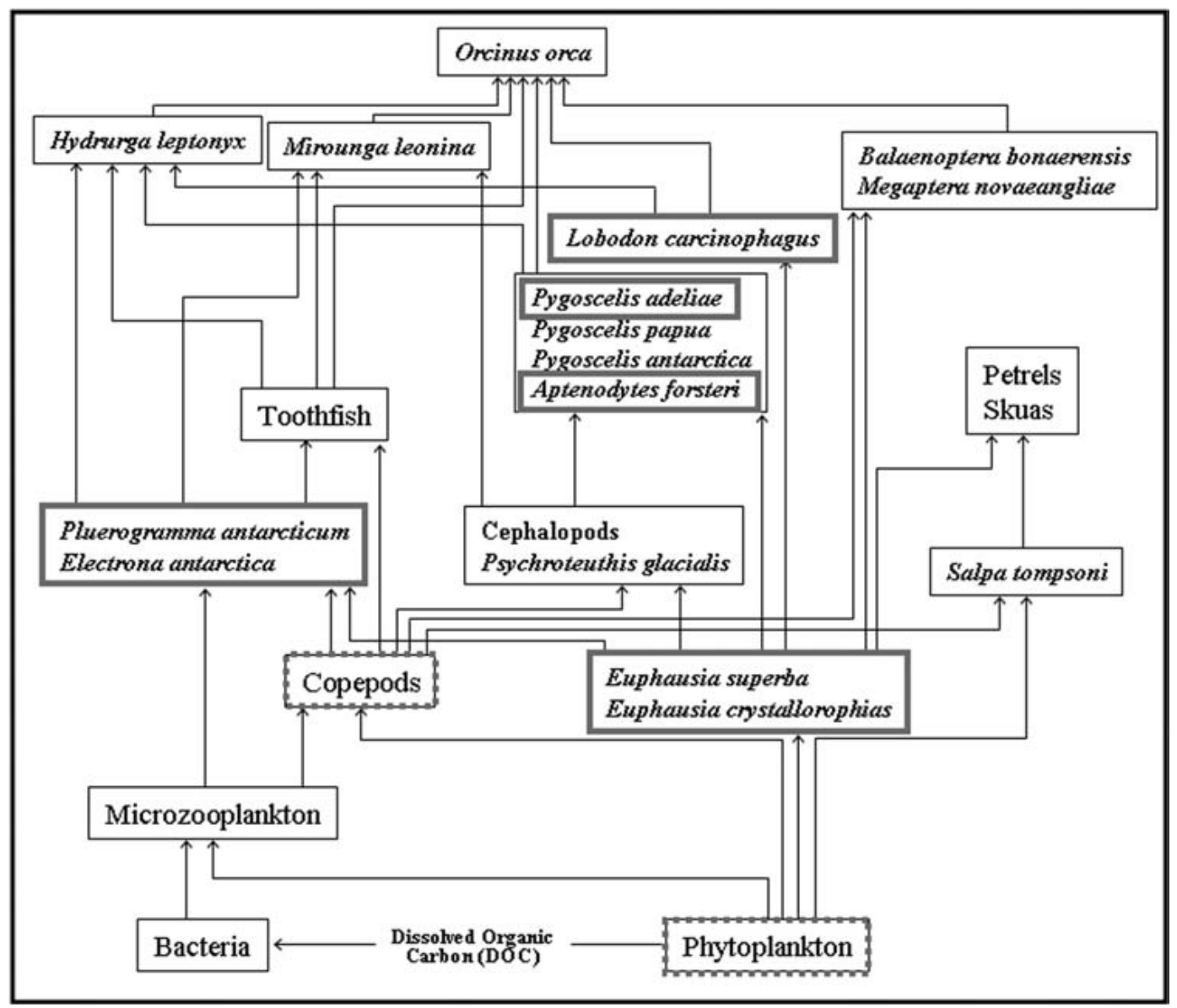

Figure 16. Depictions of the food web along the Antarctic Peninsula. Sympagic organisms are highlighted in bold gray to illustrate the importance of ice to the food-web structure. Dotted lines are around phytoplankton and copepods, as not all are ice dependent. Food web was generated based on interactions documented in the literature.

1994). In theory, survivorship of both species would be enhanced by an early ice retreat and increased availability of copepod nauplii and copepodites for first-feeding larvae (Kellermann 1996). At this juncture, insufficient data exist to determine if larval success of either species tracks with ice cover.

Little doubt exists that peaks and valleys in the extent of seasonal ice cover and the timing of its advance and retreat have the potential to influence the survivorship of Antarctic fishes. The regional warming currently occurring in the Palmer Peninsula region (Ducklow et al. 2007) is an experiment in progress that will likely change the character of the fish community there with repercussions up and down the trophic pyramid (Fig. 16).

\subsubsection{Climate-induced Changes in the Ecology of Adélie Penguins}

Antarctic marine food webs were once perceived as being relatively simple, a notion that arose at least in part from the observation that the diets of most of Antarctica's top predators, seabirds, pinnipeds, and cetaceans, were dominated by a limited number of prey species (Laws 1985). Although research during the last three decades in particular has demonstrated that these marine food webs can be as complex as they are in temperate or even tropical oceans (Barnes \& Conlan 2007; Clarke et al. 2007), an important aspect of these earlier observations has not only proven to be correct, but in fact provided key insights into the mechanistic processes linking predator-prey dynamics. 
Thus, while the perception that Antarctic top predators consume a relatively small number of prey species is correct, the reason is not that prey diversity is low, but rather that the number of species regulating energy flow between primary producers and top consumers often tends to encompass only 3-5 trophic components (Laws 1985; Knox 1994, 2007). Antarctic marine food webs, in other words, tend to be short, and the few key species involved usually dominate system dynamics in terms of both numerical abundance and standing biomass.

These attributes of Antarctic marine food webs have been instrumental in advancing our understanding of the relationships between ecosystem structure and function for two important and related reasons. The first is that with less trophic complexity, causal relationships are easier to detect above background noise (Reid et al. 1999; Fraser \& Hofmann 2003; Murphy et al. 2007). The second is that as a result, changes in the biogeography and/or population dynamics of marine top predators, such as Adélie penguins (Pygoscelis adeliae), often constitute the first evidence that food webs may be responding to climate-induced forcing. This is addressed by Fraser and Trivelpiece (1996) within the context of both evolutionary and contemporary time scales. Adélie penguins have evolved life histories that are dependent on sea ice. As long-lived, wide-ranging top predators, they subsequently integrate the effects of variability in sea-ice dynamics over large spatial and temporal scales. The expression of this variability can, for example, be measured annually as ice-induced changes in breeding success (Ainley 2002), or over the course of millennia as changes in biogeography associated with epochs of Antarctic warming and cooling (Emslie 2001; Emslie et al. 2007). Both empirically and conceptually, the matchmismatch hypothesis (cf. Cushing 1990) has provided a fundamental perspective for understanding these dynamics. This tenet is the focus of this section, and is applied in this case to illustrate how ice-induced changes in Antarctic krill populations due to climate warming are affecting aspects of the ecology of Adélie penguins in the WAP region.

The WAP marine ecosystem extends for c. $1500 \mathrm{~km}$ from its northern tip at $63^{\circ} \mathrm{S}$ to the Bellingshausen Sea at $75^{\circ} \mathrm{S}$, and the shelf averages $200 \mathrm{~km}$ in width and $400 \mathrm{~m}$ in depth (Hofmann et al. 1996; Ducklow et al. 2007). The WAP as a whole has experienced significant warming of surface air temperatures $\left(2^{\circ} \mathrm{C}\right.$ increase in annual means since 1950), but it is the midwinter record in particular that shows the strongest and most statistically significant trends (Smith et al. 1999b). Indeed, this record reveals a warming of $5-6^{\circ} \mathrm{C}$ over the last 50 years, which is unique within the last few millennia, and exceeds any other rate on Earth since the beginning of the modern instrument record (Smith et al. 1999b; Domack et al. 2003; Vaughan et al. 2003). Ocean warming has also occurred, and is intensified toward the surface above $100 \mathrm{~m}$, where an increase of over $1^{\circ} \mathrm{C}$ has been detected since the mid-1950s (Meredith \& King 2005).

These profound changes in WAP surface sea and air temperatures have had profound effects on the presence and timing of sea-ice advance and retreat across a range of spatial and temporal scales. These include, for example, a decrease in the frequency of occurrence of cold years with heavy sea-ice conditions (Fraser et al. 1992; Loeb et al. 1997), a long-term reduction in sea-ice concentrations (Vaughan et al. 2003; Liu et al. 2004), and changes in the overall length of the sea-ice season (Parkinson 2002a). The latter, which is based on a remote sensing record that began only in 1978, is within this context nothing short of dramatic, indicating that the length of the sea-ice season has decreased by nearly 3 months as a result of sea ice advancing significantly later and retreating significantly earlier (Stammerjohn et al. in press).

Rhodes and Odum (1996) suggest that one of the mechanisms by which climate warming induces change in ecosystem structure and function is its disruption of the evolved life history strategies of key component species. This 
concept forms the mechanistic core of the match-mismatch hypothesis and fundamentally implies that life history strategies will remain successful in a changing environment only if the range of variability in space and time of the critical resources they require to remain viable does not exceed the thresholds under which they evolved (Fraser \& Trivelpiece 1996; Forcada et al. 2006). Both Antarctic krill and Adélie penguins have evolved life histories that are critically dependent on the availability of sea ice, and changes in the spatial and temporal dynamics of sea ice in the WAP have been implicated as key factors in the significant population decreases both these species have experienced in the region during the last 3 decades (Fraser et al. 1992; Trivelpiece \& Fraser 1996; Fraser \& Patterson 1997; Loeb et al. 1997; Siegel et al. 1998; Atkinson et al. 2004; Forcada et al. 2006; Hinke et al. 2007). Although it is beyond the scope of this section to discuss these trends and their causal relationships in detail (see Clarke et al. 2007, Ducklow et al. 2007, and Murphy et al. 2007 for recent reviews), the match-mismatch hypothesis provides a clear foundation for understanding how climate warming and a loss of sea ice in the WAP is changing the phenology of krill abundance and availability to Adélie penguins, variables that contribute directly to important regulatory processes affecting their population dynamics ( $c f$. Fraser \& Hofmann 2003).

Adélie penguins have long been regarded as a krill-dependent species in the WAP (Conroy 1975; Volkman et al. 1980). Krill, their primary prey, are, from a biomass perspective, one of the most abundant organisms in the world's oceans (Verity \& Smetacek 1996). Moreover, the fact that krill are also phytoplankton grazers exemplifies both the short nature of these Antarctic marine food webs and the dominant ecological role held by such key secondary consumers associated with them (Laws 1985; Knox 2007). How changes in the abundance and availability of krill affect Adélie penguin populations, however, involves at least two scales of responses that share a common periodicity of $4-5$ years
(Fraser \& Hofmann 2003) and which are ultimately linked to interactions between WAP climate warming and changes in the phenology of sea-ice development.

Fundamentally, in the absence of sea ice, krill cannot reproduce successfully enough to maintain their populations (see section 2.2.1). This relationship ensues from the fact that because winter water column primary production is at a minimum, krill larvae have evolved a dependence on under-ice algae as a primary food source to survive their first winter of life after hatching (Daly 1990; Ross \& Quetin 1991; Quetin \& Ross 2001). Krill recruitment and year-class strength are, as a result, not only strongly dependent on the presence of sea ice, but, in fact, episodic in the WAP, linked to years during which the phenology of winter sea-ice development is spatially and temporally coherent with the evolved requirements of this critical aspect of krill reproduction (Fraser \& Trivelpiece 1995; Siegel \& Loeb 1995; Loeb et al. 1997; Reid et al. 1999; Fraser \& Hofmann 2003; Quetin \& Ross 2003; Quetin et al. 2007).

According to Fraser and Hofmann (2003), years of optimal sea-ice conditions conducive to good krill recruitment and strong year-class development in the WAP are occurring, on average, only once every 4.5 years. Stated differently, serial mismatches now appear to be a dominant pattern affecting WAP krill population dynamics, and, indeed, this pattern also represents an important metric insofar as understanding the responses and consequences to top predator populations, such as Adélie penguins. As previously suggested, at least two scales of responses are involved. The first is illustrated in Figure 17, which shows that episodic recruitment leads to equally episodic changes in krill abundance. However, because serial mismatches result in no additional recruitment, the abundance of the strong krill cohorts produced diminishes over time until the population is again replenished by another recruitment event. As seen in Figure 17, Adélie penguin foraging trip durations respond on very short time scales (annual) to these recruitment 


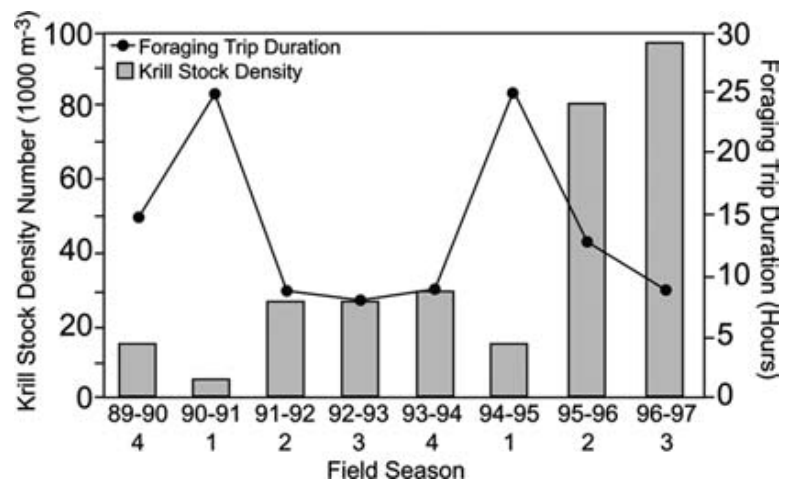

Figure 17. Variability in Adélie penguin foraging trip durations (filled circles) near Palmer Station in relation to krill stock density (gray bars) near Elephant Island. The numbers below the field season designate ice year classes. The number 1 represents winters conducive to good krill recruitment and the numbers 2, 3, and 4 track the trends in krill stock density associated with each recruitment event. The table is adapted from Fraser and Hofmann (2003) and used by permission.

events and closely track the resulting changes in krill abundance between recruitment events. Modeling studies based on these data (Salihoglu et al. 2001; Chapman et al. in press) suggest that these serial mismatches can negatively affect parental chick feeding rates, leading ultimately to Adélie penguin chicks whose fledging weights are insufficient to guarantee their own overwinter survival, which, in turn, compromises their future recruitment into the breeding population.

The second scale of response is shown in Figure 18. Adélie penguin breeding population numbers in the vicinity of Palmer Station $\left(64^{\circ} 46^{\prime} \mathrm{S}, 64^{\circ} 04^{\prime} \mathrm{W}\right)$, Anvers Island, have exhibited a $65 \%$ decrease during the years 1974 2005. This change, however, has not been linear, exhibiting in general a more rapid and statistically significant rate of decrease during the post-1990 period (Woehler et al. 2001), and specific years of particularly large, step-wise changes in 1987 and 2001, when the population decreased by $20 \%$ and $19 \%$, respectively, relative to the previous years' (1986 and 2000) censuses.

One of the more remarkable features about krill life history is their 5-6+ year longevity, which is unique among euphausiids (Nicol 1990; Siegel \& Kalinowski 1994; Verity \& Smetacek 1996), and which Fraser and Hofmann (2003) proposed is playing a pivotal role in contemporary match-mismatch dynamics if one considers that sea-ice conditions conducive to good krill recruitment are manifesting, on average, only once every 4-5 years. Indeed, a detailed analysis of sea-ice conditions and recruitment frequency by these authors in the decade prior to 1990 revealed that cohort senescence may have greatly diminished the reproductive potential of the three strong age classes generated during the early part of the decade (1979, $1980,1981)$ because it was not until 1986, or 56 years later, that sea-ice conditions were again suitable for krill reproduction (Loeb et al. 1997; Siegel et al. 2002; Fraser \& Hofmann 2003). These krill senescence events likely explain the 20\% decrease in Adélie penguin population numbers observed in 1987 (Fraser \& Hofmann 2003; Forcada et al. 2006) and the 19\% decrease noted in 2001, as a 5-year gap also separates 2001 from the previous strong krill year class, which was produced in 1996 (Loeb et al. 1997; Siegel et al. 2002; Fraser \& Hofmann 2003). Within the context of match-mismatch dynamics, these senescence events may therefore behave as additional ecosystem stressors whose effects have decadal-scale consequences from which some krill-dependent predator populations whose life histories are also reliant on sea ice may not recover.

In concluding, it should be noted that the rather focused nature of this discussion is not meant to dismiss (or simplify) the importance of other processes that are affecting WAP top predator populations and marine ecosystem dynamics. However, as Verity and Smetacek (1996) observe, marine ecosystems select the life histories of the species that populate them. It is not surprising, therefore, that the predator-prey dynamics explored in this section have analogs that are temporally coherent over spatial scales that include the seaice zones of the northern WAP and much of the southwest Atlantic sector of the Southern 


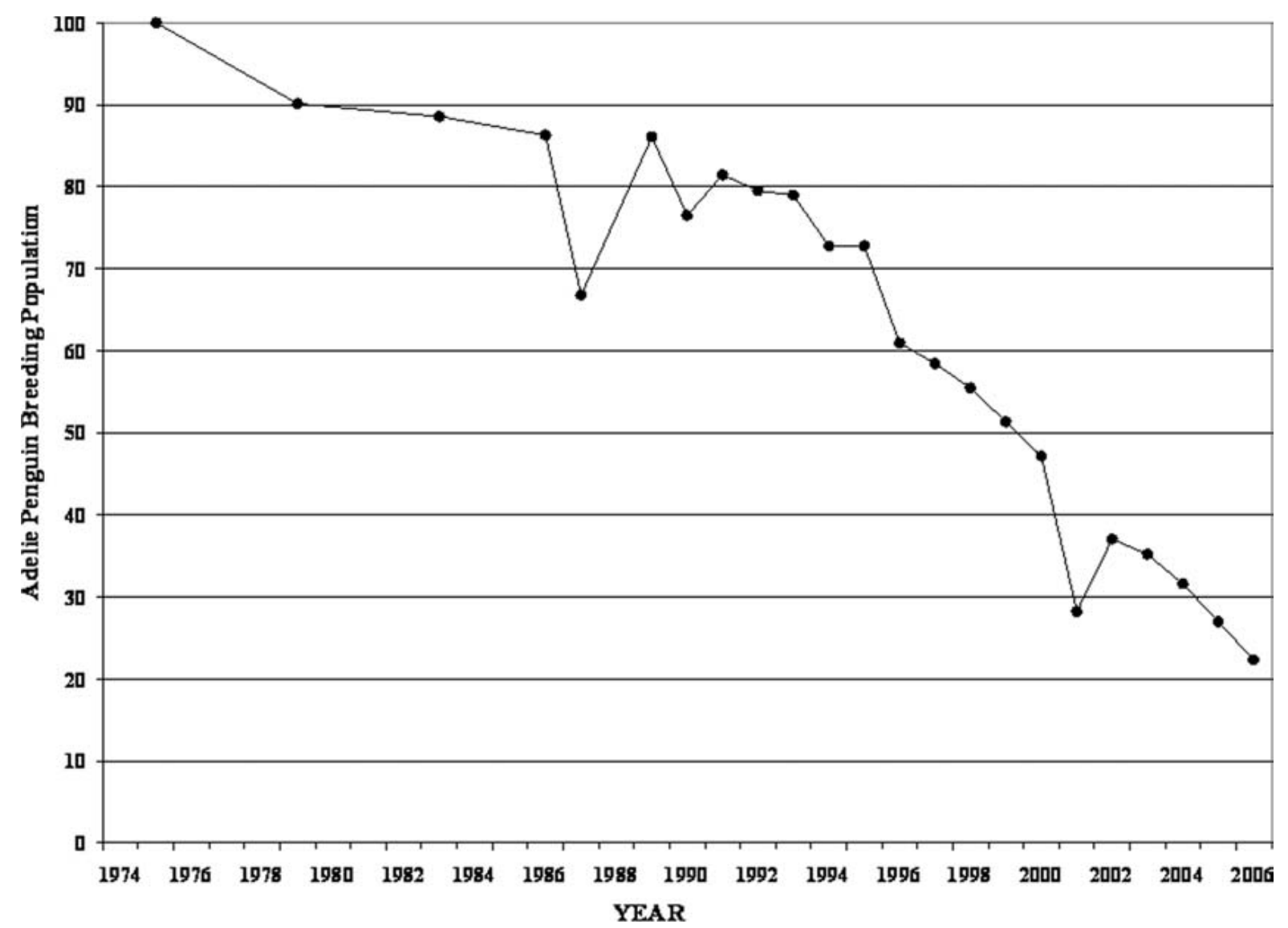

Figure 18. Long-term population trend of Adélie penguins breeding in the vicinity of Palmer Station, Anvers Island, WAP. The trend is based on percent change in breeding pairs relative to the first census in 1974.

Ocean; importantly, they also involve other krill-dependent predator groups besides Adélie penguins (Fraser \& Hofmann 2003; Forcada et al. 2006; Hinke et al. 2007; Murphy et al. 2007).

\section{Indirect Impacts of Changing Polar Hydrography}

\subsection{The Arctic Ocean}

\subsubsection{Expansion of North Atlantic Water and Food Web Impacts}

The Atlantic sector of the Arctic has experienced widespread warming and declines in ice extent. Species normally found further south have recently extended their range northward (e.g., Berge et al. 2005). The southwest coast of Spitsbergen is a particularly dynamic area with heterogeneous oceanographic conditions (Fig. 19). There are two water masses found off the southwest coast of Spitsbergen: the Sorkapp current (sometimes also referred to as the East Spitsbergen current) and the West Spitsbergen current (Fig. 19; Swerpel 1985; Swerpel \& Zajaczkowski 1990). The West Spitsbergen current flows north and originates in the North Atlantic. It is characterized by warmer temperatures and carries with it a small species of copepod, Calanus finmarchicus. The Sorkapp current also flows north after turning around the southern tip of Spitsbergen (Fig. 19). The Sorkapp current is characterized by cold temperatures and it contains high densities of the larger, more energyrich copepod, Calanus glacialis (Karnovsky et al. 2003).

The distribution and strength of these currents varies inter-annually (e.g., Schlichtholz \& 


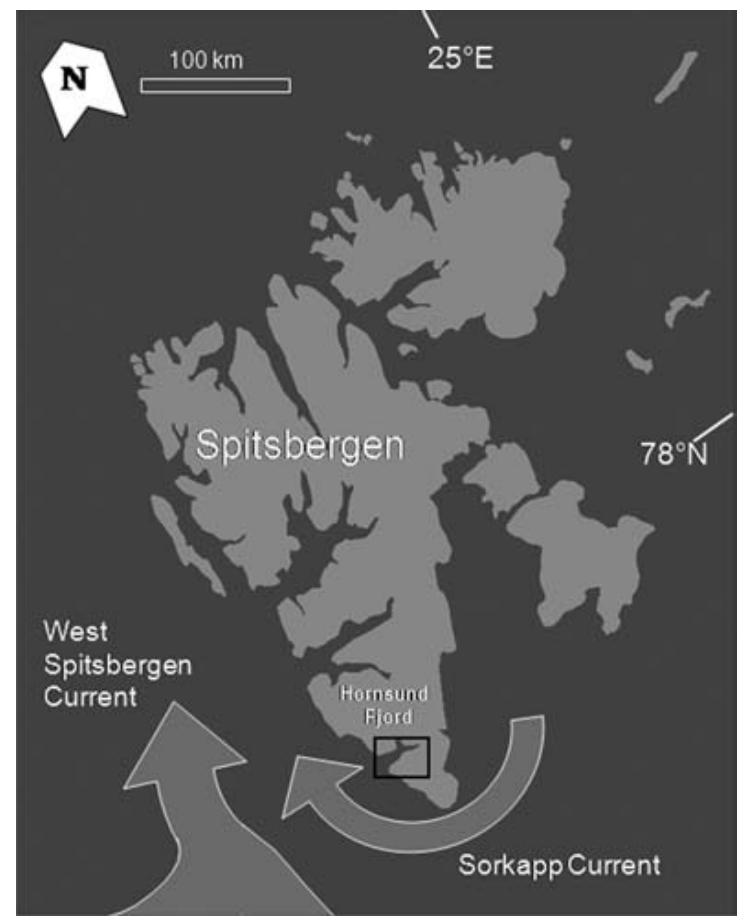

Figure 19. There are two currents flowing north along the SW coast of Spitsbergen, the Atlanticderived West Spitsbergen current and the cold, Arctic-derived Sorkapp current.

Goszczko 2006). Increases in Atlantic-derived water into the region have been linked to positive phases of the North Atlantic Oscillation (NAO) (Dickson et al. 2000). The NAO index is based on the difference between sea-level air pressure measured in Lisbon, Portugal and Stykkisholmer, Iceland and has been measured since 1864 (Hurrell 1995; Hurrell et al. 2001). Since the 1990s, the NAO has been in a predominantly positive phase with exceptionally high magnitudes (Hurrell 1995), which may be linked to anthropogenic warming (Visbeck et al. 2001). After strong positive NAO phases, there is an expansion of Atlantic-derived water in the region (Blindheim et al. 2000; Mork \& Blindheim 2000; Schlichtholz \& Goszczko 2006). Vinje (2001) found that ice extent in the region has declined over the past 135 years and that positive phases of the NAO measured in winter are negatively correlated with ice extent measured in April. In addition to changing the ice conditions, this influx influences the entire Arctic food web.
One way that increases in Atlantic water in the region change the marine food web is by advecting into the region the small, boreal species of copepod, Calanus finmarchicus as opposed to the Sorkapp current's larger, more lipid-rich copepod Calanus glacialis (Jaschnov 1961; Hirche 1991; Unstad \& Tande 1991; Karnovsky et al. 2003). The larger Arctic species, C. glacialis has 10 times the amount of lipids as C. finmarchicus (Falk-Petersen et al. 2006). On the basis of net tows in both water masses in the upper $50 \mathrm{~m}$ of the water column adjacent to Hornsund Fjord on the SW side of Spitsbergen, Karnovsky and colleagues (2003) found that the energy content of Calanus copepods in these water masses differed greatly. They estimated that there was only 2.2 $\mathrm{kJ} \mathrm{m}^{-3}$ of energy available in large-size copepods in the West Spitsbergen current (Atlanticderived water), whereas the energy content of the Sorkapp current (Arctic-derived water) was $6.9 \mathrm{~kJ} \mathrm{~m}^{-3}$ (Karnovsky et al. 2003). Interestingly, densities of zooplankton did not differ substantially between the two water masses (Karnovsky et al. 2003). Therefore, zooplanktivorous predators would have to spend three times as long to meet their energy needs when feeding in the Atlantic-derived water mass.

The Arctic marine food web is highly dependent on the consumption of large size Calanus copepods (e.g., Karnovsky \& Hunt 2002; Karnovsky et al. 2003). Therefore, increases in warm Atlantic water in the region could have widespread repercussions for the Arctic marine food web in the region, which includes many marine mammals and seabirds. The dovekie (Alle alle), for example, is a zooplanktivorous seabird (e.g., Wȩsławski et al. 1999; Karnovsky et al. 2003), which nests along the west coast of Spitsbergen (Norderhaug 1980; Stempniewicz 1981). While it can eat a diversity of zooplankton prey, the dovekie relies heavily on Calanus copepods to feed both themselves (e.g., Karnovsky \& Hunt 2002) and their chicks (e.g., Karnovsky et al. 2003). Dovekies can dive up to $35 \mathrm{~m}$ in search of their prey (Falk 


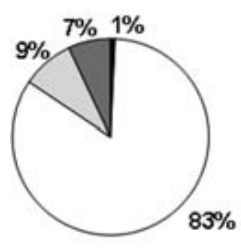

2001

$n=60$

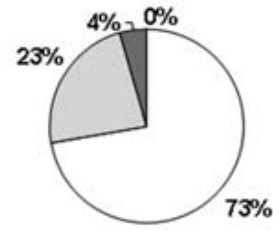

2003

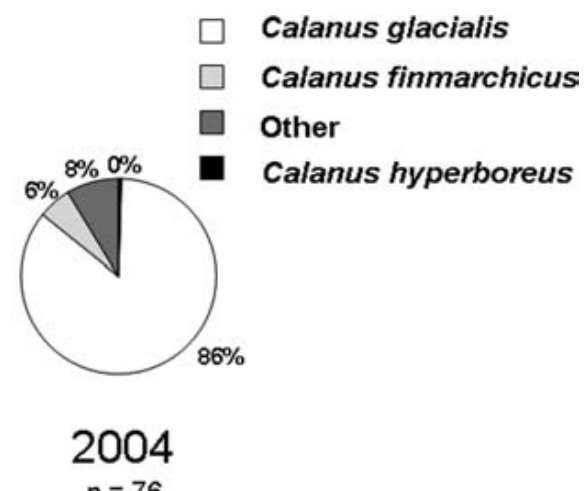

Figure 20. Percent abundance of different zooplankton prey delivered to chicks by provisioning adult dovekies in 2001, 2003, 2004; $n$, the number of chick meals analyzed. Modified from Karnovsky et al. (2003) and Jakubas et al. (2007).

et al. 2000). Both males and females carry food back to their single chick in their gular pouch. In 2001, Karnovsky and colleagues (2003) conducted at-sea surveys for seabirds and found that birds breeding in Hornsund Fjord restrict their foraging to the cold Sorkapp current. The majority of the prey that they captured to feed their chicks (93\%) were Calanus copepods. Furthermore, C. glacialis made up $76 \%$ of the biomass of the food they fed their chicks. While many of the birds (87\%) did take some C. finmarchicus, they were taken in very low numbers ( $8.9 \%$ of all prey items). The NAO index in 2001 was slightly negative. In contrast, in 2003, during a positive phase in the NAO, birds at the same colony took high numbers of C. finmarchicus (Jakubas et al. 2007). In that year, 23\% of the prey items delivered to chicks were $C$. finmarchicus (Fig. 20). The following year (2004) was an unusually cold year, with a negative phase of the NAO; only $6 \%$ of the prey delivered to chicks were G. finmarchicus. Furthermore, sympagic (ice-associated) zooplankton (Apherusa glacialis, Gammarus wiltkitzkii, Onismus littoralis) were taken in low numbers by dovekies in 2001 and 2003 (Karnovsky et al. 2003; Jakubas et al. 2007). However in 2004, these ice-associated zooplankton were taken by a much higher percentage of birds feeding their chicks. In 2004, $68 \%$ of the birds took $A$. glacialis, $35 \%$ ate $G$. wilkitzkii, and $21 \%$ fed $O$. littoralis to their chicks (Jakubas et al. 2007).
Despite the positive phase of the NAO and the influx of Atlantic water in 2003, the dovekies breeding that year were able to successfully raise their chicks. It seems that the birds were able to buffer the costs of feeding energetically inferior prey to their chicks by feeding them 1.4 times more often in a 24-hour period than in 2004 (Jakubas et al. 2007). Even though 2003 was considered a warm year, the majority of the chick meals were still made up of the larger and more energy-rich C.glacialis. The particular oceanographic conditions in which the reproductive success of these birds will be impacted are unknown.

Currently, dovekies are the most abundant bird in the Arctic and possibly in the world (Stempniewicz 2001). Declines in dovekies could indirectly impact the terrestrial Arctic ecosystem. Reindeer, geese, and other herbivores feed on the tundra fertilized by dovekies flying to and from their nests. Stempniewicz (1990) estimated that dovekies at the Hornsund colony deposit 60 tons (dry mass) of guano $\mathrm{km}^{-2}$ per year. Furthermore, dovekies themselves are prey of Arctic foxes (Alopex lagopus), glaucous gulls (Larus hyperboreus), and, on occasion, polar bears (Ursus maritimus) (Kapel 1999; Stempniewicz 1995, 2006).

Falk-Petersen and colleagues (2006) predict that with warming and further declines in ice cover in the region, C. finmarchicus will become the dominant copepod species in the region. 
C. finmarchicus will be able to expand the range where it lives and reproduces because declines in ice will create phytoplankton bloom conditions similar to what the Norwegian Sea to the south currently experiences. The regions where C. finmarchicus breeds off the Norwegian coast experience a regular, early phytoplankton bloom of smaller-sized cells which support $C$. finmarchicus. They predict that the shift from $C$. glacialis to C. finmarchicus will lead to a food web where energy is transferred from $C$. finmarchicus to herring and ultimately to Minke whales (Balaenoptera acutorostata) instead of to dovekies (Falk-Petersen et al. 2006).

Both exceptionally cold and warm years have been documented in the past (e.g., Wȩsławski \& Adamski 1987; Wȩsławski \& Kwasniewski 1990), with increases in the densities of $C$. finmarchicus during the warm years (see Fig. 9 in Hop et al. 2002). Despite the interannual variability in oceanographic conditions in the study area, there has been an overall warming trend of $1^{\circ} \mathrm{C}$ in the Sorkapp current from 1965-1997 (Blindheim et al. 2000). The temperature and thickness of the Atlantic water layer are highly correlated with positive phases of the NAO winter index, although in some areas, there is a lagged response to the NAO (Mork \& Blindheim 2000; Schlichtholz \& Goszczko 2006). With increased advection of $C$. finmarchicus into the Arctic and with the declines in sea ice, it is likely there will be a shift in the pathways of energy flow to a very different community of upper trophic predators.

Upper trophic predators that rely on the advection of prey into their foraging range are especially vulnerable to shifts in climate that result in changes in the timing, strength, and extent of water masses. Dovekies, with their reliance on the advection of large, energy-rich copepods of Arctic origin, may be especially susceptible to shifts in climate that alter either the production of prey at a distant location or the movement of these prey to near their colonies. If there is a mismatch between when they initiate breeding and when their prey is available, they may experience reproductive failure. If Arctic conditions shift to a more boreal state, dovekies may be forced to feed on lower-quality prey. A sustained increase in the distribution and strength of North Atlanticderived water in the region will change both the amount and pathways of energy flux to upper trophic predators.

\subsection{The Southern Ocean}

\subsubsection{Phytoplankton Community Response to Regional Warming}

As highlighted in sections 1.2.2 and 2.2.3, the WAP is undergoing the most rapid warming on Earth in the last few millennia. This has impacted the extent and duration of sea ice in the region, the stability of ice sheets, and the retreat of the majority of glaciers in the region (Cook et al. 2005). Dierssen and colleagues (2002) highlighted the effects of this significant seasonal glacial meltwater input on regional hydrography up to $100 \mathrm{~km}$ offshore. Increased water-column stability and potential longerterm impacts on sea-ice formation are likely secondary impacts of this increasing freshwater supply. It was also suggested that meltwater could be a cause of limiting trace elements in the region, and, in fact, phytoplankton biomass was related to the spatial and temporal regions of low salinity along the WAP (Dierssen et al. 2002). The influence of meltwater, however, could only explain about $30 \%$ of the variability in phytoplankton biomass. Previous studies in the area show significant variability in phytoplankton biomass, related to watercolumn stability (Mitchell and Holm-Hansen 1991; Moline 1998; Garibotti et al. 2005a), photo-acclimation (Moline \& Prézelin 1996; Claustré et al. 1997; Moline 1998; Moline \& Prézelin 2000), and nutrient intrusions from the CDW onto shelf waters (Prézelin et al. 2000, 2004). Despite high interannual variability in phytoplankton biomass along the coastlines of the WAP and associated shelf, a consistent and repeated pattern in phytoplankton community composition and succession has been observed along the coastline (Moline et al. 2004; Garibotti 

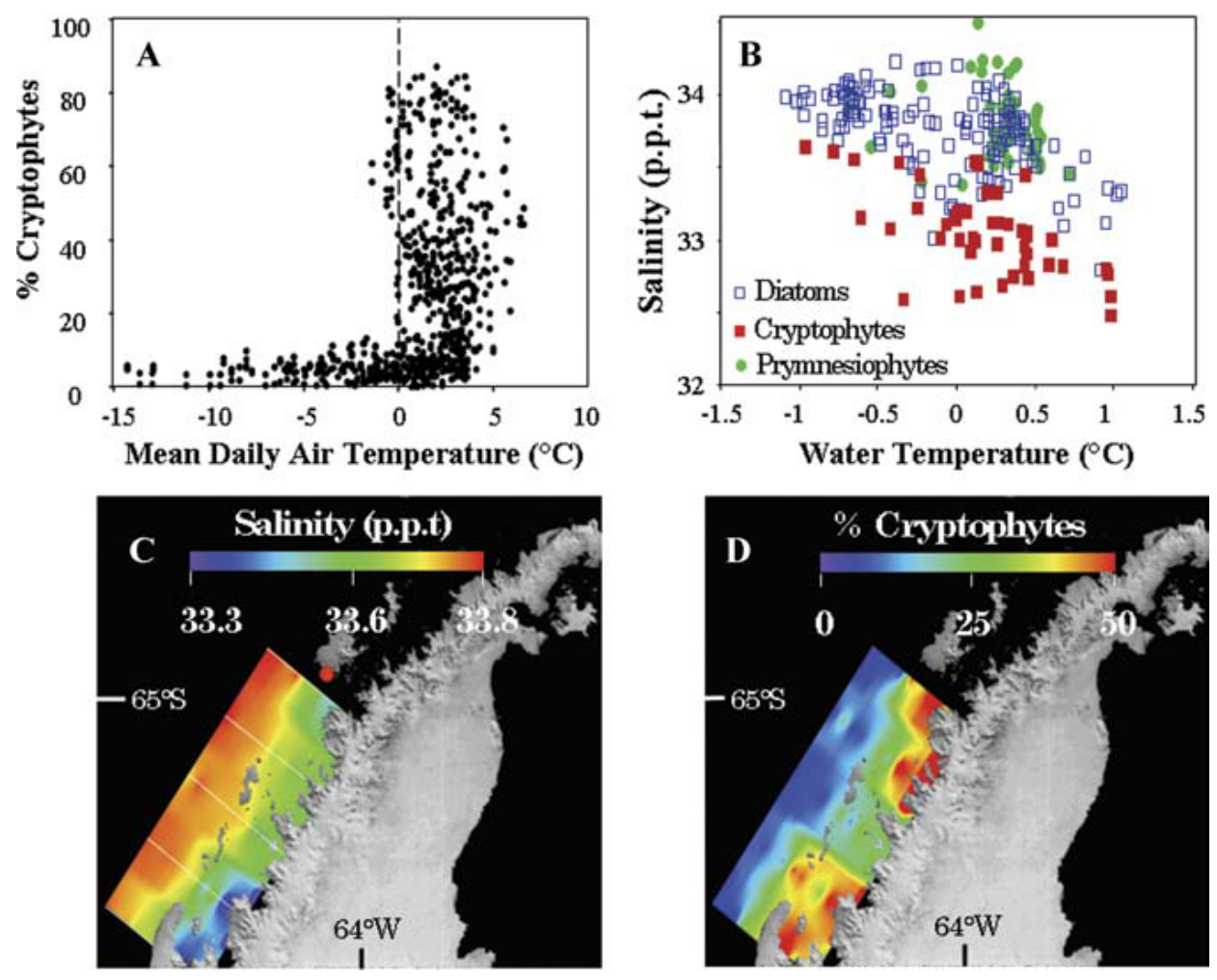

Figure 21. (A) Percent cryptophytes as a function of mean daily air temperature at Palmer Station from 1991-1996 ( $n=696)$. (B) Bivariate plot of temperature and salinity. Sample points indicate a $>50 \%$ contribution to the total phytoplankton biomass by diatoms, cryptophytes, and prymnesiophytes at Palmer Station from 1991-1994. When dominant, cryptophytes occupied significantly lower salinity water than either diatoms or prymnesiophytes. (C) Surface water salinity for a survey (December 1991 through January 1992) along the Antarctic Peninsula. Stations were occupied every $20 \mathrm{~km}$ along the historical LTER transect lines (white lines). (D) Concurrent integrated water column contribution of cryptophytes to total phytoplankton biomass. Figures adopted from Moline et al. 2004. (In color in Annals online.)

et al. 2005b). Diatoms dominated spring phytoplankton populations each year. However, there was a consistent transition from diatoms to populations of cryptophytes every summer (Moline \& Prézelin 1996; Moline et al. 2004). The dominance of cryptophytes was coincident with the occurrence of low-salinity water, which was associated with glacial meltwater input when air temperatures were above freezing (Fig. 21A). Cryptophytes dominated algal biomass during meltwater events and their presence was confined to the relatively high-temperature/lowsalinity water characteristic of the meltwater lens (Fig. 21B). While confined to surface waters, the meltwater plume often extended to depths as great as $50 \mathrm{~m}$ (Dierssen et al. 2002). In contrast, diatoms and prymnesiophytes domi- nated the phytoplankton communities in other physiochemical domains. The annual dominance of cryptophytes in low-salinity waters occurs over a large area, ranging in size from 11,000 to $48,000 \mathrm{~km}^{2}$ depending on the year and extended as far as a $100 \mathrm{~km}$ offshore (Fig. 21C, D; Garibotti et al. 2005b). This dominance of cryptophytes within low-salinity environments is consistent with observations from other coastal areas around the Antarctic continent (Kopczynska 1992; McMinn \& Hodgson 1993; Kang \& Lee 1995; Arrigo et al. 1998, Garibotti et al. 2003).

The recurrent transition from diatoms to cryptophytes represents a fundamental decrease in the size class of the phytoplankton. Bloom-forming diatoms range in size from 


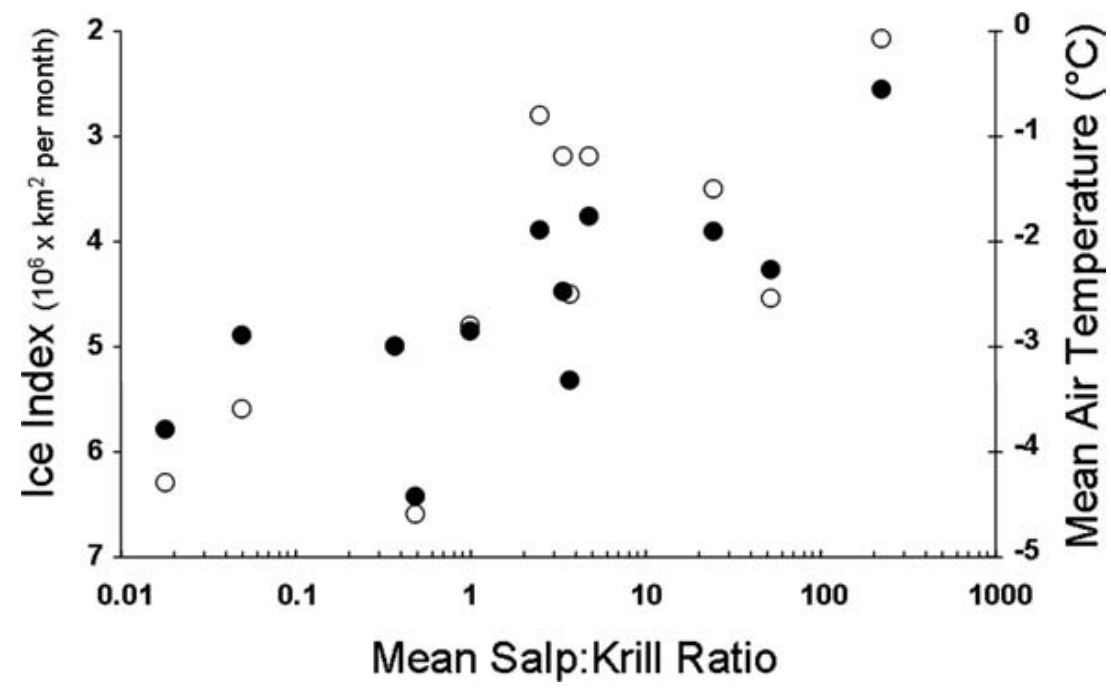

Figure 22. Ratio of mean abundances of salps to Antarctic krill (No. $1000 \mathrm{~m}^{-3}$ ) as a function of the regional sea-ice index (open circles) and mean air temperature for the Antarctic Peninsula (closed circles). Drawn from Table 1 in Loeb et al. (1997).

15-270 $\mu \mathrm{m}$ (Kopczynska 1992; Moline and Prézelin 1996), while the Antarctic cryptophytes have been measured microscopically at $8 \pm 2 \mu \mathrm{m}$ (McMinn \& Hodgson 1993). This size difference may be significant in driving the observed patterns in krill and salp abundance (Fig. 22; Kopczynska 1992; Hosie et al. 2000; Moline et al. 2004). Salps can efficiently graze food particles as small as $4 \mu \mathrm{m}$ in size (Harbison \& McAlister 1979; Deibel 1985; Harbison et al. 1986; Kremer \& Madin 1992; Madin \& Kremer 1995), but adult krill cannot. The grazing efficiency of $E$. superba decreases significantly with particles $<20 \mu \mathrm{m}$ (Meyer \& ElSayed 1983; Weber \& El-Sayed 1985; Boyd et al. 1984; Quetin \& Ross 1985); therefore it is not surprising that grazing rates of krill on cryptophytes are negligible (Haberman et al. 2003).

As the regional warming trend along the WAP is likely to continue, with glacial meltwater influencing the larger-scale hydrography, the proportion of cryptophyte biomass to total phytoplankton biomass is expected to increase. This indirect effect of climate change may be ecologically significant and would negatively impact the coastal food webs in the Antarctic. A decrease in the phytoplankton size spectrum with warming and loss of sea ice would favor an increase in salps and would not favor krill through bottom-up control (Fig. 22). As salps represent a relatively poor food source and an effective dead end in the Antarctic food web (Fig. 16; Dubischar et al. 2006), an alteration in the grazing assemblage would, in turn, lead to changes in the carbon transfer within the system. Based on published grazing rates and efficiencies, Moline and co-workers (2004) estimated that the transition in the phytoplankton community dominated by diatoms to one dominated by cryptophytes could lead to a $40-65 \%$ decrease in carbon transferred to higher trophic levels and an increase to the benthos. In fact, Gili and colleagues (2006) found that salps facilitated transfer of carbon to the benthic systems along the WAP. These alterations in the food web, if persistent, will ultimately impact biogeochemical cycling in Antarctic coastal waters (Walsh et al. 2001). Antarctic krill is central to the Antarctic marine food web and broad-scale shifts in its spatial distribution during summer (Loeb et al. 1997; Atkinson et al. 2004) would affect higher trophic levels, including penguins (see section 2.2.3), seals, and whales. The impact on higher trophic levels may be especially significant from a match-mismatch perspective, as cryptophyte dominance occurs during summer months when feeding activities are at a maximum (Laws 1985). 


\section{Conclusion}

Sea ice is recognized as a fundamental component of Earth's atmospheric and oceanic climate. Recent trends in ice dynamics in the high latitudes show rising temperatures, collapsing ice sheets, and decreased sea-ice extent and indicate that rapid environmental change is under way, with major changes in ocean chemistry (Anderson \& Kaltin 2001) and productivity regimes (Smetacek and Nicol 2005). These changes are revealing measurable and significant changes in individual organisms, populations, communities, and ecosystems, affecting energetics, predator-prey interactions, reproductive success, phenology, abundance, diversity, and demographic shifts on large scales. The largest uncertainty in forecasting the effects of climate change on ecosystems is in understanding how it will affect the nature of interactions among species (Winder \& Schindler 2004). Specifically it will depend on whether climate disruptions of predator-prey interactions are maintained or whether species have the ability to adjust their phenology (and spatial demographics) to climate change, decreasing the degree of mismatch through changes at the population level. In evolutionary history, the persistence of a given species has been largely governed by natural selection. The rapid and dramatic changes along the Antarctic Peninsula and model simulation predicting the Arctic being ice free in the summer by the latter half of the 21st century (Walsh \& Timlin 2003; Johannessen et al. 2004; Overpeck et al. 2006), suggest the time required for natural selection to occur is not available. Berteaux and colleagues (2006) advocate quantitative criteria for assessing causal relationships between ecology and climate change, which would help establish the different mechanistic links between the dynamics of populations and climate variability and help in predicting change (Stenseth et al. 2002). Accurate predictions would be required for conservation and management of polar marine populations (Simmonds \& Isaac 2007). It should also be appreciated that under conditions of climate change, scientific results and conclusions will need to be revisited frequently, for example, to redefine phenology and population boundaries (Lombard et al. 2007). This identifies the need for time series studies on appropriate spatial scales to resolve these changes (Ducklow et al. 2007). The impacts of climate on ecosystems require interdisciplinary efforts in, among others, geophysics, glaciology, geology, chemistry, biogeochemistry, and numerous branches of biology.

March 2007 marked the beginning of the International Polar Year (IPY). In an editorial describing the event, Walton (2007) suggested a public information overload and a general lack of public interest. Since that opening event, much has happened (Fig. 2), with climate change as a growing topic of public discussion (see Kerr \& Kintisch 2007; Pennisi et al. 2007; Schiermeier 2007). A significant segment of the scientific effort during the IPY is focused on climate and climate impacts. Results from these studies during a year of dramatic changes in ice dynamics will provide more perspective and serve to increase attention to the complexity, scale, and impacts of the changes occurring in polar marine ecosystems.

\section{Acknowledgments}

We would like to thank the many people who help collect data in the field for the work included here and recognize our sponsors. Section 2.1.2 was supported by a grant from the World Wildlife Fund and from long-term funding by the Friends of Cooper Island to G. Divoky. Sections 2.1.3 and 3.1.1 were supported by NSF-OPP awards 0612504 and 0301469 to N. Karnovsky and by a Mellon Foundation post-baccalaureate grant to $\mathrm{Z}$. Brown. Section 2.2.1 was supported, in part, by NSF-OPP award 0336469 to T. Frazer. Data for section 2.2.3 are based on NSFOPP awards 7421374, 7615350, 8918324, 9011927, 9103429, 9320115, 9396281, 
9505596, 9632763, 9907950, 9910095, 0130525, 0217282, 0224727, and 0523261 to W. Fraser. Section 3.2.1 was supported by NSF-OPP awards 9011927 and 9632763 to the Palmer LTER program.

\section{References}

Aagaard, K. \& E.C. Carmack. 1989. The role of sea-ice and other fresh water in the Arctic circulation. 7 . Geophys. Res. 94: 14485-14498.

Ackley, S. et al. 2003. Decadal decrease of Antarctic seaice extent inferred from whaling records revisited on the basis of historical and modern sea-ice records. Polar Res. 22: 19-25.

Agnew, D.J. \& S. Nicol. 1996. Marine disturbancescommercial fishing. In Foundations for Ecological Research West of the Antarctic Peninsula. R.M. Ross, E.E. Hofmann \& L.B. Quetin, Eds.: 417-435. American Geophysical Union. Washington, DC.

Ainley, D. 2002. The Adélie Penguin: Bellwether of Climate Change. Columbia University Press. New York. p. 310.

Ainley, D.G. et al. 1986. Antarctic pack ice structures mesopelagic nektonic communities. Science 232: 847-849.

Amstrup, S.C. 1986. Research on polar bears in Alaska, 1983085. In Proceedings of the Ninth Working Meeting of the IUCN Polar Bear Specialist Group, Edmonton, Alberta, August 1985. Gland, Switzerland: International Union for the Conservation of Nature and Natural Resources. 85-112.

Amstrup, S.C. 1993. Human disturbances of denning polar bears in Alaska. Arctic 46: 246-250.

Amstrup, S.C. \& C. Gardner. 1994. Polar bear maternity denning in the Beaufort Sea. F. Wildl. Mange. 58: $1-10$.

Amstrup, S.C. et al. 2007. Forecasting the range-wide status of polar bears at selected times in the 21 st century. Administrative Report, United States Geological Survey.

Anderson, L.G. \& S. Kaltin. 2001. Carbon fluxes in the Arctic Ocean - potential impact by climate change. Polar Res. 20: 225-232.

Andriashev, A.P. 1965. A general review of the Antarctic fish fauna. In Biogeography and Ecology in Antarctica. P. van Oye \& J. van Mieghem, Eds.: 491-550. Junk. The Hague, Netherlands.
Arndt, C.E. 2002. Feeding ecology of the Arctic iceamphipod, Gammarus wilkitzkii. Physiological, morphological and ecological studies. Berichte Polarforschung und Meeresforschung 405. 96 pp.

Arndt, C.E. \& F. Beuchel. 2006. Life history and population dynamics of the Arctic sympagic amphipods Onisimus nanseni Sars and O. glacialis Sars (Gammaridea: Lysianassidae). Polar Biol. 29: 239-248.

Arrigo, K.R. et al. 1998. Bio-optical properties of the southwestern Ross Sea. F. Geophys. Res. 103: 2168321695.

Atkinson, A. et al. 2004. Long-term decline in krill stock and increase in salps within the Southern Ocean. Nature 432: 100-103.

Auel, H. \& W. Hagen. 2002. Mesozooplankton community structure, abundance and biomass in the central Arctic Ocean. Marine Biol. 140: 1013-1021.

Auel, H. \& I. Werner. 2003. Feeding, respiration and life history of the hyperiid amphipod, Themisto libellula, in the Arctic marginal ice zone of the Greenland Sea. 7. Exp. Marine Biol. Ecol. 296: 183-197.

Auel, H. et al. 2002. Lipid biomarkers indicate different ecological niches and trophic relationships of the Arctic hyperiid amphipods Themisto abyssorum and T. libellula. Polar Biol. 25: 374-383.

Barbraud, C. \& H. Weimerskirch. 2001. Emperor penguins and climate change. Nature 411: 183186.

Barbraud, C. \& H. Weimerskirch. 2006. Antarctic birds breed later in response to climate change. Proc. Natl. Acad. Sci. 103: 6248-6251.

Barnes, D.K.A. \& K.E. Conlan. 2007. Disturbance, colonization and development of Antarctic benthic communities. Philos. Trans. R. Soc. Lond. B. 362: 11-38 (special theme issue, Antarctic Ecology: From Genes to Ecosystems, A. Rogers, E. Murphy and A.C. Clarke, Eds.).

Behrenfeld, M.J. \& P.G. Falkowski. 1997. Photosynthetic rates derived from satellite-based chlorophyll concentrations. Limnol. Oceanogr. 42: 1-20.

Behrenfeld, M.J. et al. 2005. Carbon-based ocean productivity and phytoplankton physiology from space. Global Biogeochem. Cycles 19: GB1006, doi: 10.1029/2004GB002299.

Berge, J. et al. 2005. Ocean temperature oscillations enable reappearance of blue mussels Mytilus edulis in Svalbard after a 1000 year absence. Mar. Ecol. Prog. Ser. 303: $167-175$.

Berge, J. et al. 2006. The Mytilus edulis population in Svalbard: how and why. Mar. Ecol. Prog. Ser. 309: 305306.

Bergen, S. et al. 2007. Predicting movements of female polar bears between summer sea-ice foraging habitats and terrestrial denning habitats of Alaska in the 21st century: proposed methodology and pilot 
assessment. Administrative Report, United States Geological Survey.

Berteaux, D. et al. 2006. Constraints to projecting the effects of climate change on mammals. Clim. Res. 32: 151-158.

Biuw, M. et al. 2007. Variations in behavior and condition of a Southern Ocean top predator in relation to in situ oceanographic conditions. Proc. Natl. Acad. Sci. 104: $13705-13710$.

Blake Jr., W. 2006. Occurrence of the Mytilus edulis complex on Nordaustlandet, Svalbard: radiocarbon ages and climatic implications. Polar Res. 25: 123-137.

Blindheim, J. et al. 2000. Upper layer cooling and freshening in the Norwegian Sea in relation to atmospheric forcing. Deep-Sea Res. I 47: 655-680.

Blomqvist, S. \& M. Elander. 1981. Sabine's Gull (Xema sabini), Ross's Gull (Rhodostethia rosea) and Ivory Gull (Pagophila eburnea); Gulls in the Arctic: A Review. Arctic 34: $122-132$.

Booth, B.C. \& R.A. Horner. 1997. Microalgae on the Arctic Ocean Section, 1994: species abundance and biomass. Deep-Sea Res. II 44: 1607-1622.

Born, E.W. et al. 2004. Habitat use of ringed seals (Phoca hispida) in the North Water Area (North Baffin Bay). Arctic 57: 129-142.

Boyd, C.M. et al. 1984. Feeding of the Antarctic krill, Euphausia superba. Crust. Biol. 4: 123-141.

Boyd, P.W. 2002. Environmental factors controlling phytoplankton processes in the Southern Ocean. F. Phycol. 38: 844-861.

Braune, B.M. et al. 2007. Levels and trends of organochlorines and brominated flame retardants in Ivory Gull eggs from the Canadian Arctic, 1976-2004. Sci. Tot. Environ. 378: 403-417.

Carey, A.G. 1985. Marine ice fauna: Arctic. Sea-ice biota. In R. Horner, Ed.: 173-190. CRC. Boca Raton, Florida.

Carmack, E. et al. 2006. Climate variability and physical forcing of the food webs and the carbon budget on panarctic shelves. Prog. Oceanogr. 71: 145-181.

Chapman, E.W. et al. in press. Modelling the influence of variability in Antarctic krill (Euphausia superba) spawning behavior and sex/maturity stage distribution on Adélie penguin (Pygoscelis adealiae) prey quality and chick growth. Deep Sea Res. II.

Chapman, W.L. \& J.E. Walsh. 1993. Recent variations of sea-ice and air temperature in high latitudes. Bull. Am. Meteorol. Soc. 74: 33-47.

Chardine, J.W. et al. 2004. At-sea observations of ivory gulls (Pagophila eburnea) in the eastern Canadian high Arctic in 1993 and 2002 indicate a population decline. Polar Rec. 40: 355-359.

Charrassin, J.-B. \& C.-A. Bost. 2001. Utilisation of the oceanic habitat by king penguins over the annual cycle. Mar. Ecol. Prog. Ser. 221: 285-297.
Ciannelli, L. \& K.M. Bailey. 2005. Landscape dynamics and resulting species interactions: the cod-capelin system in the southeastern Bering Sea [abstract]. Mar. Ecol. Prog. Ser. 291: 227-236. doi: MEPS 291;227-236(2005).

Ciannelli, L. et al. 2007. Spatial anatomy of species survival: Effects of predation and climate-driven environmental variability. Ecology 88: 635-646.

Clarke, A. et al. 2007. Climate change and the marine ecosystem of the western Antarctic Peninsula. Phil. Trans. R. Soc. Lond. 362: 149-166.

Claustre, H. et al. 1997. Sources of variability in the column photosynthetic cross section for Antarctic coastal waters. 7 Geophys. Res. 102: 25,047-25,060.

Comiso, J.C. 2002a. A rapidly declining perennial sea-ice cover in the Arctic. Geophys. Res. Lett. 29: 1-17, DOI 10.1029/2002GL015650.

Comiso, J.C. 2002b. Correlation and trend studies of the sea-ice cover and surface temperatures in the Arctic. Ann. Glaciol. 34: 420-428.

Conroy, J.W.H. 1975. Recent increases in penguin populations in Antarctica and the Subantarctic. In The Biology of Penguins. B. Stonehouse, Ed.: 321-336. University Park Press. London.

Cook, A.J. et al. 2005. Retreating glacier fronts on the antarctic Peninsula over the past half-century. Science 308: $541-544$.

Croxall, J. et al. 1999. Diet provisioning and productivity responses of marine predators to differences in availability of Antarctic krill. Mar. Ecol. Prog. Ser. 177: $115-131$.

Croxall, J.P. et al. 2002. Environmental Change and Antarctic Seabird Populations. Science 297: 1510 1514.

Gurran, M.A. et al. 2003. Ice Core Evidence for Antartic See Ice Decline since the 1950s. Science 302: 1203, DOI:10.1126/science.1087888.

Cushing, D.H. 1969. The regularity of the spawning season of some fishes. 7. Cons. Int. Explor. Mer. 33: 8192.

Cushing, D.H. 1982. Climate and Fisheries. Academic Press. London.

Cushing, D.H. 1990. Plankton production and year-class strength in fish populations - an update of the match mismatch hypothesis. Adv. Mar. Biol. 26: 249-293.

Cushing, D.H. 1995. Population Production and Regulation in the Sea: a Fisheries Perspective. Cambridge University Press. Cambridge.

Daly, K.L. 1990. Overwintering development, growth and feeding of larval Euphausia superba in the Antarctic marginal ice zone. Limnol. Oceanogr. 35: 1564 1567.

Daniels, R.A. 1978. Nesting behavior of harpagifer bispinis in Arthur Harbor, Antarctic peninsula. 7. Fish Biol. 12: 465-474. 
Daniels, R.A. \& J.H. Lipps. 1982. Distribution and ecology of fishes of the Antarctic peninsula. F. Biogeogr. 9: $1-9$.

Deibel, D. 1985. Clearance rates of the salp, Thalia democratica, fed naturally occurring particles. Mar. Biol. 86: $47-54$.

Derocher, A.E. \& I. Stirling. 1994. Age-specific reproductive performance of female polar bears. F. Zool. Lond. 234: $527-536$.

Derocher, A.E. \& I. Stirling. 1996. Aspects of survival in juvenile polar bears. Can. F. Zool. 74: 1246-1252.

Derocher, A.E. et al. 2000. Predation of Svalbard reindeer by polar bears. Polar Biol. 23: 675-678.

Derocher, A.E. et al. 2002. Diet composition of polar bears in Svalbard and the western Barents Sea. Polar Biol. 25: 448-452.

Derocher, A.E. et al. 2004. Polar Bears in a Warming Climate. Integr. Com. Biol. 44: 163-176.

Derocher, A.E. 2005. Population ecology of polar bears at Svalbard, Norway. Pop. Ecol. 47: 267-275.

DeVries, A.L. 1986. Antifreesers glycoproteins and peptides: interactions with ice and water. Methods Enzymol. 127: 293-303.

DeWitt, H.H. 1970. The character of the midwater fish fauna of the Ross Sea, Antarctica. In Antarctic Ecology, Vol. 1. M.W. Holdgate, Ed.: 305-314. Academic Press. London.

DeWitt, H.H. et al. 1990. Nototheniidae. In Fishes of the Southern Ocean. O. Gon \& P.C. Heemstra, Eds.: 279331. J.L.B. Smith Institute of Ichthyology. Grahamstown.

DeWitt, H.H. \& T.L. Hopkins. 1977. Aspects of the diet of the Antarctic silverfish, Pleuragramma antarcticum. In Adaptations within Antarctic Ecosystems. G.A. Llano, Ed.: 557-568. Smithsonian Institution. Washington, DC.

Dick, C. 2003. Sea-ice extent and the global climate system. Polar Res. 22: 1-4.

Dickson, R.R. et al. 2000. The Arctic Ocean response to the North Atlantic Oscillation. 7. Clim. 13: $2671-$ 2696.

Dierssen, H.M. et al. 2002. Glacial meltwater dynamics in coastal waters West of the Antarctic Peninsula. Proc. Natl. Acad. Sci. 99: 1790-1795.

Dinniman, M.S., et al. 2003. Cross shelf exchange in a model of the Ross Sea circulation and biogeochemistry. Deep-Sea Res. II 50: 3103-3120.

Divine, D. et al. 2003. Variability and climate sensitivity of fast ice extent in the north-eastern Kara Sea. Polar Res. 22: 27-34.

Divoky, G.J. 1976. The pelagic feeding habits of ivory and ross' gulls. Condor 78: 85-90.

Divoky, G.J. 1982. The occurrence and behavior of nonbreeding Horned Puffins at Black Guillemot colonies in northern Alaska. Wilson Bull. 94: 356-358.
Divoky, G.J. 1984. The pelagic and nearshore birds of the Alaskan Beaufort Sea: biomass and trophics. In The Alaskan Beaufort Sea: Ecosystems and Environments. P.W. Barnes, D.M. Schell \& E. Reimnitz, Eds.: 417-437. Academic Press. New York.

Divoky, G.J. et al. 1974. Breeding of the Black Guillemot in northern Alaska. Condor 76: 339-343.

Domack, E. et al. 2003. Marine sedimentary record of natural environmental variability and recent warming in the Antarctic Peninsula. In Antarctic Peninsula Climate Variability: Historical and Paleoenvironmental Perspectives. E. Domack, A. Leventer, A. Burnett, et al., Eds.: 205-224. American Geophysical Union. Washington, DC.

Domack, E. et al. 2005. Stability of the Larsen B ice shelf on the Antarctic Peninsula during the Holocene epoch. Nature 436: 681-685.

Donnelly, J. \& J.J. Torres. 2008. Pelagic fishes in the Marguerite Bay region of the Western Antarctic Peninsula Shelf. Deep-Sea Res. II, in press.

Donnelly, J. et al. 2004. Fishes of the eastern Ross Sea, Antarctica. Polar Biol. 27: 637-650.

Drinkwater, K.F. 2005. The response of Atlantic cod (Gadus morhua) to future climate change. ICES F. Mar. Sci. 62: 1327-1337.

Drolet, R. et al. 1991. Production of fish larvae and their prey in subarctic southeastern Hudson Bay. Mar. Ecol. Prog. Ser. 77: 105-118.

Druzhkov, N.V. et al. 2001. Phytoplankton in the southwestern Kara Sea: composition and distribution. $P_{0-}$ lar Res. 20: 95-108.

Dubischar, C.D. et al. 2006. The tunicate Salpa thompsoni ecology in the Southern Ocean II. Proximate and elemental composition. Mar. Biol. 149: 625-632, doi: 10.1007/s00227-005-0226-8.

Ducklow, H.W. et al. 2007. Marine pelagic ecosystems: the West Antarctic Peninsula. Phil. Trans. R. Soc. Lond. B 362: 67-94, doi: 10.1098/rstb.2006.1955.

Durant, J.M. et al. 2005. Timing and abundance as key mechanisms affecting trophic interactions in variable environments. Ecol. Lett. 8: 952-958.

Durant, J.M. et al. 2007. Climate and the match or mismatch between predator requirements and resource availability. Clim. Res. 33: 271-283.

Durner, G.M. et al. 2007. Predicting the future distribution of polar bear habitat in the Polar Basin from resource selection functions applied to 21 st century General Circulation Model projections of sea-ice. Administrative Report, United States Geological Survey.

Eastman, J.T. 1985. Pleuragramma antarcticum (Pisces, Nototheniidae) as food for other fishes in McMurdo Sound, Antarctica. Polar Biol. 4: 155160.

Eastman, J.T. 1993. Antarctic Fish Biology: Evolution in a Unique Environment. Academic Press. San Diego. 
Edwards, M. \& A.J. Richardson. 2004. Impact of climate change on marine pelagic phenology and trophic mismatch. Nature 430: 881-884.

Efremenko, V.N. 1986. Distribution of eggs and larvae of Myctophidae in the southern Atlantic. 7. Ichthyology 26: $141-147$.

Emslie, S.D. 2001. Radiocarbon dates from abandoned penguin colonies in the Antarctic Peninsula region. Antarctic Sci. 13: 289-295.

Emslie, S.D. et al. 2007. A 45,000 yr record of Adélie penguins in the Ross Sea, Antarctica. Geology 35: 61-64.

Everson, I. 2000. Role of krill in marine food webs: the Southern Ocean. In Krill: Biology, Ecology and Fisheries. I. Everson, Ed.: 194-201. Blackwell Science. Oxford.

Faleyeva, T.I. \& V.V. Gerasimchuk. 1990. Features of reproduction in the Antarctic sidestripe, Pleuragramma antarcticum (Nototheniidae). 7. Ichthyology 30: 416424.

Falk, K. et al. 2000. Measurements of diving depths in Dovekies (Alle alle). Auk 117: 522-525.

Falk-Petersen, S. et al. 2006. Climate variability and possible effects on arctic food chains: The role of Calanus. In Arctic Alpine Ecosystems and People in a Changing Environment. J.B. Ørbæk, R. Kallenborn, I. Tombre, et al., Eds.: 147-166. Springer-Verlag. Berlin Heidelberg.

Fichefet, T. et al. 2003. A hindcast simulation of Arctic and Antarctic sea-ice variability, 1955-2001. Polar Res. 22: 91-98.

Fischbach, A.S. et al. 2007. Landward and eastward shift of Alaskan polar bear denning associated with recent sea-ice changes. Polar Biol. 30: 1395-1405.

Forcada, J. et al. 2006. Contrasting population changes in sympatric penguin species in association with climate warming. Global Change Biol. 12: 411-423.

Fortier, L. et al. 1996. Impact of freshwater on a subarctic coastal ecosystem under seasonal sea-ice (southeastern Hudson Bay, Canada). III. Feeding success of marine fish larvae. 7. Mar. Syst. 7: 251-265.

Fortier, L. et al. 1995. The match/mismatch hypothesis and the feeding success of fish larvae in ice-covered southeastern Hudson Bay. Mar. Ecol. Prog. Ser. 120: $11-27$.

Fortier, M.L. et al. 2001. Visual predators and the diel vertical migration of copepods under Arctic sea-ice during the midnight sun. F. Plank. Res. 23: 12631278.

Fortier, M.L. et al. 2006. Survival of Arctic cod larvae (Boreogadus saida) in relation to sea-ice and temperature in the Northeast Water Polynya (Greenland Sea). Can. 7. Fisheries Aquatic Sci. 63: 16081616 ,

Fraser, W.R. \& D.L. Patterson. 1997. Human disturbance and long-term changes in Adelie penguin populations: a natural experiment at Palmer Station, Antarctic Peninsula. In Antarctic Communities: Species, Structure and Survival. Scientific Committee for Antarctic Research (SCAR), Sixth Biological Symposium. B. Battaglia, J. Valencia \& D.W.H. Walton, Eds.: 445-452. Cambridge University Press. New York.

Fraser, W.R. \& E.E. Hofmann. 2003. A predator's perspective on causal links between climate change, physical forcing and ecosystem response. Mar. Ecol. Prog. Ser. 265: 1-15.

Fraser, W.R. \& W.Z. Trivelpiece. 1995. Variability in sea-ice coverage and long-term change in the diets of Adélie penguins: implications for Southern Ocean ecosystem studies. Report of the Working Group on Ecosystem Monitoring and Management (WG-EMM 95/64, SC-CGAMLR-XIV). Hobart, CCAMLR, Australia.

Fraser, W.R. \& W.Z. Trivelpiece. 1996. Factors controlling the distribution of seabirds: winter-summer heterogeneity in the distribution of Adélie penguin populations. In Foundations for Ecological Research West of the Antarctic Peninsula, Vol. 70. R.M. Ross, E.E. Hofmann \& L.B. Quetin, Eds.: 257-272. American Geophysical Union. Washington, DC.

Fraser, W.R. et al. 1992. Increases in Antarctic penguin populations: reduced competition with whales or a loss of sea-ice due to environmental warming? Polar Biol. 11: 525-531.

Frazer, T.K. 1996. Stable isotope composition $\left(\delta^{13} \mathrm{G}\right.$ and $\delta^{15} \mathrm{~N}$ ) of larval krill, Euphausia superba, and two of its potential food sources in winter. F. Plank. Res. 18: 1413-1426.

Frazer, T.K. et al. 2002a. Energetic demands of larval krill, Euphausia superba, in winter. 7. Exp. Mar. Biol. Ecol. 277: 157-171.

Frazer, T.K. et al. 2002b. Abundance, sizes and developmental stages of larval krill, Euphausia superba, in ice covered seas west of the Antarctic Peninsula. 7. Plank. Res. 24: 1067-1077.

Frazer, T.K. et al. 1997. Abundance and distribution of larval krill, Euphausia superba, associated with annual sea-ice in winter. In Antarctic Communities. B. Battaglia, J. Valencia \& D.W.H. Walton, Eds.: 107-111. Cambridge University Press. Cambridge.

Friedlaender, A.S. et al. 2007. Variation in Ice Cover on the East Coast of Canada, February-March, 19692006: Implications for harp and hooded seals. International Fund for Animal Welfare (IFAW) Technical Report 2007-1. 8 pp.

Garibotti, I. et al. 2003. Phytoplankton spatial distribution patterns along the western Antarctic Peninsula (Southern Ocean). Mar. Ecol. Prog. Ser. 261: 21-39.

Garibotti, I. et al. 2005a. Marine phytoplankton distribution during three summers in the seasonal sea-ice 
zone west of the Antarctic Peninsula. 7. Plank. Res. 27, 825-843.

Garibotti, I. et al. 2005b. Annually recurrent phytoplanktonic assemblages during summer in the seasonal ice zone west of the Antarctic Peninsula (Southern Ocean). Deep-Sea Res. II 52: 1823-1841. doi: 10.1016/j.dsr.2005.05.003.

Gilchrist, H.G. \& M.L. Mallory. 2005. Declines in abundance and distribution of the ivory gull (Pagophila eburnea) in Arctic Canada. Biol. Conserv. 121: 303309.

Gili, S. et al. 2006. A new trophic link between the pelagic and benthic systems on the Antarctic shelf. Mar. Ecol. Prog. Ser. 322: 43-49, doi: 10.3354/meps322043.

Gradinger, R. 1995. Climate change and biological oceanography of the Arctic Ocean. Philos. Trans.: Phys. Sci. Eng. 352: 277-286.

Gradinger, R. et al. 2004. Arctic Census of Marine Life (ArcCoML) Program Proposal. University of Fairbanks. Fairbanks, Alaska. 35 pp.

Gradinger, R.R. \& B. Bluhm. 2004. In-situ observations on the distribution and behavior of amphipods and Arctic cod (Boreogadus saida) under the sea-ice of the High Arctic Canada Basin. Polar Biol. 27: 595-603.

Grebmeier, J.M. et al. 2006. A Major Ecosystem Shift in the Northern Bering Sea. Science 311: 1461-1464.

Greely, T.M. et al. 1999. Age and growth of Electrona antarctica (Pisces: Myctophidae) the dominant mesopelagic fish of the Southern Ocean. Mar. Biol. 133: 145158.

Gutt, J. 2001. On the direct impact of ice on marine benthic communities, a review. Polar Biol. 24: 553564.

Haberman, K.L. et al. 2003. Diet of Antarctic krill (Euphausia superba Dana): II. Selective grazing in mixed phytoplankton assemblages. 7. Exp. Mar. Biol. Ecol. 283: 97-113.

Hamilton, L.C. \& R.L. Haedrich. 1999. Ecological and population changes in fishing communities of the North Atlantic Arc. Polar Res. 18: 383-388.

Hammill, M.O. \& Smith, T.G. 1991. The role of predation in the ecology of the ringed seal in Barrow Strait, Northwest Territories, Canada. Mar. Mamm. Sci. 7: 123-135.

Harbison, G.R. \& V.L. McAlister. 1979. The filter-feeding rates and particle retention efficiencies of three species of Cyclosalpha (Tunicata, Thalliacca). Limnol. Oceanogr. 24: 875-892.

Harbison, G.R. et al. 1986. The response of the salp, Pegea confoederata, to high levels of particulate material: starvation in the midst of plenty. Limnol. Oceanogr. 31: 371-382.

Harden-Jones, F.R. 1968. Fish Migration. Edward Arnold. London.

Harington, C.R. 1968. Denning habits of the polar bear
(Ursus maritimus Phipps). Report Series, No. 5. Ottawa: Canadian Wildlife Service. 30 p.

Hassol, S. 2004. Impacts of a warming Arctic: Arctic Climate Impact Assessment. Cambridge University Press. Cambridge, UK.

Hinke, J.T. et al. 2007. Divergent responses of Pygoscelis penguins reveal a common environmental driver. Oecologia 135: 845-855.

Hirche, H.J. 1991. Distribution of dominant calanoid copepod species in the Greenland Sea during late fall. Polar Biol. 11: 351-362.

Hofmann, E.E. et al. 1996. Water mass distribution and circulation west of the Antarctic Peninsula and including the Bransfield Strait. In Foundations for Ecological Research West of the Antarctic Peninsula, Vol. 70. R.M. Ross, E.E. Hofmann \& L.B. Quetin, Eds.: 1560. American Geophysical Union. Washington, DC.

Hofmann, E.E. \& T.M. Powell. 1998. Environmental variability effects on marine fisheries: four case histories. Ecol. Appl. 8: S23-S32.

Hoekstra, P. et al. 2002. Trophic ecology of bowhead whales (Balaena mysticetus) compared with that of other arctic marine biota as interpreted from carbon-, nitrogen- and sulfur-isotope signatures. Can. 7. Zool. 80: 223-231.

Hop, H. et al. 2002. The marine ecosystem of Kongsfjord, Svalbard. Polar Res. 21: 167-208.

Hopkins, T.L. 1985. Food web of an Antarctic midwater ecosystem. Mar. Biol. 89: 197-212.

Horne, J.K. \& D.C. Schneider. 1995. Spatial Variance in Ecology. Oikos 74: 18-26.

Hosie, G.W. et al. 2000. Macrozooplankton community structure off East Antarctica (80-1501E) during the Austral summer of 1995/1996. Deep-Sea Res. 47: 2437-2463.

Hourigan, T.F. \& R.L. Radtke. 1989. Reproduction of the Antarctic fish, Nototheniops nudifrons. Mar. Biol. 100: 277-283.

Hubold, G. 1985. The early life history of the highAntarctic silverfish, Pleuragramma antarcticum. In Antarctic Nutrient Cycles and Food Webs. Proceedings of the 4th SCAR symposium on Antarctic Biology. W.R. Siegfried, P.R. Condy \& R.M. Laws, Eds.: 445451. Springer-Verlag. Berlin.

Hubold, G. 1990. Seasonal patterns of ichthyoplankton distribution and abundance in the southern Weddell Sea. In Ecological Change and Conservation, Antarctic Ecosystems. K.R. Kerry \& G. Hempel, Eds. SpringerVerlag. Berlin, Heidelberg, New York.

Hubold, G. \& P. Tomo. 1989. Age and growth of the Antarctic silverfish Pleuragramma antarcticum Boulenger 1902, from the southern Weddell Sea and the Antarctic Peninsula. Polar Biol. 9: 205-212.

Hulley, P.A. 1990. Family myctophidae lantern fishes. In Fishes of Southern Ocean. O. Gon \& P.G. Heemstra, 
Eds.: 146-178. JCB Institute of Ichthyology Grahamstown, South Africa.

Hunt, G. 1990. The pelagic distribution of marine birds in a heterogeneous environment. Polar Res. 8: 43-54.

Hunt Jr., G.L. et al. 2002. Climate change and control of the southeastern Bering Sea pelagic ecosystem. Deep Sea Res. II 49: 5821-5853.

Hureau, J.-C. 1966. Biologie de Chaenichthyes rhinoceratus Richardson et probleme du sang incolore des Chaenichthyidae, poissons des mers australes. Bulletin de la Societe Zoologique de France 91: 735751.

Hurrell J.W. et al. 2001. The North Atlantic Oscillation. Science 291: 603-605.

Hurrell, J.W. 1995. Decadal trends in the North Atlantic Oscillation: regional temperatures and precipitation. Science 269: 676-679.

IPCC. 2001. Third Assessment Report of the Intergovernmental Panel on Climate Change, IPCC (WG I \& II). Cambridge University Press. Cambridge.

IPCG. 2007. Fourth Assessment Report of the Intergovernmental Panel on Climate Change, IPCC (WG I \& II). Cambridge University Press. Cambridge.

Jakubas, D. et al. 2007 Response of dovekie to changes in food availability. Waterbirds 30: 421-428.

Jaschnov, V.A. 1961. Water masses and plankton. 1. Species of Calanus finmarchicus s.l. as indicators of definite water masses. Zoologicheskii Zh 40: 1314 1334.

Jiuxin, S. et al. 2005. Distribution of Pacific-origin water in the region of the Chukchi Plateau in the Arctic Ocean in the summer of 2003 [abstract]. Acta Oceanologica Sinica 24: 12-24.

Johannessen, O.M. et al. 2004. Arctic climate change: Observed and modeled temperature and sea-ice variability. Tellus 56: 328-341.

Johnston, D.W. et al. 2005. Variation in sea-ice cover on the east coast of Canada from 1969 to 2002: climate variability and implications for harp and hooded seals [abstract]. Clim. Res. 29: 209-222.

Kang, S-H. \& S. Lee. 1995. Antarctic phytoplankton assemblage in the western Bransfield Strait region, February 1993: composition, biomass, and mesoscale distributions. Mar. Ecol Prog. Ser. 129: 253 267.

Kapel, G.M. 1999. Diet of Arctic foxes (Alopex lagopus) in Greenland. Arctic 52: 289-293.

Karnovsky, N.J. \& G.L. Hunt, Jr. 2002. Carbon flux through dovekies (Alle alle) in the North Water. Deep Sea Res. II 49: 5117-5130.

Karnovsky, N.J., et al. 2003. The foraging behavior of little auks in a heterogeneous environment. Mar. Ecol. Prog. Ser. 253: 289-303.

Kellermann, A.K. 1986. Geographical distribution and abundance of post-larval and juvenile Pleura- gramma antarcticum (Pisces; Notothenioidei) off the Antarctic Peninsula. Polar Biol. 6: 111-119.

Kellermann, A.K. 1996. Midwater Fish Ecology. In Foundations for Ecological Research West of the Antarctic Peninsula. R.M. Ross, E.E. Hofmann \& L.B. Quetin, Eds.: 231-256. American Geophysical Union. Washington, DC.

Kellermann, A.K. \& S. Schadwinkel. 1991. Winter aspects of the ichthyoplankton community in Antarctic Peninsula waters. Polar Biol. 11: 117-127.

Kerr R.A. \& E. Kintisch. 2007. GLOBAL WARMING: Nobel Peace Prize Won by Host of Scientists and One Crusader. Science 318: 372-373, doi: 10.1126/science.318.5849.372.

Kingsley, M.C.S. et al. 1985. The distribution and abundance of seals in the Canadian High Arctic, 19801985. Can. 7. Fish. Aqu. Sci. 42: 1189-1210.

Knox, G.A. 1994. The Biology of the Southern Ocean. Cambridge University Press. Cambridge.

Knox, G.A. 2007. The Biology of the Southern Ocean. 2nd edn. Cambridge University Press. Cambridge.

Kock, K.H. 1992. Antarctic Fish and Fisheries. Cambridge University Press. Cambridge.

Kock, K.H. \& A.K. Kellermann. 1991. Reproduction in Antarctic notothenioid fish. Ant. Sci. 3: 125150 .

Kondratyev, A.Y. et al. 2000. The breeding seabirds of the Russian Far East. Seabirds of the Russian Far East. In A.Y. Kondratyev, N.M. Litvinenko \& G.W. Kaiser, Eds.: 37-81. Can. Wildl. Fed. Ottawa, Ontario, Canada.

Kooyman, G.L. et al. 2007. Effects of giant icebergs on two emperor penguin colonies in the Ross Sea, Antarctica. Ant. Sci. 19: 31-38.

Kopczynska, E.E. 1992. Dominance of microflagellates over diatoms in the Antarctic areas of deep vertical mixing and krill concentrations. 7. Plank. Res. 14: 1031-1054.

Koszteyn, J.S. et al. 1995. Size structure of Themisto abyssorum (Boeck) and Themisto libellula (Mandt) populations in European Arctic seas. Polar Biol. 15: 8592.

Krajick, K. 2003. In search of the ivory gull. Science 301: 1840-1841.

Kremer, P. \& L.P. Madin. 1992. Particle retention efficiency of salps. 7. Plank. Res. 14: 1009-1015.

Lack, D. 1968. Ecological Adaptations for Breeding in Birds. Chapman \& Hall. London. 409 p.

La Mesa, M. et al. 2004. The role of notothenioid fish in the food web of the Ross Sea shelf waters: a review. Polar Biol. 27: 321-338.

Lancraft, T.M. et al. 2004. A krill-dominated micronekton and macrozooplankton community in Croker Passage, Antarctica with an estimate of fish predation. Deep-Sea Res. II 51: 2247-2260. 
Law, K.S. \& A. Stohl. 2007. Arctic Air Pollution: Origins and Impacts. Science 315: 1537-1540.

Laws, R.M. 1985. The ecology of the Southern Ocean. Am. Sci. 73: 26-40.

Lentfer, J.W. 1975. Polar bear denning on drifting sea-ice. 7. Mammal. 56: 716.

Liu, J. et al. 2004. Interpretation of recent Antarctic seaice variability. Geophys. Res. Lett. 31: L02205, doi: 10.1029/2003GL018732.

Loeb, V. et al. 1997. Effects of sea-ice extent and krill or salp dominance on the Antarctic food web. Nature 387: 897-900.

Lombard, A.T. et al. 2007. Conserving pattern and process in the Southern Ocean: designing a Marine Protected Area for the Prince Edward Islands. Ant. Sci. 19: $39-54$.

Lønne, O.J. \& B. Gulliksen. 1989. Size, age and diet of polar cod, Boreogadus-Saida (Lepechin 1773), in ice covered waters. Polar Biol. 9: 187-191.

Lønne, O.J. \& B. Gulliksen. 1991a. On the distribution of sympagic macro-fauna in the seasonally ice covered Barents Sea. Polar Biol. 11: 457-469.

Lønne, O.J. \& B. Gulliksen. 1991b. Sympagic macrofauna from multiyear sea-ice near Svalbard. Polar Biol. 11: 471-477.

Lovejoy, C. et al. 2006. Diversity and distribution of marine microbial eukaryotes in the arctic ocean and adjacent seas. Appl. Environ. Microbiol. 72: 3085-3095, doi: 10.1128/AEM.72.5.3085-3095.2006.

Lovejoy, C. et al. 2007. Distribution, phylogeny, and growth of cold-adapted picoprasinophytes in Arctic seas. 7. Phycol. 43: 78-89.

Macnaughton, M.O. et al. 2007. Sympagic amphipods in the Arctic pack ice: redescriptions of $E u$ sirus holmii Hansen, 1887 and Pleusymtes karstensi (Barnard, 1959). Polar Biol. 30: 1013-1025, doi: 10.1007/s00300-007-0260-8.

Madin, L.P. \& P. Kremer. 1995. Determination of the filter-feeding rates of salps (Tunicata, Thaliacea) ICES. 7. Mar. Sci. 52: 583-595.

Mallory, M.L. et al. 2003. Local ecological knowledge of ivory gulls in Nunavut, Canada. Arctic 56: 293298.

Martin, S.K. \& G.J. Jonkel. 1983. Use of sea-ice habitat by polar bears. Int. Conf. Bear Res. Manage. 5: 255259.

Marschall, H.-P. 1988. The overwintering strategy of Antarctic krill under the pack-ice of the Weddell Sea. Polar Biol. 9: 243-250.

Maslanik, J.A. et al. 1996. Recent decreases in Arctic summer ice cover and linkages to atmospheric circulation anomalies. Geophys. Res. Lett. 23: 1677-1680.

McMinn, A. \& D. Hodgson. 1993. Summer phytoplankton succession in Ellis Fjord, eastern Antarctica. 7 . Plank. Res. 15: 925-938.
McMinn, A. et al. 2004. Effect of seasonal sea-ice breakout on the photosynthesis of benthic diatom mats at Casey, Antarctica. F. Phycol. 40: 62-69.

Meredith, M.P. \&J.C. King. 2005. Rapid climate change in the ocean west of the Antarctic Peninsula during the second half of the 20th century. Geophys. Res. Lett. 32: L19604, doi: 10.1029/2005GL024042.

Meyer, M.A. \& S.Z. El-Sayed. 1983. Grazing of Euphausia superba Dana on natural phytoplankton populations. Polar Biol. 1: 193-197.

Michaud,J.L. et al. 1996. Feeding success and survivorship of Arctic cod larvae, Boreogadus saida, in the Northeast Water polynya (Greenland Sea). Fisheries Oceanogr. 5: 120-135.

Mitchell, B.G. \& O. Holm-Hansen. 1991. Observations and modeling of the Antarctic phytoplankton crop in relation to mixing depth. Deep-Sea Res. 38: 9811007.

Mizobata, K. \& J. Wang. 2006. Recent summer chlorophyll reduction affected by the warm Pacific Summer Water in the Chukchi Sea: Observation and modeling [abstract]. Eos Trans. AGU 87, Fall Meet. Suppl.

Moline, M.A. 1998. Photoadaptive response during the development of a coastal Antarctic diatom bloom and relationship to water column stability. Limnol. Oceanogr. 43: 146-153.

Moline, M.A. \& B.B. Pŕzelin. 1996. Palmer LTER 1991-1994: long-term monitoring and analyses of physical factors regulating variability in coastal Antarctic phytoplankton biomass, in situ productivity and taxonomic composition over subseasonal, seasonal and interannual time scales phytoplankton dynamics. Mar. Ecol. Prog. Ser. 145: 143160.

Moline, M.A. \& B.B. Prézelin. 2000. Optical fractionation of chlorophyll and primary production for coastal waters of the Southern Ocean. Polar Biol. 23: 129136.

Moline, M.A. et al. 2004. Alteration of the food web along the Antarctic Peninsula in response to a regional warming trend. Global Change Biol. 10: 1973-1980. doi: $10.1111 /$ j.1365-2486.2004.00825.x.

Monnett, C. \& J.S. Gleason. 2006. Observations of mortality associated with extended open-water swimming by polar bears in the Alaskan Beaufort Sea. Polar Biol. 29: 681-687.

Mork, K.A. \& J. Blindheim. 2000. Variations in the Atlantic inflow to the Nordic Seas, 1955-1996. Deep-Sea Res. I 47: 1035-1057.

Murphy, E.J. et al. 2007. Spatial and temporal operation of the Scotia Sea ecosystem: a review of large-scale links in a krill centred food web. Phil. Trans. R. Soc. Lond. B. 362: 113-148.

Nicol, S. 1990. The age-old problem of krill longevity. BioScience 40: 833-836. 
Nicol, S. 2006. Krill, currents, and sea ice: Euphausia superba and its changing environment. BioScience 56: 111-120.

Nihashi, S. \& D.J. Cavalieri. 2006. Observational evidence of a hemispheric-wide ice-ocean albedo feedback effect on Antarctic sea-ice decay. F. Geophys. Res. 111: C12001, doi: 10.1029/2005JC003447.

Norderhaug, M. 1980. Breeding biology of the Little Auk (Plautus alle) in Svalbard. Norsk Polarinst Skrift 173: $1-45$

NSIDC. 2007 Arctic Sea-ice News. Fall 2007. http:// nsidc.org/news/press/2007_seaiceminimum/2007 0810_index.html (accessed November 15, 2007).

Obbard, M.E. et al. 2007. Polar Bear Population Status in Southern Hudson Bay, Canada. Administrative Report, United States Geological Survey.

Ogi, M. \& J.M. Wallace. 2007. Summer minimum Arctic sea-ice extent and the associated summer atmospheric circulation. Geophys. Res. Lett. 34: L12705, doi: 10.1029/2007GL029897.

Oro, D. et al. 2004. Influence of food availability on demography and local population dynamics in a longlived seabird. Proc. R. Soc. Lond. B 271: 387-396, doi: 10.1098/rspb.2003.2609.

Ottersen, G. et al. 2006. Changes in spawning stock structure strengthen the link between climate and recruitment in a heavily fished cod (Gadus morhua) stock. Fisheries Oceanogr. 15: 230-243.

OverpeckJ.T. et al. 2006. Paleoclimatic evidence for future ice-sheet instability and rapid sea-level rise. Science 311: 1747-1750, doi: 10.1126/science. 1115159.

Owrid, G. et al. 2000. Spatial variability of phytoplankton, nutrients and new production estimates in the waters around Svalbard. Polar Res. 19: 155-171.

Pakhomov, E.A. et al. 1996. Prey composition and daily rations of myctophid fishes in the Southern Ocean. Mar. Ecol. Prog. Ser. 134: 1-14.

Palmisano, A.C. \& C.W. Sullivan. 1982. Physiology of sea-ice diatoms. I. Response of three polar diatoms to a simulated summer-winter transition. 7. Phycol. 18: $489-498$.

Parkinson, C.L. 2002a. Trends in the length of the Southern Ocean Sea-ice Season. Annals Glaciol. 34: 435440 .

Parkinson, G.L. 2002b. Arctic Ocean. Encyclopedia of Global Environmental Change. In M.C. MacCracken \& J.S. Perry, Eds.: 199-201. John Wiley and Sons. Chichester, UK.

Parkinson, G.L. 2006. Earth's cryosphere: Current state and recent changes. Annu. Rev. Environ. Resour. 31: 33-60, doi: 10.1146/annurev.energy. 31.041105 .095552 .

Pennisi, E. et al. 2007. Momentous Changes at the Poles [introduction]. Science. 315: 1513.

Percy, J.A. \& F.J. Fife. 1985. Energy distribution in an
Arctic coastal macrozooplankton community. Arctic 38: $39-42$.

Perovich, D.K. et al. 2007. Increasing solar heating of the Arctic Ocean and adjacent seas, 1979-2005: Attribution and role in the ice-albedo feedback. Geophys. Res. Lett. 34: L19505, doi: 10.1029/2007GL031480.

Poltermann, M. et al. 2000. Life under Arctic sea-ice - reproduction strategies of two sympagic (iceassociated) amphipod species, Gammarus wilkitzkii and Apherusa glacialis. Mar. Biol. 136: 913-920.

Pomeroy, L.R. 1997. Primary production in the Arctic Ocean estimated from dissolved oxygen. 7. Mar. Syst. 10: $1-8$.

Portenko, L.A. 1989. Birds of the Chukchi Peninsula and Wrangel Island. Amerind Publishing Co., Pvt. Ltd. Springfield, VA.

Prézelin, B.B. et al. 2000. The linkage between upper circumpolar deep water (UCDW) and phytoplankton assemblages on the West Antarctic Peninsula continental shelf. 7. Mar. Res. 58, 165-202, doi: 10.1357/002224000321511133.

Prézelin, B.B. et al. 2004. Physical forcing of phytoplankton community structure and primary production in continental shelf waters of the Western Antarctic Peninsula. 7. Mar. Res. 62: 419-460, doi: 10.1357/0022240041446173.

Prokopowicz, A. \& L. Fortier. 2002. Population structure of three dominant Calanus species in North Water Polynya, Baffin Bay. Polish Polar Res. 23: 241-252.

Proshutinsky, A.Y. et al. 1999. Climate states and variability of Arctic ice and water dynamics during 19461997. Polar Res. 18: 135-142.

Quetin, L.B. \& R.M. Ross. 1985. Feeding by Antarctic krill, Euphausia superba: does size matter? In Antarctic Nutrient Cycles and Food Webs. W.R. Siegfried, P.R. Condy \& R.M. Laws, Eds.: 372-377. SpringerVerlag. Berlin.

Quetin, L.B. \& R.M. Ross. 2001. Environmental variability and its impact on the reproductive cycle of Antarctic Krill. Amer. Zool. 41: 74-89.

Quetin, L.B. \& R.M. Ross. 2003. Episodic recruitment in Antarctic krill, Euphausia superba, in the Palmer LTER study region. Mar. Ecol. Prog. Ser. 259: 185-200.

Quetin, L.B. et al. 1994. Krill energetics: seasonal and environmental aspects of the physiology of Euphausia superba. In Southern Ocean Ecology: The BIOMASS Perspective. S.Z. El-Sayed, Ed.: 165-184. Cambridge University Press. Cambridge.

Quetin, L.B. et al. 1996. Factors affecting distribution and abundance of zooplankton, with an emphasis on Antarctic krill, Euphausia superba. Foundations for Ecological Research West of the Antarctic Peninsula. Antarctic Research Series, Vol. 70. In R.M. Ross, E.E. Hofmann \& L.B. Quetin, Eds.: 357-371. American Geophysical Union. 
Quetin, L.B. et al. 2007. Ecological responses of Antarctic krill to environmental variability: can we predict the future? Ant. Sci. 19: 253-266.

Quetin, L.B. et al. 2003. Growth of larval krill, Euphausia superba, in fall and winter west of the Antarctic Peninsula. Mar. Biol. 143: 833-843.

Radtke, R.L. et al. 1993. Otolith structural and chemical analyses - the key to resolving age and growth of the Antarctic silverfish, Pleuragramma antarcticurn. Ant. Sci. 5: $51-62$.

Radtke, R.L. \& T.F. Hourigan. 1990. Age and growth of the Antarctic fish Nototheniops nudifrons. Fish. Bull. 88: $557-571$.

Ralph, P.J. et al. 2007. Melting out of sea-ice causes greater photosynthetic stress in algae than freezing in. 7. Phycol. 43: 948-956.

Ramsay, M.A., \& I. Stirling. 1986. Research and management of polar bears (Ursus maritimus). Polar Res. 23: 167-176.

Ramsay, M.A., \& I. Stirling. 1988. Reproductive biology and ecology of female polar bears (Ursus maritimus). 7. Zool. (London) Ser. A 214: 601-634.

Regehr, E.V. et al. 2005. Population decline of polar bears in western Hudson Bay in relation to climactic warming. Abstract submitted for the 16th Biennial Conference on the Biology of Marine Mammals, San Diego, California.

Reid, K. et al. 1999. Krill population dynamics at South Georgia 1991-1997, based on data from predators and nets. Mar. Ecol. Prog. Ser. 177: 103114.

Reisenbichler, K.R. 1993. Growth and chemical composition in two populations of the Antarctic Silverfish, Pleuragramma antarcticum (Pisces, Nototheniidae). M.A. University of California at Santa Barbara, Santa Barbara.

Renaud, W.E. \& P.L. McLaren. 1982. Ivory Gull (Pagophila eburnea) distribution in late summer and autumn in eastern lancaster sound and western baffin bay. Arctic 35: $141-148$.

Rhodes, O.E. Jr. \& E.P. Odum. 1996. Spatiotemporal approaches in ecology and genetics: the road less traveled. In Population Dynamics in Ecological Space and Time. O.E. Rhodes Jr., R.K. Chesser \& M.H. Smith, Eds.: 1-8. University of Chicago Press. Chicago.

Ribic, G.A., D.G. Ainley \& W.R. Fraser. 1991. Habitat selection by marine mammals in the marginal ice zone. Ant. Sci. 3: 181-186.

Rigor, I.G. et al. 2002. Response of sea-ice to the Arctic oscillation. 7. Clim. 15: 2648-2663.

Rode, K.D., S.C. Amstrup \& E.V. Regehr. 2007. Polar bears in the Southern Beaufort Sea III: stature, mass, and cub recruitment in relationship to time and seaice extent between 1982 and 2006. Administrative Report, United States Geological Survey.
Ross, R.M. \& L.B. Quetin. 1991. Ecological physiology of larval euphausiids, Euphausia superba (Euphausiacea). Memoirs of the Queensland Museum 31: 321333.

Ross, R.M. et al. 1996. Distribution of Antarctic krill and dominant zooplankton west of the Antarctic Peninsula. Foundations for Ecological Research West of the Antarctic Peninsula. Antarctic Research Series, Vol. 70. In R.M. Ross, E.E. Hofmann \& L.B. Quetin, Eds.: 199-218. American Geophysical Union. Washington, DC.

Ross, R.M. et al. 2000. Growth limitation of in young Euphuasia superba under field conditions. Limnol Oceanog. 45: $31-43$.

Rowedder, U. 1979. Feeding ecology of the myctophid, Electrona antarctica (Gunther, 1878) (Teleostei). Meeresforschung 27: 252-263.

Russell, R. 1975. The food habits of polar bears of James Bay and southwest Hudson Bay in summer and autumn. Arctic 28: 117-129.

Rutishauser, M.R. et al. 2004. Ecological implications of body composition and thermal capabilities in young Antarctic fur seals (Arctocephalus gazella). Physiol. Biochem. Zool. 77: 669-681.

Sakshaug, E. et al. 1994. Structure, biomass, distribution and energetics of the pelagic ecosystem in the Barents Sea, a synopsis. Polar Biol. 14: 405-411.

Sakshaug, E. 2004. Primary and Secondary Production in the Arctic Seas. In The Organic Carbon Cycle in the Arctic Ocean. R. Stein \& R.W. MacDonald, Eds.: 57-81. Springer-Verlag. Berlin.

Salihoglu, B. et al. 2001. Factors affecting fledging weight of Adélie penguin (Pygoscelis adeliae) chicks: a modeling study. Polar Biol. 24: 328-337.

Salomonsen, F. 1950. Gronlands fugle/The Birds of Greenland. Enjnar Munksgaard. København. 608 pp.

Saloranta, T.M. \& H. Svendsen. 2001. Across the Arctic front west of Spitsbergen: high-resolution CTD sections from 1998-2000. Polar Res. 20: 177-184.

Schiermeier, Q. 2007. The new face of the Arctic [news feature]. Nature 446: 133-135.

Schlichtholz, P. \& I. Goszczko. 2006. Interannual variability of the Atlantic water layer in the West Spitsbergen Current at $76.5^{\circ} \mathrm{N}$ in summer 1991-2003. Deep-Sea Res. I 53: 608-626.

Schnack-Schiel, S.B. \& W. Hagen. 1994. Life cycle strategies and seasonal variations in distribution and population structure of four dominant calanoid copepod species in the eastern Weddell Sea, Antarctica. 7 . Plank. Res. 16: 1543-1566.

Schneider, D. 1990. Seabirds and fronts: a brief overview. Polar Res. 8: 17-21.

Schweinsburg, R.E. \& L.J. Lee. 1982. Movement of four satellite-monitored polar bears in Lancaster Sound, Northwest Terrritories. Arctic 35: 504-511. 
Scott, C.L. et al. 1999. Lipids and trophic interactions of ice fauna and pelagic zooplankton in the marginal ice zone of the Barents Sea. Polar Biol. 21: 6570 .

Serreze, M.C. et al. 2003. A new record minimum Artic sea ice and extent in 2002. Geophys. Res. Lett. 30: doi: 10.1029/2002GL016406.

Serreze, M.C. et al. 2007. Perspectives on the Arctic's Shrinking Sea-Ice Cover. Science 315: 1533-1536, doi: 10.1126/science.1139426.

Shapiro, I. et al. 2003. April sea-ice extent in the Barents Sea, 1850-2001. Polar Res. 22: 5-10.

Shimada, K. et al. 2004. Penetration of the 1990s warm temperature anomaly of Atlantic Water in the Canada Basin [abstract]. Geophys. Res. Lett. 31: L20301, doi: 10.1029/2004GL020860.

Siegel, V. \& J. Kalinowski. 1994. Krill demography and small-scale processes: a review. In Southern Ocean Ecology: The BIOMASS Perspective. S.S.Z. El-Sayed, Ed.: 145-163. Cambridge University Press. Cambridge.

Siegel, V. \& V. Loeb. 1995. Recruitment of Antarctic krill Euphausia superba and possible causes for its variability. Mar. Ecol. Prog. Ser. 123: 45-56.

Siegel, V. et al. 1998. Krill (Euphausia superba) density, proportional and absolute recruitment and biomass in the Elephant Island region (Antarctic Peninsula) during the period 1977 to 1997. Polar Biol. 19: 393-398.

Siegel, V. 2000. Krill life history and aspects of population dynamics. Can. F. Fish. Aquat. Sci. 57: 130-150.

Siegel, V. et al. 2002. Demography of krill in the Elephant Island area during summer 2001 and its significance for stock recruitment. Ant. Sci. 14: 162-170.

Siegel, V. 2005. Distribution and population dynamics of Euphausia superba: summary of recent findings. Polar Biol. 29: 1-22.

Simmonds, M.P. \& S.J. Isaac. 2007. The impacts of climate change on marine mammals: early signs of significant problems. Oryx 41: 19-26.

Sims, D.W. 2006. Encounter success of free-ranging marine predator movements across a dynamic prey landscape. Proc. R. Soc. Lond. B 273: 1195-1201, doi: 10.1098/rspb.2005.3444.

Sinclair, M. 1988. Marine Populations. An Essay on Population Regulation and Speciation. University of Washington Press. Seattle.

Sinclair, M. \& T.D. Iles. 1989. Population regulation and speciation in the oceans. F. Cons. Int. Explor. Mer. 45: 167-175.

Sirenko, B. et al. 2006. New evidence of invertebrate invasion in the Chukchi Sea from the Northern Pacific [abstract]. Eos Trans. AGU 87, Ocean Sci. Meet. Suppl.

Skvarca, P. et al. 1999. Climatic trend and the retreat and disintegration of ice shelves on the Antarctic Peninsula: an overview. Polar Res. 18: 151-157.
Smetacek, V. et al. 1990. Seasonal and regional variation in the pelagial and its relationship to the life history cycle of krill. Antarctic Ecosystems: Ecological Change and Conservation. In K.R. Kerry \& G. Hempel, Eds.: 103114. Springer-Verlag. Berlin.

Smetacek, V. \& S. Nicol. 2005. Polar ecosystems in a changing world. Nature 437: 362-368.

Smith, D.A. et al. 1999a. Hydrography and circulation of the West Antarctic Peninsula continental shelf. DeepSea Res. I 46: 925-949.

Smith, R.C. et al. 1996. Phytoplankton biomass and productivity in the western Antarctic Peninsula region. Foundations for ecological research west of the Antartic Peninsula. In R.M. Ross, E.E. Hofmann \& L.B. Quetin, Eds.: 333-356. American Geophysical Union. Washington, DC.

Smith R.C. et al. 1999b. Marine ecosystem sensitivity to climate change. BioScience 49: 393-404.

Smith R.C. \& S.E. Stammerjohn. 2001. Variations in surface air temperature and sea-ice extent in the western Antarctic Peninsula region. Ann. Glaciol. 33: 493-500.

Smith, J.A. et al. 2007. George VI Ice Shelf: past history, present behaviour and potential mechanisms for future collapse. Ant. Sci. 19: 131-142.

Smith, T.G. \& I. Stirling. 1975. The breeding habitat of the ringed seal (Phoca hispida). The birth lair and associated structures. Can. F. Zool. 52: 11911198.

Smith, W.O. \& E. Sakshaug. 1990. Polar Phytoplankton. In Polar Oceanography Part B: Chemistry, Biology, and Geology. W.O. Smith, Ed.: 477-525. Academic Press. San Diego.

Stammerjohn, S.E. \& R.C. Smith. 1996. Spatial and temporal variation of western Antarctic Peninsula seaice overage. Foundations for Ecological Research West of the Antarctic Peninsula. In R.M. Ross, E.E. Hofmann \& L.B. Quetin, Eds.: 81-104. American Geophysical Union. Washington. DG.

Stammerjohn, S.E. et al. 2008. Trends in Antarctic annual sea-ice retreat and advance and their relation to ENSO and southern annular mode variability. 7 . Geophys. Res. 113: doi:10.1029/2007JC004269.

Stammerjohn, S.E. et al. in press. Sea-ice in the Palmer LTER region: spatio-temporal variability from ecological and climate change perspectives. Deep Sea Res.

Stein, R. \& R.W. MacDonald (Eds). 2004. The Organic Carbon Cycle in the Arctic Ocean. Springer. Berlin, Germany. ISBN 3-540-01153-6. XIX, 363 pp.

Stempniewicz, L. 1981. Breeding biology of the Little Auk (Plautus alle) in the Hornsund region, SW Spitsbergen. Acta Ornithol. 18: 141-165.

Stempniewicz, L. 1990. Biomass of Dovekie Excreta in the vicinity of a breeding colony. Colonial Waterbirds 13: 62-66. 
Stempniewicz, L. 1993. The polar bear Ursus maritimus feeding in a seabird colony in Frans Josef Land. Polar Res. 12: 33-36.

Stempniewicz, L. 1995. Predatory-prey interactions between Glaucous gull Larus hyperboreus and Little Auk Alle alle in Spitsbergen. Acta Ornithol. 29: 155-170.

Stempniewicz, L. 2001. Alle alle Little Auk. The journal of the birds of the Western Palearctic. BWP Update, Vol. 3. Oxford University Press. Oxford, pp. 175-201.

Stempniewicz, L. 2006. Polar bear predatory behaviour toward molting Barnacle geese and nesting Glaucous gulls on Spitzbergen. Arctic 59: 247-251.

Stenhouse, I.J. et al. 2004. Recoveries and survival rate of Ivory Gulls banded in Nunavut, Canada, 19711999. Waterbirds 27: 486-492.

Stenseth, N.C. et al. 2002. Ecological effects of climate fluctuations. Science 297: 1292-1296.

Stern, H.L. \& Heide-Jørgensen, M.P. 2003. Tends and variability of sea-ice in Baffin Bay and Davis Strait, 1953-2001. Polar Res. 22: 11-18.

Stirling, I. 1997. The importance of polynyas, ice edges, and leads to marine mammals and birds. F. Mar. Syst. 10: 9-21.

Stirling, I. 2002. Polar Bears and Seals in the Eastern Beaufort Sea and Amundsen Gulf: A synthesis of Population Trends and Ecological Relationships over Three Decades. Arctic 55: 59-76.

Stirling, I. et al. 1999. Long-term Trends in the Population Ecology of Polar Bears in Western Hudson Bay in Relation to Climate Change. Arctic 52: 294-306.

Stirling, I. et al. 1977. The ecology of the polar bear (Ursus maritimus) along the western coast of Hudson Bay. Canadian Wildlife Service Occasional Paper 33. Can. Wildl. Serv. Ottawa. 64 pp.

Stirling, I. et al. 2007. Polar bear populations status in the northern beaufort sea. Administrative Report, United States Geological Survey.

Stirling, I., \& A.E. Derocher. 1993. Possible impacts of climatic warming on polar bears. Arctic 46: 240-245.

Stirling, I., \& N.J. Lunn. 1997. Environmental fluctuations in Arctic Marine Ecosystems as Reflected by Variability in Reproduction of Polar Bears and Ringed Seals. In Ecology of Arctic Environments. S.J. Woodin \& M. Marquiss, Eds.: 167-181.. Oxford: Blackwell Science Ltd.

Stretch, J.J. et al. 1988. Foraging behaviour of Antarctic krill, Euphausia superba, on sea-ice microalgae. Mar. Ecol. Prog. Ser. 44: 131-139.

Stroeve J.G. et al. 2005. Tracking the Arctic's shrinking ice cover: Another extreme September minimum in 2004. Geophys. Res. Lett. 32: doi: 10.1029/2004GL021810.

Stroeve J.C. et al. 2007. Arctic sea-ice decline: Faster than forecast. Geophys. Res. Lett. 34: L09501, doi: 10.1029/2007GL029703.
Summerhayes, V.S., \& C.S. Elton. 1928. Further contributions to the ecology of Spitsbergen. 7. Ecol. 16: 193-268.

Swerpel, S. \& M. Zajaczkowski. 1990. Physical environment of South Spitsbergen. In Atlas of the Marine Fauna of Southern Spitsbergen. R.Z. Klekowski \& J.M. Wȩsławski, Eds.: 25-41. Ossolineum. Wroclaw.

Swerpel, S. 1985. The Hornsund Fiord: Water Masses. Polish Polar Res. 6: 475-496.

Tremblay,J-E. et al. 2006. Trophic structure and pathways of biogenic carbon flow in the eastern North Water Polynya. Prog. Oceanogr. 71: 402-425.

Trivelpiece, W.Z. \& W.R. Fraser. 1996. The breeding biology and distribution of Adélie Penguins: Adaptations to environmental variability. In Foundations for Ecological Research West of the Antarctic Peninsula, Vol. 70. R.M. Ross, E.E. Hofmann \& L.B. Quetin, Eds.: 273285. American Geophysical Union. Washington, DC.

Tynan, C.T. \& D.P. DeMaster. 1997. Observations and predictions of Arctic climate change: potential effects on marine mammals. Arctic 50: 308322.

Unstad, K.H. \& K.S. Tande. 1991. Depth distribution of Calanus finmarchicus and C. glacialis in relation to environmental conditions in the Barents Sea. In E. Sakshaug, C.C.E. Hopkins \& N.A. Øritsland, Eds.: Proc Pro Mare Symp Polar Marine Ecology, Trondheim, 12-16 May 1990. Polar Res. 10: 409-420.

Vacchi, M. et al. 2004. Early life stages of the Antarctic Silverfish, Pleuragramma antarcticum boulenger 1902, in Terra Nova Bay (Ross Sea, Antarctica). Ant. Sci. 16: $299-305$.

van Franeker, J.A. et al. 2001. Unexpected effects of climate change on the predation of Antarctic petrels. Ant. Sci. 13: 430-439.

Vaughan, D.G. et al. 2003. Recent rapid regional climate warming on the Antarctic Peninsula. Clim. Change 60: $243-274$.

Verity, P.G. \& V. Smetacek. 1996. Organism life cycles, predation and the structure of marine pelagic ecosystems. Mar. Ecol. Prog. Ser. 130: 277-293.

Vinje, T. 2001. Anomalies and trends of ice extent and atmospheric circulation in the Nordic Seas during the period 1864-1998. 7. Clim. 14: 255267.

Visbeck, M.H. et al. 2001. The North Atlantic Oscillation: past present and future. Proc. Natl. Acad. Sci. 98: 12876-12877.

Visser, M.E. et al. 2004. Global climate change leads to mistimed avian reproduction. Adv. Ecol. Res. 35: 89 110.

Volkman, N.J. et al. 1980. Diets of Pygoscelid penguins at King George Island, Antarctica. Condor 82: 373378. 
Walsh, J.E. \& M.S. Timlin. 2003. Northern Hemisphere sea-ice simulations by global climate models. Polar Res. 22: 75-82.

Walsh, J.J. et al. 2001. A numerical analysis of carbon dynamics of the Southern Ocean phytoplankton community: the roles of light and grazing in effecting both sequestration of atmospheric CO2 and food availability to larval krill. Deep-Sea Res. 48: 148.

Walther, G.-R. et al. 2002. Ecological responses to recent climate change. Nature 416: 389-395.

Walton, D.W.H. 2007. International Polar Year [editorial]. Ant. Sci. 19: 1.

Watson, G.E. \& G.J. Divoky. 1972. Pelagic bird and mammal observations in the eastern Chukchi Sea, early fall 1970. An ecological survey in the eastern Chukchi Sea, September-October 1970. U.S. Coast Guard Oceanogr. Report 50, pp. 111-172.

Weber, L.H. \& S.Z. El-Sayed. 1985. Spatial variability of phytoplankton and the distribution and abundance of krill in the Indian sector of the Southern Ocean. In Antarctic Nutrient Cycles and Food Webs. W.R. Siegfried, P.R. Condy \& R.M. Laws, Eds.: 283-293. SpringerVerlag. Berlin.

Welch, H.E. et al. 1993. Occurrence of Arctic Cod (Boreogadus saida) schools and their vulnerability to predation in the Canadian High Arctic. Arctic 46: 331339.

Werner, I. \& R. Gradinger. 2002. Under-ice amphipods in the Greenland Sea and Fram Strait (Arctic): environmental controls and seasonal patterns below the pack ice. Mar. Biol. 140: 317-326.
Werner, I. et al. 2007. Sea-ice algae in Arctic pack ice during winter. Polar Biol. 30: 1493-1504.

Wȩsławski, J.M. \& P. Adamski. 1987. Cold and warm years in South Spitsbergen coastal marine ecosystem. Polish Polar Res. 8: 95-106.

Weşlawski,J.M. \& S. Kwaśniewski. 1990. The consequences of climatic fluctuation for the food web in Svalbard coastal water. Proc. 24 -EMBS Symposium, Aberbeen University Press, pp. 281-295.

Wȩsławski, J.M. et al. 1999. Summer feeding strategy of the little auk (Alle alle) from Bjørnøya, Barents Sea. Polar Biol. 21: 129-134.

Węsławski, J.M. et al. 1994. Diet of ringed seals (Phoca hispida) in a fjord of West Svalbard. Arctic 47: 109114.

Winder, M. \& D.E. Schindler. 2004. Climate change uncouples trophic interactions in an aquatic ecosystem. Ecology 85: 2100-2106.

Winther, J-G. et al. 2004. Surface reflectance of sea-ice and under-ice irradiance in Kongsfjorden, Svalbard. Polar Res. 23: 115-118.

Woehler, E.J. et al. 2001. A Statistical Assessment of the Status and Trends of Antarctic and Subantarctic Seabirds. SCAR/CGAMLR/NSF. Bozeman, Montana, 43 pp.

Yuan, X. 2004. ENSO-related impacts on Antarctic sea-ice: a synthesis of phenomenon and mechanisms. Ant. Sci. 16: 415-425, doi: 10.1017/S0954102004002238415.

Zwally, H.J. et al. 2002. Variability of Antarctic seaice 1979-1998. 7. Geophys. Res. 107: NO. C5, doi: 10.1029/2000JC000733. 